Florida International University FIU Digital Commons

10-20-2014

\title{
UV-Induced Melanoma Mouse Model Dependent on Endothelin 3 Over-Expression
}

Ana Paula Benaduce

Florida International University, adasi004@fiu.edu

DOI: $10.25148 /$ etd.FI14110725

Follow this and additional works at: https://digitalcommons.fiu.edu/etd

Part of the Cancer Biology Commons

\section{Recommended Citation}

Benaduce, Ana Paula, "UV-Induced Melanoma Mouse Model Dependent on Endothelin 3 Over-Expression" (2014). FIU Electronic Theses and Dissertations. 1613.

https://digitalcommons.fiu.edu/etd/1613

This work is brought to you for free and open access by the University Graduate School at FIU Digital Commons. It has been accepted for inclusion in FIU Electronic Theses and Dissertations by an authorized administrator of FIU Digital Commons. For more information, please contact dcc@fiu.edu. 


\title{
FLORIDA INTERNATIONAL UNIVERSITY
}

Miami, Florida

\section{UV-INDUCED MELANOMA MOUSE MODEL DEPENDENT ON ENDOTHELIN 3 OVER-EXPRESSION}

\author{
A dissertation submitted in partial fulfillment of \\ the requirements for the degree of \\ DOCTOR OF PHILOSOPHY \\ in \\ BIOLOGY \\ by
}

Ana Paula da Silva Benaduce 
To: Interim Dean Michael R. Heithaus

College of Arts and Sciences

This dissertation, written by Ana Paula da Silva Benaduce, and entitled UVInduced Melanoma Mouse Model Dependent on Endothelin 3 Over-Expression, having been approved in respect to style and intellectual content, is referred to you for judgment.

We have read this dissertation and recommend that it be approved.

$\begin{array}{r}\hline \text { James Grichnik } \\ \hline \text { John Makemson } \\ \hline \text { M. Alejandro Barbieri } \\ \hline \text { Lichard Bone } \\ \hline\end{array}$

Date of Defense: October 20, 2014

The dissertation of Ana Paula da Silva Benaduce is approved.

Interim Dean Michael R. Heithaus

College of Arts and Sciences

Dean Lakshmi N. Reddi

University Graduate School

Florida International University, 2014 


\section{DEDICATION}

I dedicate this Dissertation to my beloved husband, Allan Filgueiras, my father, Paulo Benaduce, my mother, Clédia Benaduce and my sister, Ana Laura Benaduce. Your confidence in me, even when I doubted myself the most, was of infinite importance in the achievement of this degree. 


\section{ACKNOWLEDGMENTS}

I would like to thank my major advisor Dr. Lidia Kos for giving me the opportunity to join the Kos Lab family. Besides being an exceptional advisor who gave me the freedom to choose my project, encouraged me whenever I had insecurities, and supported me to pursue my goals, Dr. Kos became a dear friend. Thank you for always believing in me, for all personal and scientific dialogues, for always having a kind word, for helping me become a more optimistic person and a better scientist. I am very fortunate to have had you as a mentor. Thank you so much!

I would like to thank my committee members Dr. James Grichnik, Dr. John Makemson, Dr. M. Alejandro Barbieri and Dr. Richard Bone who generously gave their time and shared with me their expertise providing me with valuable comments toward improving my work. I also would like to thank Dr. Clara Milikowski, from the University of Miami, for all the time, dedication and effort she put towards this project. Marbella Chavarria, also from the University of Miami, thank you for your assistance with tissue processing. I would also like to thank

Dr. Paulette Johnson who helped with some of the statistical analyses of my data, as well as Dr. Ranjan Perera and Dr. Jian-Liang Li, from the Sanford Burnham Medical Institute, for the next generation sequencing analyses.

I deeply thank Dr. Richard Brinn who gave me the opportunity to come to FIU to do research. Dr. Richard Brinn, his wife, Dr. Mari Brinn, and their entire family became precious friends that always encouraged and supported me since 
the day I stepped in the USA. I am eternally grateful for everything you all did for me.

I am very thankful to Dr. Frank Jochem for giving me the opportunity to work as a Laboratory Technician, for his help and understanding with my language barrier. I am also grateful to Dr. Arvind Agarwal and Dr. Debrupa Lahiri who I had the opportunity to collaborate with on a side project, from which I learned a lot about nanoindentation and nanomaterials. Thank you Debrupa for being a good friend and for making those infinite hours of melanocyte and melanoma cells nanoindentation go by faster.

I must also thank Dean Maureen Donnelly for believing in me. She gave me the opportunity to conquer a dream. I will always remember all positive and motivational words you told me every time we saw each other. Thank you!

I cannot forget friends who were by my side during this journey, cheered me on, and celebrated each accomplishment with me especially Adriana Galvis, Shabnam Namin, Sushmita Mustafi, and Dina Stanic. Thank you all!!!

I would like to extend my gratitude to all current and previous Kos Lab members. I am very grateful to Flavia Carneiro for mentoring me when I first joined the lab and also for becoming such a close and caring friend. I would be oblivious if I did not thank a very special colleague and friend Amy Saldaña. Amy is the most helpful and kind person a colleague-friend can ask. I will always remember the countless number of nights that would be just the two of us working late in the lab. Amy helped me improve my English, proofread a lot of my work and always passed me confidence when I needed it. Professional and 
personal issues were deeply discussed between us. I will carry a lot of pleasant memories about us for the rest of my life. Thank you Amycita! Marcy Loweinstein, Nikeisha Chin, Natasha Fernandez, Juliano Freitas, Xiaoshuang Li, Javier Pino, Ruslan Garcia and Manuel Borobia. I feel very fortunate to have met you and worked with you all these years. Each of you mean a lot to me. Thank you for every single time you helped me in any way. A very special thanks to the undergraduate students who worked with me and made the completion of this project possible, Deannys Batista, Gabriel Grilo, Karen Jorge and Diana Cardero. I thank the entire Kos Lab for the support and for providing a good work environment. We were all colleagues and became good friends. You all made these years very memorable, I felt like we were a big family!

I cannot imagine my present situation without the love and support from my family. My heartfelt thanks to my beloved parents, Clédia and Paulo, for all dedication and efforts made to provide a good education for my sister and I. I will always be short of words to describe how important and immense is the part the two of you and Ana Laura have in my accomplishments. Thank you for the lighted candles, prayers, endless patience, love, encouragement and reassurance. My dearest sister, Ana Laura, thank you for being my best friend, for always being there for me, and for making our parents' life so cheerful with your presence given me piece of mind all this period I am far away. Thank you so much! Also, a big thanks to all my relatives, especially to my grandparents who were always so proud and so confident in me. Vó Laura and Vó Hélia, your prayers were, and still are, of great help throughout my life. Thank you! 
There are no proper words to express my deep gratitude to my husband and best friend Allan. His love, support, encouragement and cheerful nature help me getting through all this process in the most positive way. For him, any little achievement I had was always an immense accomplishment. I have been blessed with your presence in my life. Thank you for all kind and motivational words! Thank you for always believing in me! Thank you for everything!

Many thanks to Giulia and Nathalia, and to my four-legged kids Hércules and Benhur, for their generous love and for entertaining me when I was deeply worried and stressed. I also would like to thank my mother-in-law and father-inlaw, Regina and Douglas, my sister-in-law, Tamara, and my brother-in-law, Icaro, for their affection, support, and for cheering with me at every great moment.

I would like to acknowledge the FIU Teaching Assistantship program and the MBRS/RISE (NIH/NIGMS R25 GM061347) fellowship for their support. I thank all the MBRS/RISE and Biology Department staff that were of assistance throughout all these years, especially Dr. Charles Bigger, Dr. Robert Lickliter, Erin Doud, Ileana Lindsay, Eliana Guzman, Thelma Robles and Courtney Aiken. Thomas Pitzer, thank you for trusting me to be the Head TA for the Human Biology Laboratory. A very special thanks to Helen Forlong for her kindness and for the many times she helped me during the PhD program.

I would like to gratefully acknowledge John Wiley and Sons for permission to reprint Chapter 2 which originally appeared in the Pigment Cell \& Melanoma Research Journal volume 27 issue 5 . Finally, yet importantly, a debt of gratitude to all the mice I worked with during this project that gave their life for science. 


\section{ABSTRACT OF THE DISSERTATION \\ UV-INDUCED MELANOMA MOUSE MODEL DEPENDENT ON ENDOTHELIN 3 \\ OVER-EXPRESSION}

by

Ana Paula da Silva Benaduce

Florida International University, 2014

Miami, Florida

Professor Lidia Kos, Major Professor

Melanoma is one of the most aggressive types of cancer. It originates from the transformation of melanocytes present in the epidermal/dermal junction of the human skin. It is commonly accepted that melanomagenesis is influenced by the interaction of environmental factors, genetic factors, as well as tumor-host interactions. DNA photoproducts induced by UV radiation are, in normal cells, repaired by the nucleotide excision repair (NER) pathway. The prominent role of NER in cancer resistance is well exemplified by patients with Xeroderma Pigmentosum (XP). This disease results from mutations in the components of the NER pathway, such as XPA and XPC proteins. In humans, NER pathway disruption leads to the development of skin cancers, including melanoma. Similar to humans afflicted with $X P, X p a$ and $X p c$ deficient mice show high sensibility to UV light, leading to skin cancer development, except melanoma. The Endothelin 3 (Edn3) signaling pathway is essential for proliferation, survival and migration of melanocyte precursor cells. Excessive production of Edn3 leads to the accumulation of large numbers of melanocytes in the mouse skin, where they are 
not normally found. In humans, Edn3 signaling pathway has also been implicated in melanoma progression and its metastatic potential. The goal of this study was the development of the first UV-induced melanoma mouse model dependent on the over-expression of Edn3 in the skin. The UV-induced melanoma mouse model reported here is distinguishable from all previous published models by two features: melanocytes are not transformed a priori and melanomagenesis arises only upon neonatal UV exposure. In this model, melanomagenesis depends on the presence of Edn3 in the skin. Disruption of the NER pathway due to the lack of Xpa or Xpc proteins was not essential for melanomagenesis; however, it enhanced melanoma penetrance and decreased melanoma latency after one single neonatal erythemal UV dose. Exposure to a second dose of UV at six weeks of age did not change time of appearance or penetrance of melanomas in this mouse model. Thus, a combination of neonatal UV exposure with excessive Edn3 in the tumor microenvironment is sufficient for melanomagenesis in mice; furthermore, NER deficiency exacerbates this process. 


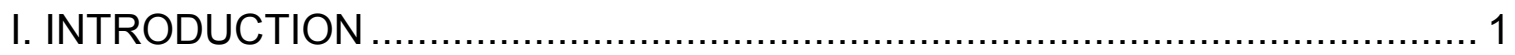

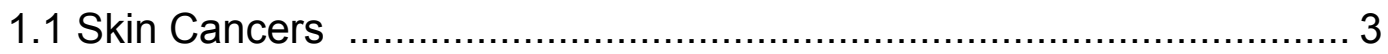

1.2 Ultraviolet Radiation ........................................................... 5

1.3 Role of UV Radiation in Skin Cancer ............................................ 6

1.4 Role of UV Radiation in DNA Damage and DNA Repair ................... 9

1.5 Role of UV Radiation in Immunosuppression and Skin Cancer ........ 13

1.6 Skin Cancer Diagnoses ............................................................ 16

1.7 Current Available Treatments for Melanoma .................................. 21

1.8 UV-Induce Melanoma Mouse Models ............................................. 27

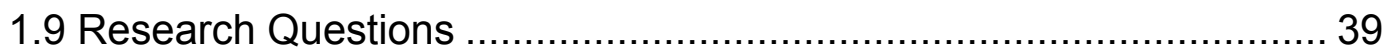

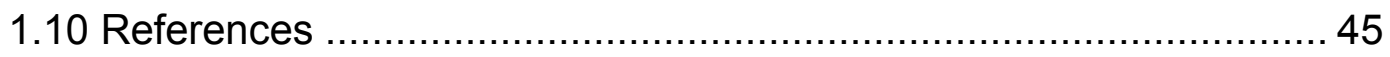

II. NOVEL UV-INDUCE MELANOMA MOUSE MODEL DEPENDENT ON

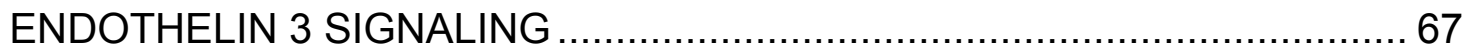

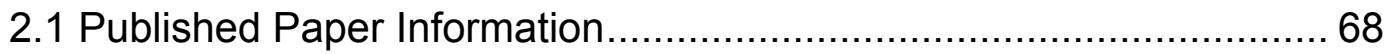

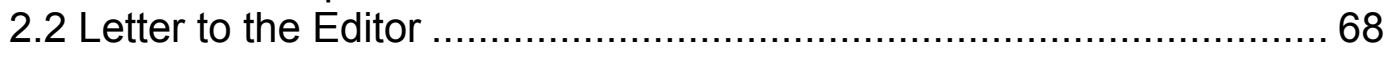

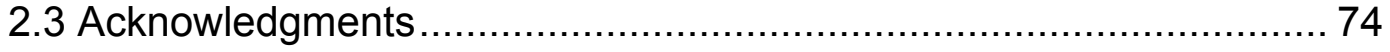

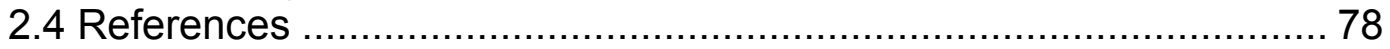

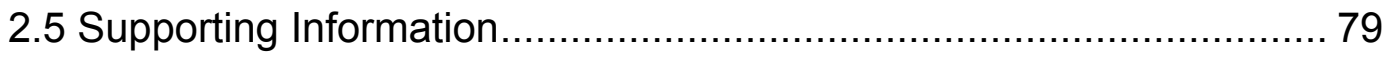

2.5.1 Materials and Methods .................................................. 79

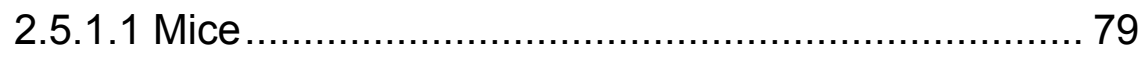

2.5.1.2 Induction of Skin Tumors by UV Radiation .............. 80

2.5.1.3 Histological and Immunostaining Analysis of

Tumors ......................................................... 80

2.5.1.4 Proliferating Cells ........................................... 81

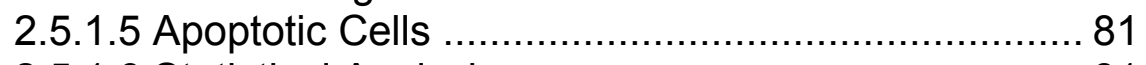

2.5.1.6 Statistical Analysis............................................ 81

2.5.1.7 References ................................................... 84

III. NUCLEOTIDE EXCISION REPAIR DEFFICIENCY ENHANCES MELANOMA PHOTOCARCINOGENESIS IN TRANSGENIC K5-EDN3

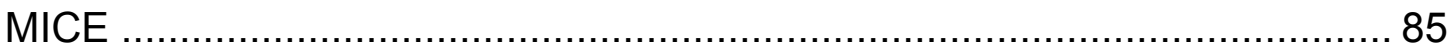

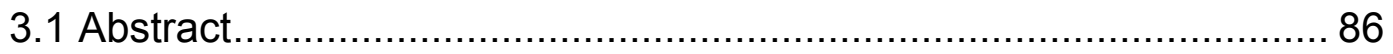

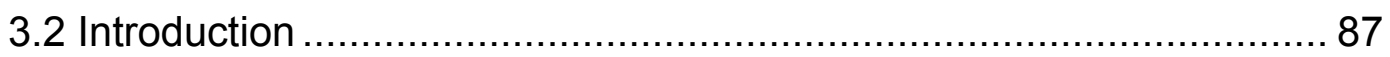

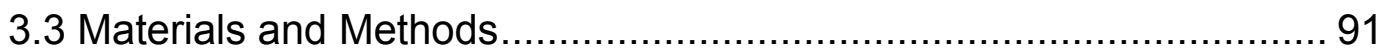

3.3.1 Mice ................................................................... 91

3.3.2 Induction of Skin Tumors by UV Radiation ......................... 92

3.3.3 Histological and Immunostaining Analysis of Tumors ......... 93

3.3.4 Thymine-Dimer Detection................................................... 94

3.3.5 Detection and Analyses of Melanoma Mutations ................. 95

3.3.6 Statistical Analysis .......................................................... 96 
3.4 Results

3.4.1 NER Deficiency Exacerbates UV-Induced Melanomagenesis in Neonatal K5-Edn3 Transgenic Mice .. 96

3.4.2 K5-Edn3 Transgenic Mice Skin Shows Decreased Levels of Direct DNA Photodamage 100

3.4.3 Melanoma Mutations Screening ..................................... 100

3.5 Discussion 101

3.6 References 113

IV. CONCLUSION, FUTURE DIRECTIONS AND IMPLICATIONS 118

4.1 Conclusion and Future Directions 119

4.2 Implications 124

4.3 References 125

VITA 127 


\section{LIST OF FIGURES}

FIGURE

PAGE

CHAPTER I

1.1 The effects of UV radiation on the human skin .............................. 42

1.2 Ways in which UV radiation can give rise to skin cancer ................... 43

1.3 Relationship of skin type, UV radiation and skin cancer risk ............. 44

CHAPTER II

2.1 Lesions in UV-irradiated K5-Edn3 transgenic mice ........................ 76

Figure S1. Lymph nodes in UV-irradiated K5-Edn3 transgenic mice ....... 82

Figure S2. Distribution of melanin and quantification cleaved

Caspase-3 positive cells in neonatal UV-irradiated dorsal

skin

CHAPTER III

3.1 Melanoma lesions in UV-irradiated K5-Edn3 transgenic mice 108

3.2 Cumulative survival of melanoma-free mice as a function of age (Kaplan-Meier analysis) in UV-irradiated K5-Edn3 and non-K5-Edn3 mice with and without Xpc deficiency....

3.3 Cumulative survival of melanoma-free mice as a function of age (Kaplan-Meier analysis) in UV-irradiated K5-Edn3 and non-K5-Edn3 mice with and without Xpa deficiency

3.4 Distribution and quantification of melanin and thymine-dimer positive cells in neonatal UV-irradiated dorsal skin 


\section{LIST OF ABREVIATIONS AND ACRONYMS}

6-4PP

6-4 photoproduct

8-oxodG 8-oxo-7,8-dihydro-2'-deoxyguanosine

A Adenine

ABCDE ....... Asymmetry, border irregularity, color variation, diameters, elevation ANOVA Analysis of variance $\mathrm{AP}$ Apurinic/apyrimidinic ARF Alternative reading frame B-lymphocytes Bursa-derived lymphocytes BCC Basal cell carcinoma BER Base excision repair $\mathrm{bp}$ Base pair BRAF B-raf proto-oncogene serine/threonine protein kinase

C Cysteine C Cytosine CDK Cyclin-dependent kinase CDK4 Cyclin-dependent kinase 4 CDK6 Cyclin-dependent kinase 6 CDKN2A Cyclin-dependent kinase inhibitor $2 \mathrm{~A}$ cDNA complimentary DNA $\mathrm{cm}$ Centimeter CPD Cyclobutane pyrimidine dimer CTLA-4 Cytotoxic T-Lymphocyte Antigen 4 
Del Deletion

DMBA

.7,12-dimethylbenz(a)anthracene

DNA Deoxyribose nucleic acid

DTIC Dacarbazine

E Glutamic acid

EdnrA Endothelin receptor $A$

EdnrB Endothelin receptor B EDTA Ethylene diaminetetra acetic acid End1 Endothelin 1 End3 Endothelin 3 ERCC1 Excision repair cross-complementing 1 definition ERK Extracellular signal regulated kinase FDA Food and Drug Administration FVB Friend leukemia virus B G. Glycine G. Guanine G1 Growth phase 1 GDP Guanosine diphosphate GGR Global genome repair pathway GPCR G-coupled protein receptor GTP Guanosine triphosphate GTPases Guanosine triphosphatases $H \& E$ Hematoxylin and Eosin 
HMGB1 High Mobility Group 1

HRAS Harvey rat sarcoma viral oncogene homolog IACUC Institutional Animal Care and Use Committee IHC Immunohistochemistry Ink4a Inhibitor of Cyclin-Dependent Kinase 4A Ins Insertion $\mathrm{K}$ Lysine K5 Keratin 5 KRAS Kirsten rat sarcoma viral oncogene homolog MAPK Mitogen-activated protein kinase MC1R Melanocortin 1 receptor MEK. Mitogen-extracellular signal regulated kinase $\mathrm{mL}$ Milliliter $\mathrm{MM}$ Malignant melanoma $\mathrm{mM}$ Milimolar $\mathrm{mm}$ Millimeter $\mathrm{MSH}$ Melanocyte stimulating hormone $\mathrm{n}$ Sample size NER Nucleotide excision repair $\mathrm{NIH}$ National Institute of Health $\mathrm{nm}$ Nanometer $\mathrm{Nm} 23$ Nonmetastatic 23 
PBS .Phosphate buffer solution

PCR Polymerase chain reaction

PD-1 Programmed death-1 PDL-1 Programmed death ligand-1

$\mathrm{pH}$ Potential hydrogen

$\mathrm{PI}$ Propidium lodide PI3K. Phosphatidylinositol-4,5-bisphosphate 3-kinase Q. Glutamine $\mathrm{R}$ Arginine Raf Raf proto-oncogene serine/threonine protein kinase

Ras Rat sarcoma $\mathrm{RB}$ Retinoblastoma RGP Radial growth phase $S$ Synthesis SC Scatter factor SCC Squamous cell carcinoma SCF Stem cell factor SV40 T-antigen Simian virus 40 tumor antigen T-lymphocytes Thymus lymphocytes $\mathrm{T}$ Thymine 

Ultraviolet radiation $\mathrm{A}$ UVB Ultraviolet radiation $\mathrm{B}$ UVC Ultraviolet radiation C UVR Ultraviolet radiation

V Valine VGP Vertical growth phase vs versus World Health Organization $\mathrm{XP}$ Xeroderma pigmentosum

XPA Xeroderma pigmentosum, complementation group $\mathrm{A}$ XPB Xeroderma pigmentosum, complementation group B XPC Xeroderma pigmentosum, complementation group $\mathrm{C}$ XPD Xeroderma pigmentosum, complementation group $\mathrm{D}$ XPE Xeroderma pigmentosum, complementation group $\mathrm{E}$ XPF Xeroderma pigmentosum, complementation group $\mathrm{F}$ 
$\delta$ Delta

$\varepsilon$ .. Epsilon

$\mu g$. Microgram 
CHAPTER I.

INTRODUCTION 


\section{INTRODUCTION}

Cells in an organism are regulated by several external and internal pathways leading to the maintenance of homeostasis. Disruption in pathways related with cell cycle and cell differentiation trigger unrestrained cell proliferation and abnormal differentiation which, consequently, lead to cancer. As a result, transformed cells, lose their original finality, invade and disturb adjacent tissues, forming new tumors called metastases. Skin cancer is a very common type of cancer (American Cancer Society, 2014a). The different types of skin cancer are associated to their cells of origin: aberrant melanocytes give rise to malignant melanoma (MM), while aberrant keratinocytes give rise to non-melanoma skin cancer (NMSC), which is divided into basal cell carcinoma (BCC) and squamous cell carcinoma (SCC). Sunlight exposure is the most important environmental risk factor of skin cancer development. Ultraviolet (UV) rays can directly and indirectly damage DNA and cause immunosuppression (de Gruijl et al., 2001; Welsh et al., 2008). In normal human cells, depending on the type of DNA damage, different types of repair pathways are activated. When excessive DNA damage that cannot be repaired occurs, the apoptotic pathway is activated causing cells to undergo programmed cell death. Genetic factors also contribute to UV-mediated skin cancer development. Individuals who have defects in the pathways mentioned above and/or are immunosuppressive are greatly more susceptible to skin cancers. In this chapter, an overview of epidemiological and genetic links of UV radiation and skin carcinogenesis are described. Skin cancer diagnoses, 
available treatments for the most aggressive type of skin cancer and mouse models are also reviewed.

\subsection{Skin Cancers}

Skin cancer, or cutaneous carcinogenesis, is the most frequent form of cancer diagnosed in white populations and it is, by far, the most common of all types of cancer (American Cancer Society, 2014b; Diepgen and Mahler, 2002; Rogers et al., 2010). Skin cancers are mainly divided into three types: Basal Cell Carcinoma (BCC), Squamous Cell Carcinoma (SCC) and Cutaneous Melanoma. BCC and SCC are referred together as non-melanoma skin cancer (NMSC) whereas the cutaneous melanoma is referred as malignant melanoma (MM) or just melanoma. The occurrence of NMSC is 20 times higher than melanoma; however melanoma is responsible for most of the skin cancer mortalities (American Cancer Society, 2014b; Diepgen and Mahler, 2002).

Non-melanoma skin cancer and melanoma are derived from different types of cells: NMSC arises from transformed epidermal keratinocytes, while melanoma arises from transformed melanocytes. Melanocytes produce melanin, a pigment that helps to protect the genetic material in the epidermis basal cells against light-induced damage. Therefore, melanocytes decrease the lethality of NMSC (Markovic et al., 2007). Melanocytes are uniformly dispersed in the basal layer of the epidermis in human skin. They correspond between $1-2 \%$ of the cell population, whereas, keratinocytes represent about $95 \%$ of the total cells present in human epidermis (Figure 1) (Holbrook et al., 1989; Yaar and Gilchrest, 2001). 
Reporting of NMSCs to the cancer registries is not a requirement, making it challenging to precisely estimate their occurrence. An analysis of the incidence of NMSCs in the United States population estimated that over 3.5 million cases were diagnosed and more than 2.2 million individuals were treated for the disease in 2006 (Rogers et al., 2010). Basal cell carcinoma constitutes approximately $80 \%$ of the NMSCs and is characterized by slow growth and infrequent metastasis, whereas SCC comprises the remaining $20 \%$, shows quick growth and, when neglected, can metastasize (American Cancer Society, 2014c). The major part of all NMSC cases is highly curable, especially if diagnosed in early stages (American Cancer Society, 2014a).

Melanoma is the most aggressive of the three main types of skin cancer and, this aggressiveness is attributed to its high capacity to metastasize. For the last 30 years, melanoma incidence rates have been increasing. In 1935, the lifetime risk of developing melanoma was 1 in 1500. Currently, the risk is 1 in 59 (Rigel, 2010). Melanoma incidence increases with age and shows an altered pattern between women and men (Rigel, 2010). In 2014, in the United States, it is estimated that 76,100 new cases of melanoma will be diagnosed and that 9,710 patients will die from the disease (American Cancer Society, 2014a). Metastatic melanoma presents an unpredictable biological behavior, frequently metastasizing in brain, bones, liver, lungs and viscera (Tas, 2012). Melanoma metastasis is characterized by rapid dissemination making its treatment very challenging. The 5-year survival rate for patients with metastatic melanoma is only 16\% (American Cancer Society, 2014a). Most recurrences occur in the 
period of the first three years, and rare cases have been described of over 30 years of latency (Geisler et al., 2013).

\subsection{Ultraviolet Radiation}

Solar UV radiation has a broad spectrum: low-energy UVA band (wavelengths of 320 to $400 \mathrm{~nm}$, visible light of 400 to $700 \mathrm{~nm}$ ), high-energy UVB band ( 280 to $320 \mathrm{~nm}$ ) and UVC band (below $280 \mathrm{~nm}$ ). The UVC band is totally absorbed by the ozone layer. Most of the UVB rays are absorbed while passing through the ozone layer; however the UVA rays are almost not affected. Therefore, 5 to $10 \%$ of UVB and 90 to $95 \%$ of UVA arrives at the earth's surface level and are capable of reaching human skin (Figure 1) (Daya-Grosjean and Sarasin, 2005). While UVB is filtered by window glass, UVA is not affected by it. It is estimated that $50 \%$ of UVA exposure happens in the shade (Schaefer et al., 1998).

Earth's radiation depends on the solar altitude which varies according to the geographic location, time of the day and season (Holzle and Honigsmann, 2005). It is important to point out that with the depletion of the ozone layer, higher amounts of UV rays, mainly UVB, are reaching the Earth' surface (McKenzie et al., 2011; United Nations Environment Programme et al., 2012).

Compared to UVB rays, UVA rays possess the longest wavelengths and thus penetrate deeper into the skin. As such, UVA rays have a higher chance of reaching the basal layers where melanocytes and dividing stem cells are located (Halliday and Cadet, 2012) (Figure 1). The UVB rays penetrate superficially into the skin and have higher absorption rate by DNA than UVA, as well as being 
considered more mutagenic and cytotoxic than UVA (Cadet et al., 1997; Jhappan et al., 2003). Additionally, a UVA dose has to be 1000 times stronger than that of UVB to produce the same level of erythema (Parrish et al., 1982).

Ultraviolet radiation is responsible for several different chronic and acute effects on the skin. Chronic responses include photoaging and photocarcinogenesis, both caused by cumulative damaged effects of UVA (mostly formation of reactive oxygen species) and UVB (formation of pyrimidine dimers) radiation in the cells. The acute responses are very diverse and include erythema, DNA photodamage, apoptosis, immunosuppression, synthesis of vitamin D and increased pigmentation (Burke, 2010; Fisher et al., 2002; Ichihashi et al., 2003; Mason and Reichrath, 2013; Min et al., 2014; Ullrich, 2002; Yamaguchi et al., 2008).

\subsection{Role of UV Radiation in Skin Cancer}

In the human body the primary and largest target for UV radiation is the skin. The ozone layer filters UV waves before it reaches the earth's surface. Since the early seventies, concerns about ozone layer depletion have gained considerable attention and different studies have tried to predict its detrimental effects on skin cancer incidence (Kelfkens et al., 1990) as well as other impacts on the earth. As a result of the depletion of the ozone layer, the filtration of UV rays is less efficient and, the human skin is exposed to a higher amount of UV rays (Lemus-Deschamps and Makin, 2012; Norval et al., 2011; United Nations Environment Programme et al., 2012). As a consequence of the high intensities of UV radiation that humans experience, more damage is being caused to the 
cells in a shorter period of time than it did before (Lemus-Deschamps and Makin, 2012).

The incidence of NMSC and melanoma are mainly related to the interaction of environmental factors (such as UV light) and genetic factors (such as skin type, gender, inherited disorders) (Agbai et al., 2014; Barrett et al., 2014; Goldstein and Tucker, 2001; Pennello et al., 2000; Tamura et al., 2014; Vogel et al., 2014). Ultraviolet radiation has an important influence in skin cancer development in two ways: directly, by causing DNA damage (mutations in cellular DNA) in skin cells and, indirectly, by suppressing the anti-tumor immune response, which promotes cancer development and facilitates metastasis (Figure 2) (Bald et al., 2014; Chacon-Salinas et al., 2014; Del Bino et al., 2013; Ichihashi et al., 2003; Katiyar and Mukhtar, 2001; Meeran et al., 2008; Russo et al., 2008; Welsh et al., 2008). For these reasons, UV is considered the major etiological factor of skin cancer (Daya-Grosjean and Sarasin, 2005).

People living in world areas with elevated annual sunlight average or increased erythemogenic UV rays show higher risks of skin cancers, especially SCC followed by BCC and then melanoma (Armstrong and Kricker, 2001). Recent studies showed that the incidence of SCC and BCC, in outdoor workers, increases with proximity to the equator (Bauer et al., 2011; Schmitt et al., 2011).

Chronic, cumulative lifetime UV exposure is the major risk factor for SCC, whereas intermittent UV exposure is considered to be primarily important in the pathogenesis of BCC (Armstrong and Kricker, 2001; Rosso et al., 1996). Melanoma development is related to intense, intermittent solar UV radiation 
exposure and blistering sunburns in childhood and adolescence leading to cumulative DNA damage in skin cells (Armstrong and Kricker, 2001; Kauffmann et al., 2008; Rigel, 2010; Whiteman et al., 2001). Skin cancer risk is associated with the amount of UV radiation exposure and the skin pigmentation level (Figure 3) (Armstrong and Kricker, 2001; Del Bino et al., 2013; Diepgen and Mahler, 2002; Rosso et al., 1996).

Individuals with fair skin and red hair (pigmentation phenotype I of Fitzpatrick scale), characterized by high pheomelanin (red/yellow pigment) to eumelanin (black/brown pigment) ratio, have the tendency to burn easily rather than tan and are associated with higher risks of developing skin cancer than other pigmentation types (Diepgen and Mahler, 2002; Fitzpatrick et al., 1977; Pathak et al., 1980; Rigel, 2010). Genetically, inactivating polymorphisms of the melanocortin 1 receptor $(M C 1 R)^{1}$ gene are, in particular, correlated with this phenotype (Valverde et al., 1995). The melanocyte stimulating hormone (MSH) and its antagonistic agouti protein are MC1R ligands on melanocytes. Increased MC1R activity by MSH stimulates the production of eumelanin, whereas minimal receptor activity either by the binding of the agouti protein or by MC1R inactivating polymorphisms, leads to the production of pheomelanin pigment (Lu et al., 1994; Valverde et al., 1995). Population studies of MC1R variant alleles have shown strong genetic associations between red hair/ fair skin phenotypes and an increased risk of all forms of skin cancer (Sturm, 2002). This

${ }^{1}$ Formatting of gene and protein nomenclature according to The Jackson Laboratory, 2014 and Wain et al., 2002. 
link is believed to be associated with the fact that pheomelanin has weak shielding capacity against UV radiation in comparison to eumelanin and also that pheomelanin has a high potential to generate free radicals upon UV radiation and was shown that its presence increases the sensibility to UVA-induced DNA damage (D'Orazio et al., 2006; Ranadive et al., 1986; Wenczl et al., 1998). Furthermore, recent data suggest that pheomelanin is carcinogenic for melanoma development via oxidative damage even independently of UV radiation (Mitra et al., 2012).

\subsection{Role of UV Radiation in DNA Damage and DNA Repair}

The DNA photodamage is one of the major acute effects caused by UV radiation. Ultraviolet radiation can cause molecular DNA rearrangements directly by formation of base dimers and indirectly by oxidative base damage (de Gruijl et al., 2001). Damaged DNA can in turn lead to the generation of defective proteins, which can disrupt signaling pathways and, later on, result in skin cancer. Luckily, most of the DNA damage is efficiently and accurately repaired in normal cells.

Ultraviolet radiation A and UVB, by different mechanisms, can cause DNA damage and so both are considered to have important roles in skin carcinogenesis. The UVB rays that reach earth' surface can easily be absorbed by DNA bases, mainly by the pyrimidine bases, such as cytosine (C) and thymine $(T)$, leading to the formation of pyrimidine dimers. It can also be absorbed by some proteins that have aromatic amino acids, such as tyrosine and tryptophane (Young, 1997). As a consequence, UVB photon absorption leads to chemical reactions that can alter DNA structure and composition (de Gruijl et al., 2001). 
The UVA effects, on the other hand, are mainly mediated by the formation of radicals; therefore, it causes indirect damage to DNA (Kullavanijaya and Lim, 2005). Recently, UVA was also shown to lead to pyrimidine dimers lesions on DNA by direct absorption (Jiang et al., 2009; Mouret et al., 2006; Mouret et al., 2010).

Non-DNA endogenous photosensitizers such as melanin, quinone, flavins and porphyrins, absorb UVA rays and by photochemical interaction produce reactive oxygen species including hydrogen peroxide, hydroxyl radical, peroxynitrite and singlet oxygen (Cadet and Douki, 2011; Cadet et al., 2009). Reactive oxygen species are extremely unstable and reactive molecules that can lead to DNA strand breaks, oxidation of nucleic acids and cause damage to cellular proteins (Peak and Peak, 1991; Wenczl et al., 1997). Guanine (G) is the main oxidized DNA base upon UVA irradiation. Guanine oxidation gives rise to 8oxo-7,8-dihydro-2'-deoxyguanosine (8-oxodG) (Cadet et al., 2009), which causes transversion G:C to T:A mutations. This happens because the 8-oxodG is paired with adenine (A) instead of cytosine (C) during replication (Shibutani et al., 1991).

The DNA oxidized bases are removed either by the nucleotide excision repair (NER) or by the base excision repair (BER) pathways. The NER pathway plays a secondary role repairing this type of damage while BER plays a crucial role. The BER pathway is divided into two subpathways: short-patch BER (excision of one nucleotide) and long patch BER (excision of two or more nucleotides) (Matsumoto et al., 1999; Pascucci et al., 1999). The first step of the BER pathway is the action of a DNA glycosylase. This enzyme removes the 
oxidized DNA base leaving a non-instructive apurinic/apyrimidinic (AP) site. The remaining sugar fragments are removed by AP endonucleases. The repair is finalized by the action of DNA polymerase $\beta, \delta$ or $\varepsilon$ and DNA ligase (Matsumoto et al., 1999; Pascucci et al., 1999).

The most common photoproduct of UV radiation exposure is pyrimidine dimers (Brash and Haseltine, 1982). Ultraviolet rays, especially shortwave such as UVB, are absorbed by two neighboring pyrimidine bases in the DNA, leading to the formation of di-pyrimidine sites resulting in either 6-4 photoproduct (6-4PP: thymine-cytosine dimers) (Varghese and Patrick, 1969) or cyclobutane pyrimidine dimer (CPD: thymine dimers, cytosine dimers) (Setlow and Carrier, 1964). Interestingly, after 60 minutes of sun exposure at noon in Kobe, Japan, during the summer, approximately 100,000 CPD molecules per cell are produced in human epidermis (reviewed by Ichihashi et al., 2003). Formation of pyrimidine dimers disrupts the double strand DNA helix (Park et al., 2002). This bulky lesion in the DNA is recognized and repaired by the NER pathway (Rastogi et al., 2010; Setlow and Carrier, 1964). It has been reported that the excision of 6-4 PP is faster than CPD (Rastogi et al., 2010).

Nucleotide excision repair malfunction is one important step for UV radiation to cause skin cancer development (Pfeifer and Besaratinia, 2012; Yarosh et al., 2005). For instance, Xeroderma Pigmentosum (XP) is a rare autosomal recessive disease characterized by a deficient NER system. As a result, the photoproducts induced by UV radiation are not repaired, resulting in a malignant phenotype (Cleaver et al., 2009; Stary and Sarasin, 2002). Xeroderma 
Pigmentosum patients are extremely sensitive to sun exposure and, compared with unaffected individuals under 20 years of age, they have a 1,000-fold elevated risk of UV-induced skin cancers, including cutaneous melanoma (Kraemer et al., 1994).

Nucleotide excision repair has two distinct subpathways: the transcriptioncoupled repair pathway (TCR) which rapidly repairs DNA regions that are transcriptionally active, and the global genome repair pathway (GGR) which works less quickly than TCR pathway but repairs both transcriptionally active and inactive regions (Hoeijmakers, 2001). Both subpathways are a multi-step process where at least 25 proteins are involved, including the seven XP complementation group of proteins (XPA, XPB, XPC, XPD, XPE, XPF, and XPG) (Wood et al., 2005; Wood et al., 2001). Briefly, the NER pathway recognizes DNA photoproducts via distinct protein complexes, depending on whether the TCR or the GGR pathway is used. After DNA damage recognition, the transcription factor IIH (TFIIH) together with two DNA helicases, XPB and XPD, unwind the double stranded DNA, creating single-stranded DNA. Two endonucleases, the ERCC1XPF complex and XPG, make respective incisions 5' and 3' at the sides of the lesion releasing a 25-27 nucleotide fragment containing the photoproduct (Friedberg, 2001; Hoeijmakers, 2001). As in the BER pathway, DNA polymerase and DNA ligase complete the repair.

Ultraviolet radiation can lead to genomic mutations, which threaten the genomic integrity of the cell and can contribute to tumorigenic processes. Mutation in critical genes that encode for proteins related to cell cycle control, 
DNA repair or apoptosis, affecting the function of these important proteins, are strongly connected with early stages of skin cancer (Ortonne, 2002; Pfeifer and Besaratinia, 2012).

\subsection{Role of UV Radiation in Immunosuppression and Skin Cancer}

More than 30 years ago Fisher and Kriple (1977) demonstrated that inoculating UV-irradiated mice with lymphoid cells from another UV-exposed mice made the recipients unable to reject tumor transplantation, whereas UVirradiate mice inoculated with lymphoid cells from non-UV-irradiated mice became resistant to tumor grow (Fisher and Kripke, 1977). Their main conclusion was that UV radiation exposure could affect the immune system and prevent host anti-tumor response (Fisher and Kripke, 1977).

Ultraviolet-induced immunosuppression is strongly linked with the development of melanoma and NMSC (Chapman et al. 1995). The suppression of the immune system by UV radiation assists skin cancer development and progression, enabling an easier dispersion of cancer cells throughout the body. The ability of tumor cells to escape immune system detection is called tumor immune escape (Pardoll, 2003).

Immune system responses can be divided into two main categories: innate, which act rapidly and has a non-specific response; and, adaptive, which takes more time because of the response specificity to each antigen and, in many cases, the antigen is picked up and processed by antigen-presenting cells, such as langerhans cells, macrophages and dendritic cells. Afterwards, antigen 
portions are recognized by T-lymphocytes, which then are triggered to proliferate and produce immune cytokines (Sirisinha, 2014).

Ultraviolet radiation has multiple negative effects in the immune system and, since early years, it was found to be capable to suppress adaptive immune responses (Kripke, 1974). Some of these effects include: (1) suppression of the amount and functionality of antigen-presenting cells (Hill et al., 1999; Nghiem et al., 2002); (2) induction of the release of immunosuppressive cytokinesis (Bald et al., 2014; Nghiem et al., 2002); and, (3) induction of T-lymphocytes into apoptosis (Hill et al., 1999; Ozawa et al., 1996).

Ultraviolet radiation is capable of downregulating already established immune responses (Damian et al., 1998; Narbutt et al., 2005; Wang et al., 2008). Increasing amounts of UVB radiation exposure was shown to have a direct relationship with increasing levels of immune suppression (Matthews et al., 2010a; Noonan and De Fabo, 1990). On the other hand, UVA exposure displays a bell-shaped dose response for immune suppression (Matthews et al., 2010b).

The cellular and molecular mechanisms through which UVA and UVB radiation affect the immune system depends on the amount of exposure. Upon sub-inflammatory doses of UVB radiation, regulatory B-lymphocytes are activated (Byrne et al., 2005; Byrne and Halliday, 2005), whereas regulatory Tlymphocytes generally require inflammatory doses (Gorman et al., 2007). Low doses of UVA exposure has been shown to trigger the alternative complement pathway inducing systemic immunosuppression (Stapelberg et al., 2009), while greater doses of UVA was associated to immune protection due to the activation 
of heme oxygenase (enzyme related to oxidative stress protection) (Reeve and Tyrrell, 1999) and interferon $y$ (immune system cytokine) (Reeve et al., 1999). Also, UVA and UVB radiation exposure were shown to have interaction effects that are far superior than the addition of their effects individually (Poon et al., 2005).

Skin of newborn children is immunologically immature. There has been speculations that immune responses from early life stage could determine melanoma outcomes later in life (Muller et al., 2008). Exposure of neonatal mouse skin to UV radiation induces a poor inflammatory response compared to adult skin response, which has an acute inflammatory response within minutes, thus limiting the development of immunity and promoting a tolerogenic environment (Muller et al., 2008). Additionally, UV-exposed neonatal mouse skin revealed microenvironment modifications that can lead to the generation of antigen-specific regulatory T-lymphocytes, which persists for life. Thus, these early modulating events may be relevant for the UV-induced melanomagenesis during adulthood (Muller et al., 2008).

Induced immunosuppression therapy, common in organ transplant patients, significantly increases skin cancer risk (Feuerstein and Geller, 2008; Garg et al., 2009; Jemec and Holm, 2003; Tessari and Girolomoni, 2012; Ulrich et al., 2004). These individuals develop skin cancer more often and typically a more aggressive form with quicker metastases than normal individuals with a non-suppressed immune system (Jemec and Holm, 2003). Moreover, skin cancer rates decrease when the immune suppressive therapy is decreased 
(Jemec and Holm, 2003). Interestingly, while the ratio of SCC:BCC in nontransplanted population is $1: 4$, this ratio in transplanted population is $4: 1$, the complete inversion (Tessari and Girolomoni, 2012).

\subsection{Skin Cancer Diagnoses}

Macroscopically, a useful clinical evaluation for pigmented lesions is the so-called $A B C D E$ rule - Asymmetry, Border irregularity, Color variation, Diameters greater than $6 \mathrm{~mm}$ and Elevation (Rigel et al., 2005). There is no similar detection rule for NMSC (Soyer et al., 2012)

It is well established that melanoma tumor thickness is the greatest prognostic indicator; superficial tumors can be easily cured with a simple surgery, whereas mortality is closely correlated with increasing in tumor depth (Rigel and Carucci, 2000; Sahin et al., 1997). Besides the depth measurement of melanoma, other histological prognostic factors include ulceration (absence of an intact epidermal layer overlying the melanoma), mitotic rate (an indicator of tumor proliferation in the dermis) and lymphatic invasion (Balch et al., 2009). Both ulceration and mitotic rate have a direct relationship with metastasis and lethality; the worse ulceration and the higher mitotic rate, the higher the risk for metastasis and subsequent death (Edge and Compton, 2010; Grande Sarpa et al., 2006).

Histopathologically, cutaneous melanoma is classified into four main types: superficial spreading melanoma, lentigo maligna melanoma, acral lentiginous melanoma and nodular melanoma (Crowson et al., 2006). World Health Organization (WHO) includes rare melanoma variants, such as desmoplastic melanoma, in their classification (LeBoit et al., 2006). Very briefly, 
superficial spreading melanoma is characterized by single or nested malignant melanocytes spreading within the epidermis; lentigo maligna melanoma usual pattern is the proliferation of atypical melanocytes, single or nested, along the epidermal-dermal junction, that frequently extends deeply into the appendageal epithelium; acral lentiginous melanoma is a relatively rare type of melanoma that arises on non hair bearing plantar, palmar and subungual skin sites, characterized by atypical melanocyte proliferation, single or nested, along the epidermal-dermal junction; nodular melanoma share several histological features with superficial spreading melanoma with the significant difference that they are very sharply circumscribed (Smoller, 2006). Desmoplastic melanoma is characterized by the proliferation of single or nested atypical melanocytes (with spindled morphology) that tends to extend deeply into the reticular dermis (lower layer of the dermis), and is very poorly circumscribed (Magro et al., 2006).

All main types of melanomas exist as in situ lesions (non-invasive) or invasive, with the exception of nodular melanoma (Geisler et al., 2013). Also, nodular melanoma lacks the radial growth phase, which leads to the sudden appearance of a malignant neoplasm in previously normal skin (Crowson et al., 2006). Radial growth phase (RGP) involves neoplastic melanocytes, located intraepidermally, multiplying and dispersing as single or small group of cells. Without further events, RGP is not capable of generating metastatic events, and it is virtually always curable through surgery with rare exceptions (Crowson et al., 2006). On the other hand, vertical growth phase (VGP) implies the ability of a melanoma to metastasize. Early VGP is differentiated from the RGP by the 
occurrence of a dominant nest (25-50 cells) within the papillary dermis (uppermost layer of the dermis); this nest has to be larger than any nest within the epidermis or the neighboring dermis, and cytologically distinct (shape, size, cytoplasmic or nuclear features, absence or presence of pigment) from intraepidermal group of cells (Crowson et al., 2006). Presence of mitotic figures, and of dominant nest that fills and wide the papillary dermis, extends to the papillary-reticular dermal interface or into the reticular dermis and/or subcutaneous fat are particular characteristics of fully evolved VGP (Crowson et al., 2006). Furthermore, VGP is subclassified by cell phenotype: spindle cell vertical growth phase (less tendency to widespread metastasis) and epithelioid vertical growth phase (most commonly associated with widespread metastases) (Crowson et al., 2006).

Systematic meta-analyses of melanoma risks revealed that physical attributes such as blue eyes, fair skin and red hair have, respectively, 1.47, 2.06, 3.64 higher relative risk of developing melanoma than dark colors (Gandini et al., 2005). High density of freckles showed a relative risk of 2.10 (Gandini et al., 2005). The presence of a dysplastic nevus leads to a slight increase (2-fold) in overall risk for melanoma (Tucker et al., 1997), but the annual risk of any single nevus becoming melanoma is quite small, less than 1 in 200,000 for both men and women younger than 40 years old (Tsao et al., 2003). Having a primary family member with melanoma or a parent with multiple melanomas are also associated with higher relative risks (1.74 and 61.78, respectively) (Hemminki et al., 2003). 
Histologically, basal cell carcinoma is derived from the basal lamina and/or the root sheaths of the outer hair follicle (Kolk et al., 2014). The morphological classification of BCC includes: nodular (including micronodular), infiltrative (including sclerosing or morphemic), superficial and mixed subtype (Rippey, 1998). The WHO's classification uses differentiating patterns to classify BCC types: superficial, nodular, micronodular, infiltrating, fibroepithelial, basal cell carcinoma with adnexal differentiation, basosquamous carcinoma, keratotic basal cell carcinoma and other variants which includes cystic, adenoid, sclerosing/morpheiform, infundibulocystic, pigmented and miscellaneous (Kossard et al., 2006). From the point of view of simplicity and good reproducibility, Rippey's (1998) classification is the most acceptable. Some of the histological features common to all these types of tumor are: basaloid cells with a thin cytoplasm surrounding round or oval nuclei that is bigger and darker than nuclei of epidermal keratinocytes. Mitosis and apoptotic cells are frequent. Excluding the rare pleomorphic (giant cell) type of $\mathrm{BCC}$, the majority of $\mathrm{BCC}$ cases do not present cellular atypia (Calonje et al., 2012).

Basal cell carcinoma is a malignant tumor with a low mortality rate, slow growth and rare metastasis events. However, they can be very destructive causing, in particular, extensive local tissue damage and have a high recurrence rate after treatment (Cockerell et al., 2011). The risk factors for BCC recurrence include: body location (specially central part of the face, such as periocular, perioral and nasal); large size (over $2 \mathrm{~cm}$ ); perineural and/or perivascular invasion; prior recurrence (Samarasinghe et al., 2011). Based on the main and 
most frequent histological types, infiltrative and superficial types of BCC show higher probability of aggressive local behavior, recurrence and subclinical spread, in comparison to the nodular type (Rippey, 1998; Vantuchova and Curik, 2006).

Histologically, squamous cell carcinoma consists of nests, sheets and strand of keratinocytes with variable squamous differentiation; these cells arise from the epidermis and can extend superficially or deeply into the dermis (Weedon et al., 2006). Squamous cell carcinoma spreads by local infiltration and may follow tissue conducts and planes such as blood vessels, lymphatics and nerves (Weedon et al., 2006). According to WHO, SCC subtypes are: acantholytic, spindle-cell squamous cell carcinoma, verrucous, pseudovascular and adenosquamous carcinoma (Weedon et al., 2006). Acantholytic SCC is histologically defined by the loosening of the keratinocytes intercellular attachments resulting in acantholysis (separation of keratinocytes from each other within the epidermis); pseudovascular SCC is a very aggressive type of SCC characterized by marked acantholysis resulting in angiosarcoma-like areas; adenosquamous carcinoma arises from pluripotent cell related to acrosyringia (epidermal keratinocytes around sweat gland ducts), characterized by the formation of mucin secreting glands; spindle-cell is an uncommon type of SCC that exhibit prominent spindle-cell morphology and is poorly differentiated; verrucous is a rare variant of well-differentiated SCC with low metastatic probability (Weedon et al., 2006). 
Squamous cell carcinoma is a malignant tumor responsible for the majority of NMSC deaths. It grows relatively rapidly, with an invasive nature that may progress to lymph nodes and distant organs metastasis (Weinberg et al., 2007). The risk factors for SCC recurrence include tumor location (face specially lips, and ears), size, depth, poor differentiation, perineural invasion, acantholytic features, prior reappearance (Weedon et al., 2006; Weinberg et al., 2007).

\subsection{Current Available Treatments for Melanoma}

Treatment options for melanoma are based on the stage of the disease at the time of diagnoses and include surgery, possibly followed by adjuvant therapy. Surgery is the optimal approach and, currently, it is the only potential curative treatment for melanoma (Geisler et al., 2013). Until recently, no adjuvant therapy had demonstrated to be life extending. Different treatments and combinations of treatments had been tested and none had ever demonstrated survival improvement. Luckily, in recent years, completely new medical options have dramatically changed melanoma treatment (Geisler et al., 2013).

Chemotherapy regimens, such as Dacarbazine (DTIC) and Temozolomide, are considered "standard therapy" for advanced melanoma. Dacarbazine, an alkylating agent that interferes with tumor cell growth, is considered the most active single agent in patients with melanoma, and it is the only chemotherapeutic agent approved by the Food and Drug Administration (FDA) for treatment despite its low response rates and no indication of survival advantage (Ives et al., 2007; Serrone et al., 2000). Whereas DTIC is administrated intravenously, Temozolomide is an oral alkylating agent that differs 
from DTIC by its ability to penetrate the blood-brain barrier; yet a trial comparing both drugs showed similar response rates, progression-free survival slightly prolonged in the Temozolomide treatment (1.9 months vs. 1.5 months) but no statistical difference in survival (7.7 months vs. 6.4 months) was observed (Middleton et al., 2000).

Immunotherapy is a very promising idea that consists of increasing immune mechanisms responsible for naturally eradicating cancer cells (Mansh, 2011). Interleukin-2, a T-lymphocyte cytokine, was the first immunotherapy to be approved by the FDA for treatment of advanced melanoma. Interleukin-2, like the chemotherapy drug DTIC, shows low response rates even at high doses of treatment (Agarwala, 2009; Atkins et al., 2000; Atkins et al., 1999). Furthermore, it is associated with substantial toxicity including capillary leak syndrome, hemodynamic instability and, high risk of infection (Antony and Dudek, 2010). Interferon a 2-b, an adjuvant immunotherapy drug, received FDA approval in 2011 for treatment of melanoma with microscopic or gross nodal involvement. Clinical trials showed that in patients with high-risk cutaneous melanoma, this adjuvant treatment lead to a significant improvement in both disease-free survival and overall survival (Mocellin et al., 2010). However, a more recent analysis did not find a significant long-term overall survival benefit (Petrella et al., 2012).

In 2011, Ipilimumab, the first anti-CTLA-4 monoclonal antibody, was approved by the FDA for treatment of metastatic melanoma (Traynor, 2011). Ipilimumab enhances T-lymphocyte activity and tumor infiltration by blocking Cytotoxic T-lymphocyte Antigen 4 (CTLA-4) inhibitory signals, which allows 
unregulated and prolonged activation of T-lymphocytes in a non-specific manner. Fundamentally, this drug enhances patient's antitumor response by blocking immune-regulatory mechanisms, which are responsible for suppressing host responses to tumor-associated antigens (Mansh, 2011). Clinical trials demonstrated an overall survival improvement in patients that had been previously treated for metastatic melanoma; the median survival rate was 10.1 months in the Ipilimumab therapy group vs. 6.4 months in the control group (Hodi et al., 2010). Side effects of this drug include enterocolitis, hepatitis, and dermatitis (Hodi et al., 2010).

Another novel treatment based on directing the immune system to activate T-lymphocytes against cancer cells is the PD-1/PDL-1 pathway inhibitors, such as nivolumab (Patnaik et al., 2012). This anti-PD-1 monoclonal antibody is showing promising clinical trial results, however it is not currently FDA-approved. The ligand PDL-1 (Programmed Death Ligand-1) binds to the PD-1 (Programmed Death-1) receptor expressed in T-cells. Activation of this pathway blocks T-cell identification and the subsequent destruction of the tumor cells (Keir et al., 2008), which it is believed to be of advantage in tumor survival (Hirano et al., 2005). Nivolumab phase I clinical trial revealed increase in antitumor activity in patients with advanced malignancy, including melanoma (Brahmer et al., 2010). Advanced melanoma patients showed a medium overall survival of 16.8 months, with $40 \%$ of patients alive at 3 years (Sznol et al., 2013). These promising results encouraged further clinical trials. Currently, there is an ongoing 
phase III clinical trial comparing Nivolumab versus DTIC in patients with metastatic melanoma (ClinicalTrials.gov, 2014).

Targeted therapy is characterized by the development of a drug that inhibits specific proteins, enzymes and pathways related to cancer development and progression. The Ras/Raf/mitogen activated protein kinase (MAPK) pathway is one of the major signaling networks involved if melanomagenesis and progression (Hocker et al., 2008). The B-raf proto-oncogene serine/threonine protein kinase (BRAF) is found constitutively active in the majority of human melanomas. BRAF ${ }^{\mathrm{V} 600}$, the most common mutated form of the BRAF gene, is known to play a role in proliferation and survival of melanoma cells via MAPK pathway activation (Besaratinia and Pfeifer, 2008; Davies et al., 2002).

The BRAF inhibitors are drugs that work by inhibiting the mutated BRAF protein. Vemurafenib (PLX4720) was the first FDA-approved agent that targets mutated BRAF (Heakal et al., 2011). It is an oral inhibitor of the mutated $\mathrm{BRAF}^{\mathrm{V} 600}$ kinase domain that leads to a decrease in cell proliferation through the phosphorylation of ERK (Extracellular signal regulated kinase) and Cyclin D1 (Jang and Atkins, 2013; Tsai et al., 2008). In a phase III clinical trial, untreated patients carrying the $B R A F^{V 600 E}$ mutations received either Vemurafenib or DTIC. Vemurafenib treatment led to significant reduction in the risk of death (63\%) and in the risk of either death or disease progression (74\%) (Chapman et al., 2011). Despite the success of Vemurafenib, most, if not all, patients ultimately develop resistance resulting in disease progression at a median time of approximately 6 months. Multiple resistance mechanisms have been considered including the 
reactivation of MAPK pathway, which is downstream of BRAF, in a BRAFindependent manner (Swaika et al., 2014; Wagle et al., 2011).

Dabrafenib (GSK2118436) is another inhibitor of mutated $\mathrm{BRAF}^{\mathrm{V} 600}$, recently approved by the FDA (Ballantyne and Garnock-Jones, 2013). Its mechanism of action is similar to Vemurafenib, but it has a shorter half-life (Hauschild et al., 2012). A clinical trial carried out in untreated patients carrying the $\mathrm{BRAF}^{\mathrm{V} 600}$ mutations demonstrated that Dabrafenib significantly improved progression-free survival compared with DTIC (5.1 vs. 2.7 months, respectively) (Hauschild et al., 2012).

The MAPK pathway is immediately downstream of BRAF. For this reason, MAPK pathway inhibitors have been investigated as monotherapy as well as in combination with BRAF inhibitors. Trametinib (GSK1120212) a selective oral inhibitor of MEK (Mitogen-extracellular signal regulated kinase), approved by the FDA in 2013, showed to increase the progression-free survival in patients carrying mutated $\mathrm{BRAF}^{\mathrm{V} 600}$ (Falchook et al., 2012). A phase III trial comparing Trametinib with chemotherapy drugs (DTIC or Paclitaxel) showed a significant improvement of both median progression-free survival (4.8 months vs. 1.5 months) and overall survival ( $81 \%$ vs. $67 \%)$ when Trametinib was used (Flaherty et al., 2012b).

Based on the evidence that the resistance to therapy with BRAF Kinase inhibitors is associated with reactivation of MAPK pathway, a combined treatment of Dabrafenib (a selective BRAF ${ }^{\mathrm{V} 600}$ inhibitor) and Trametinib (a selective MAPK inhibitor) was started. Results showed that this combination increased median 
progression-free survival (9.4 months vs. 5.8 months in the monotherapy group), and improved the rate of complete or partial response $(76 \%$ vs. $54 \%$ with monotherapy) (Flaherty et al., 2012a). Because of these results, the use of these two drugs in combination has received accelerated FDA approval this year (Menzies and Long, 2014).

Endothelin receptor $B(E d n r B)$ and Endothelin receptor $A(E d n r A)$ are the two G-coupled protein receptors (GPCR) that mediate physiological responses upon endothelin ligand binding (Saldana-Caboverde and Kos, 2010). The EdnrB, an important protein in melanocyte development, has been implicated in the progression and metastatic capability of melanoma cells (Demunter et al., 2001; Lahav, 2005). Blockage of this receptor by small molecule inhibitors has shown to affect the growth and survival of melanoma cells (Bagnato et al., 2004; Lahav et al., 1999; Lahav et al., 2004). Bosentan, a targeted drug that competitively inhibits specific ligand binding to EdnrA and EdnrB is, consequently, an EdnrA and EdnrB antagonist (Clozel et al., 1994). Human melanoma cell lines treated with Bosentan showed decreased melanoma cell viability and DNA synthesis, inhibition of proliferation, and induction of apoptosis (Berger et al., 2006). These results instigated the testing in a clinical setting. Bosentan monotherapy was tested in stage IV metastatic melanoma patients and it appeared to be of benefit, achieving disease stabilization in 6 out of the $32(19 \%)$ patients at week 6 , with confirmation at week 12; five patients were still stable after 24 weeks and two persisted stable for longer than 2 years on study treatment (Kefford et al., 2007). As a consequence of these positive results, a phase II randomized clinical trial 
was carried out, in a similar patient population, in combination with first-line DTIC chemotherapy. This study revealed no beneficial effect on time to tumor progression, progression-free survival and overall survival when Bosentan was combined with DTIC (Kefford et al., 2010). Failure of this trial could be attributed to the abnormally high time to tumor progression observed in the control group and/or the strict selection criteria of patients (Kefford et al., 2010).

Advances in immunotherapy and targeted therapy have positively transformed malignant melanoma treatment. Even though there has been remarkable progress in the management of this disease, no existing treatment has been completely successful. Therefore, much is needed to be learned, and optimizations of existing therapies along with innovative therapies for recurrent and metastatic melanoma are still necessary.

\subsection{UV-Induced Melanoma Mouse Models}

Experimental animal models create a unique platform that enables the development of strategies to further elucidate pathogenesis. Genetically engineered mouse models opened the doors for further investigations on the relevance of UV radiation on melanomagenesis, and important information was gained from studies employing these models. A description of available UVinduced melanoma mouse models and the rationale for their creation is reviewed here.

Mutations in the tumor suppressor locus CDKN2A (cyclin-dependent kinase inhibitor $2 \mathrm{~A}$ ), located at $9 \mathrm{p} 21$, have been mostly linked to familial melanoma (Haluska and Hodi, 1998; Soufir et al., 2004). Yet, the CDKN2A is 
also found functionally inactivated in a significant percentage of non-familial (sporadic) melanomas (Castellano and Parmiani, 1999). This locus encodes two proteins, $\mathrm{p} 16^{\mathrm{INK} 4 \mathrm{a}}$ and $\mathrm{p} 14^{\mathrm{ARF}}$ (Sharpless, 2005). p16 ${ }^{\mathrm{INK} 4 \mathrm{a}}$ is a Cyclin-dependent kinase (CDK) inhibitor that specifically inhibits Cyclin-dependent kinase 4 (CDK4) or Cyclin-dependent kinase 6 (CDK6) complexes, consequently blocking Retinoblastoma (RB) phosphorylation and preventing G1/S cell cycle progression (Chin et al., 1998). p14 ${ }^{\mathrm{ARF}}$ promotes p53 stabilization, which in turn can promote cell cycle arrest in Growth phase 1 (G1) and apoptosis in response to oncogenic stimuli (Zhang et al., 1998). Absence of functional $\mathrm{p} 16^{\mathrm{INK} 4 \mathrm{a}}$ and $\mathrm{p} 14^{\mathrm{ARF}}$ proteins, disrupts tumor suppression by RB and $\mathrm{p} 53$ pathways, and is believed to contribute to melanomagenesis. The ablation of these proteins could be one of the reasons why P53 protein is found mutated in a small percentage of human melanomas (Meier et al., 1998). Furthermore, most of the melanoma cases that have $p 53$ mutations had no concurrent mutations in $p 16^{I N K 4 a}$ or $p 14^{A R F}$ (Hodis et al., 2012).

The first UV-induced melanoma mouse model reported used a transgenic mouse in which the melanocyte-specific tyrosinase promoter drives expression of the Simian virus 40 tumor antigen (SV40 T-antigen) (Klein-Szanto et al., 1994). Expression of the transgene resulted in the inactivation of both p53 and RB pathways, which is functionally equivalent to the loss of the CDNK2A locus (Klein-Szanto et al., 1994). High expressers of the transgene were UV irradiated for up to 4 consecutive days, starting at 4 days of age. These mice developed melanomas, particularly ocular melanomas (Klein-Szanto et al., 1994). Due to 
the aggressiveness of the ocular tumors, mice did not live long enough to allow the investigation of cutaneous melanoma with full progression (Klein-Szanto et al., 1994). Mice that were low expressers of the transgene provided a more significant model in which chronic neonatal UV exposure for 5 days starting at 3 days of age resulted in $26 \%$ incidence of cutaneous malignant melanoma (Kelsall and Mintz, 1998).

The Rat sarcoma (RAS) proteins are small GTPases localized on the internal side of the plasma membrane. They function as critical mediators of cell growth, proliferation and differentiation (Lowy and Willumsen, 1993; Trahey and McCormick, 1987). RAS activity is controlled through cycling between a guanosine triphosphate (GTP)-bound state (active) and guanosine diphosphate (GDP)-bound state (inactive) (Downward, 1996). GTP-bound RAS is able to trigger the phosphatidylinositol-4,5-bisphosphate 3-kinase (PI3K) signaling pathway and to activate the RAS associated protein BRAF. Activated BRAF, in turn phosphorylates and triggers the ERK signaling pathway (Marais et al., 1995; Rodriguez-Viciana et al., 1994). Through the activation of these effectors, RAS proteins regulate cell survival, proliferation and differentiation. Neuroblastoma RAS viral (v-ras) oncogene homolog (NRAS) is the most commonly mutated RAS isoform in human melanoma (15-20\%) whereas Harvey rat sarcoma viral oncogene homolog (HRAS) and Kirsten rat sarcoma viral oncogene homolog (KRAS) mutations are rare (1-2\%) (Milagre et al., 2010). The most frequent RAS mutations are found at codons for glycine 12 (G12), glycine 13 (G13) or glutamine 61 (Q61). These mutations lead to the disruption of RAS intrinsic 
GTPase activity, locking it into a constitutively activated state in which RAS stimulates downstream effectors, even in the lack of ligands that bind specific membrane receptors (Barbacid, 1987; Bos, 1989). Approximately $77 \%$ of the KRAS mutants involve $G 12$, whereas over $80 \%$ of the NRAS and HRAS mutations involve Q61 (Milagre et al., 2010). Mutations in BRAF gene are found in approximately $66 \%$ of human melanomas (Davies et al., 2002). In melanomas carrying BRAF mutations, 92\% occurs in a single codon valine 600 (V600) (Besaratinia and Pfeifer, 2008).

The Tyr::Hras ${ }^{G 12 V}$ (Tpras) mouse also serves as a UV-induced melanoma mouse model. This transgenic mouse has the activated human T-24 Ha-ras gene expressed under the control of the tyrosinase promoter, which targets the transgene to melanocytes (Powell et al., 1995). The Tpras mice exhibit melanocytic hyperplasia and/or hyperpigmentation. Although they do not develop spontaneous cutaneous melanoma (Powell et al., 1995), a low percentage develop ocular melanoma (Kramer et al., 1998). The Tpras mice are highly prone to developing malignant melanoma even after a single neonatal dose of UV radiation (Hacker et al., 2005); however, they do not develop melanoma by chronic adult UV exposure (Broome Powell et al., 1999). Neonatal exposure of Tpras in a CDK4 ${ }^{\mathrm{R} 24 C / R 24 C}$-null background (mutation that makes this kinase insensitive to p16/Ink4a inhibition) (Rane et al., 1999) greatly decreases age of onset and enhances melanoma aggressiveness (Hacker et al., 2006). Another Tyr::Hras ${ }^{G 12 V}$ transgenic mouse (the regulatory region used to create the transgene was slightly different than the one used for the Tpras mouse) on a 
$\mathrm{p} 19^{\mathrm{ARF}}$ ( $\mathrm{p} 14^{\mathrm{ARF}}$ mouse analog)-null background showed a significant decrease in melanoma latency and an increase in penetrance upon neonatal UV-exposure when compared to non UV-exposed mice (Kannan et al., 2003). In sharp contrast, this enhancement was not observed in neonatal UV-exposed Tyr::Hras ${ }^{G 12 V}$ homozygous for $p 16^{\text {INK4a }}$ deficiency (Kannan et al., 2003), suggesting that a defect in the p53 pathway may be required for UV-induced melanoma. However, analyses of melanoma lesions from Tyr::Hras ${ }^{G 12 V} ;$ p19 $9^{A R F--}$ revealed that nearly $50 \%$ of the tumors presented amplification of CDK6 and loss of $p 16^{\text {INK4a }}$, leading to the conclusion that UV-induced melanoma arises exclusively on Tyr::Hras ${ }^{\mathrm{G} 12 \mathrm{~V}}$ when both $\mathrm{p} 53$ and RB pathways are disrupted (Sharpless et al., 2003).

Analyses of hereditary melanomas that carry germline $p 16^{I N K 4 a}$ mutation revealed that $95 \%$ of these patients presented NRAS mutation at codon Q61 (Eskandarpour et al., 2003). A mouse model with $N R A S^{Q 61 K}$ mutation was developed and it consists of melanocytic expression of $N R A S^{Q 61 K}$ under the control of the tyrosinase promoter, Tyr::Nras ${ }^{\mathrm{Q} 61 \mathrm{~K}}$ (Ackermann et al., 2005). This transgenic mouse presents a hyperpigmented skin phenotype and, at low percentages $(29 \%)$ and long latency ( $\sim$ year), develops spontaneous melanoma (Ackermann et al., 2005). A significant increase in melanoma penetrance (94\%) and a decrease in melanoma latency ( $\sim$ months) are observed when Tyr::Nras ${ }^{\text {Q61K }}$ is on a CDKN2A-deficient background (Ackermann et al., 2005). Tyr::Nras ${ }^{\text {Q61K }}$ carrying a CDK $4^{R 24 C / R 24 C}$ null homozygous mutation also develops spontaneous melanoma, and a single neonatal UV dose significantly decreases 
the age of onset and increases tumor penetrance (Hacker et al., 2010). Treatment of Tyr::Nras ${ }^{\mathrm{Q} 61 \mathrm{~K}} ; C D K 4^{R 24 C / R 24 C}$ neonatal mice with Dimericine (a T4 endonuclease $\mathrm{V}$ liposome lotion known to accelerate the removal of DNA damage induced by UV radiation) prior to UV-exposure do not lead to significant difference in the onset of melanoma development (Hacker et al., 2010), suggesting that neonatal UV-initiated melanomas may be driven by other mechanisms besides the large CPD load and/or their inefficient repair (Hacker et al., 2010).

Mutations in proteins of the NER pathway such as XPA and XPC, and subsequent reduced DNA photodamage repair capacity, result in high indices of skin cancer, including melanoma (Kraemer et al., 1987). In view of that, attempts to generate UV-dependent melanoma mouse models based on NER deficiency were made in order to elucidate the underlying pathogenic mechanisms. Chronic UVB exposure of Xpa null homozygous adult mice did not lead to melanoma development, however it did lead to the development of other forms of skin cancer (Nakane et al., 1995). When Xpa and Ink4a/Arf targeted mutations were combined in a pigmented hairless background mouse and subjected to different UVB exposure regimens, an increased amount of UV-induced nevi was observed, but none of the $\mathrm{Xpa}^{-/} ;$Ink4a/Arf ${ }^{-\alpha}$ developed melanoma (van Schanke et al., 2006). In another study, Stem Cell Factor transgenic (SCF-Tg) mice, which have epidermal melanocytes and are hyperpigmented, carrying a homozygous null Xpa mutation were repeatedly exposed to UV radiation (3 times a week for 10 weeks, starting at $8-10$ weeks of age). Melanoma was observed in $33 \%$ of the 
irradiated mice and, out of those, $55 \%$ showed local metastasis (Yamazaki et al., 2005).

In an Ink4a/Arf deficient background, the loss of Xpc protein leads to a significant increase in melanomagenesis rates after a single neonatal dose of UV radiation (Yang et al., 2007). A recent study carried out with transgenic mice that have $B R A F^{V 600 E}$ mutated gene expressed under the mouse tyrosinase enhancer and promoter, revealed that loss of $p 19^{A R F}$ enhances neonatal UVB-induced melanomagenesis by transcriptionally repressing $X p c$ and, consequently reducing DNA repair damage (Luo et al., 2013).

In a very recent published study, BRAF ${ }^{\mathrm{V} 600 \mathrm{E}}$ melanocytic expression was induced in transgenic mice at 2 months of age with the intention of representing somatic mutation acquisition (Viros et al., 2014). One month later these mice started to be UV-exposed weekly, mimicking mild sunburn in humans, for a period of 6 months. During these exposures, some mice had their back partially covered with UV-proof cloth or topically treated with sunscreen. Results revealed that UV radiation significantly increases melanomagenesis in mice carrying the $B R A F^{V 600 E}$ mutation, that application of UV-proof cloth or sunscreen delayed the onset of UV-induced melanoma, and sunscreen protection leads to reduction in the number of melanomas in UV-exposed $B_{R A F^{V 600 E}}$ transgenic mice. In addition, some $p 53$ mutations that were previously identified in humans are found in the melanoma lesions of these mice, suggesting a direct role of UV radiation in the creation of p53 mutations in melanomas (Viros et al., 2014). In humans, primary and metastatic melanomas have low incidences of $p 53$ point mutations 
or allelic loss; however p53 loss is frequently associated to melanoma progression (Yang et al., 2001).

One of the most well recognized UV-induced melanoma mouse models is the Hepatocyte Growth Factor/Scatter Factor (HGF/SF) transgenic mouse (Noonan et al., 2000; Noonan et al., 2001). This model is very successful because of the amount of major similarities it has with human melanoma, such as the requirement of neonatal UV radiation recapitulating the critical childhood sunlight exposure in melanoma development (Whiteman et al., 2001), adult exposure as an additional factor (Autier and Dore, 1998) and general melanoma histopathological features (Smoller, 2006). In the HGF/SF transgenic mouse, the metallothionein-gene promoter drives the overexpression of HGF/SF to a wide variety of tissues. The HGF/SF binds to the receptor tyrosine kinase Met, promotes melanocyte proliferation and migration, which leads to accumulation of large numbers of melanocytes in the dermis, epidermis and dermal-epidermal junction, similar to their distribution in human skin (Takayama et al., 1996). These mice spontaneously develop melanoma with the mean age onset of approximately 21 months. Chronic UV-exposure of these transgenic mice do not accelerate melanomagenesis in comparison with non UV-exposed mice; however it induces the development of non-melanocytic tumors such as squamous cell carcinomas, squamous papillomas and sarcomas (Noonan et al., 2000). In contrast, a single neonatal erythemal dose to 3.5 day old HGF/SF mice induces cutaneous melanoma with significantly reduced latency and most of these lesions histologically resemble human lesions at various stages of 
progression, including metastasis (Noonan et al., 2001). Exposure of HGF/SF neonates to a second UV erythemal dose at 6 weeks, does not accelerate melanomagenesis, however it significantly increases the number of melanocytic lesions arising per mouse as well as the incidence of non-melanocytic tumors (Noonan et al., 2001). The rates of neonatal UVB-induced melanoma appearance in pigmented HGF (Noonan et al., 2012) and albino HGF transgenic mice (De Fabo et al., 2004) are not significantly different. However, melanomas are initiated by UVA in pigmented HGF (Noonan et al., 2012) but not in albino FVB-HGF mice (De Fabo et al., 2004). These results suggested that the initiation of melanoma by UVB is pigment independent whereas melanoma induction by UVA is completely pigment dependent. Analyses of direct DNA damage in pigmented and albino mice after either neonatal UVB-exposure or UVA-exposure revealed that amounts of CPD formation were not significantly different between pigmented and albino mice, suggesting that UV-induced CPD formation was not the reason for the difference in melanoma induction between pigmented and albino animals. Analyses of indirect DNA damage revealed a strikingly increased amount of oxidative DNA damage in pigmented mice after UVA-exposure but not in albino mice; and the production of oxidative DNA damage required both UVA and melanin (Noonan et al., 2012). In conclusion, these results showed that the presence of melanin ( $>90 \%$ eumelanin and $<10 \%$ pheomelanin) is a requirement for melanoma induction by UVA, but not UVB in HGF/SF transgenic mice (Noonan et al., 2012). The inverse of this result was observed when albino 
HGF/SF transgenic neonatal mice are UV-exposed; in this case UVB, but not UVA, was found to be the melanomagenic waveband (De Fabo et al., 2004).

Deletion of the Nonmetastatic 23 (Nm23) gene, the first metastasis suppressor gene to be described, in neonatal UV-exposed HGF/SF transgenic mice led to the development of melanomas with aggressive metastatic potential especially to the same organs observed in human melanoma metastasis, such as lymph nodes, lung and liver (Jarrett et al., 2013). Another study showed that a single neonatal erythemal UV dose of HGF/SF mice carrying a null Ink4a/Arf mutation, significantly decreased melanomagenesis median onset to just 50 days versus the 238 days observed in HGF/SF mice with wild type Ink4a/Arf (Recio et al., 2002). An experiment carried out in HGF/SF transgenic mice with $C D K 4^{R 24 C / R 24 C}$ null mutation, revealed that a single neonatal UV dose decreases the latency and accelerates the growth of primary melanomas resulting in a significant reduction in the time between melanoma onset and death (61 days vs. 96 days). Moreover, lung metastases are more frequently observed in UVirradiated than in the untreated cohort of HGF/SF; CDK $4^{R 24 C / R 24 C}$ mice $(73 \%$ vs. 47\%) (Gaffal et al., 2011). In a recently published study, the carcinogen DMBA (7,12-dimethylbenz(a)anthracene) was applied in the dorsal skin of adult HGF/SF; $C D K 4^{R 24 C / R 24 C}$ mice to first initiate melanomagenesis and afterwards these primary cutaneous melanomas were UV-exposed twice a week for a period of 6 weeks (Bald et al., 2014). Results revealed that UV radiation of the skin stimulates keratinocytes to release the High Mobility Group 1 (HMGB1) cytokine leading to the recruitment and activation of neutrophils to the skin and initiation of 
inflammatory response. This inflammatory environment is believed to stimulate angiotropism and promote the migration of melanoma cells, which results in metastasis (Bald et al., 2014). This result complements the findings that UVRinduced inflammation promotes melanomagenesis in neonatal mice via interferon- $\gamma$ secretion by recruited macrophages (Zaidi et al., 2011). interferon- $\gamma$ was believed to be beneficial to an innate immune system defense against cancer, however now it is believed that, under specific circumstances, it may instead promote melanomagenesis (Zaidi and Merlino, 2011).

Twenty years ago, the first UV-induced melanoma mouse model (KleinSzanto et al., 1994) was reported. Since then, several models were developed based on different signaling pathways that have been associated to melanomagenesis. Studying these models revealed different mechanisms by which these specific pathways could lead to melanomagenesis. An important pathway that, up to now, has not been explored for the creation of a melanoma mouse model is the Endothelin signaling pathway. The signaling pathway of Endothelin 3 (Edn3) ligand and its seven-transmembrane receptor EdnrB is essential for many aspects of melanocyte development. In vitro studies demonstrated that Edn3 markedly increases the proliferation of pluripotent neural crest cells, stimulates the production of large numbers of melanocyte precursors and eventually leads to their differentiation as pigmented cells (Lahav et al., 1996; Opdecamp et al., 1998; Reid et al., 1996; Stone et al., 1997). Many studies infer that the Edn3/EdnrB signaling pathway regulates several processes in the development of different types of cancers such as ovarian, pulmonary, colorectal, 
cervical, breast cancer, and also malignant melanoma (Bagnato et al., 2004). The association of this pathway with the progression and metastatic potential of melanoma cells has been reported (Bagnato and Natali, 2004; Lahav et al., 2004; Rosano et al., 2004). Melanoma cell lines treated with the EdnrB specific antagonist BQ788 showed increased apoptosis and increased Vascular Endothelial Growth Factor gene expression. In vivo, administration of BQ788 to immunocompromised mice slowed down human melanoma tumor growth by decreasing cell viability (Lahav et al., 1999; Lahav et al., 2004). Treatment of melanoma cells with Endothelin 1 (Edn1) and Edn3 results in downregulation of E-cadherin, and upregulation of $\mathrm{N}$-cadherin and matrix metalloproteinases, which are important for cell-cell adhesion and cell-cell communication. These results could be linked to the disruption of normal tumor-host interactions and progression of cutaneous melanoma (Bagnato et al., 2004; Rosano et al., 2004). Gene expression analysis of metastatic melanoma cells from tissue biopsies revealed an abnormal upregulation of the EDN3 gene. Further, an increase in metastatic melanoma cell survival was observed Edn3-treated cells in vitro (Tang et al., 2008).

Although experiments on genetically modified mice have provided us with a better understanding of how UV radiation can initiate and stimulate progression in melanoma, novel UV-induced mouse models are in need to be developed to help fill out the vast amount of gaps that still exists, in order to optimally fight this life-threatening malignancy. 


\subsection{Research Questions}

Melanomagenesis is influenced by environmental and genetic factors as well as tumor-host interactions. There is great amount of evidence that UV radiation exposure has a major impact in DNA damage and other molecular events, and that UV acts as a carcinogen with both initiating and promoting properties. It is commonly accepted in cancer biology that transcription factors and signaling pathways that direct the development of a specific cell lineage will most likely be deregulated in transformed cells that descend from that cell lineage during the process of tumorigenesis. One of the critical pathways that regulate various aspects of melanocyte development, the Edn3/EdnrB signaling pathway, has also been associated with melanoma progression (SaldanaCaboverde and Kos, 2010). The NER pathway repairs photoproducts induced by UV radiation and its disruption leads to skin carcinogenesis, including melanoma (Yarosh et al., 2005). Given that over-activation of the Edn3/EdnrB signaling pathway may be involved in the malignant progression and metastatic spread of melanoma and that DNA damage caused by UV radiation is a causative agent in melanoma development, my research questions directly address if UV radiation exposure combined with NER loss and over-activation of the Edn3/EdnrB pathway can lead to melanomagenesis:

Question \#1: Is UV exposure of transgenic mice that express Endothelin 3 under the Keratin 5 (K5) promoter sufficient for melanoma development?

Our laboratory generated transgenic mice that produce excessive Edn3 by epidermal keratinocytes throughout development (K5-Edn3) (Garcia et al., 2008). 
These mice have hyperpigmented skin as a result of the accumulation of large numbers of melanocytes in the epidermal/dermal junction where they are not normally found (Garcia et al., 2008). This condition could serve as the basis for melanocytic tumor formation and, upon neonatal UV exposure, I hypothesize that K5-Edn3 transgenic mice will develop melanoma.

Question \#2: Does NER disruption affect melanoma penetrance and latency in UV-exposed transgenic mice that express Endothelin 3 under the K5 promoter?

The Xpa and Xpc proteins have important roles in the NER pathway (Cleaver et al., 2009; Ortonne, 2002). It is well established that mutations in this pathway reduces DNA photodamage repair capacity, resulting in high indices of skin cancer, including melanoma (Kraemer et al., 1987). Thus, I hypothesize that Xpa or Xpc deficiency will result in increased penetrance and a decreased latency in the UV-induced melanoma mouse model.

Question \#3: What is the mutation profile of melanoma lesions that arise in UVexposed transgenic mice that express Endothelin 3 under the $\mathrm{K} 5$ promoter?

UV-induced DNA damage causes typical genetic mutations, $\mathrm{C}$ to $\mathrm{T}$ and $\mathrm{CC}$ to TT transitions, called "UV signature mutations". This type of mutations is prominently found in human cutaneous melanoma (Berger et al., 2012; Pleasance et al., 2010). Several human cancers, including melanoma, present mutations in the three human RAS genes (NRAS, KRAS, HRAS) (Ball et al., 1994; Omholt et al., 2002) and, mutations in the RAS effector protein BRAF have been identified in $66 \%$ of melanoma patients (Davies et al., 2002). Interestingly, mutations found in BRAF and NRAS genes in human melanomas are not UV-signature mutations (Hodis et al., 2012). I 
hypothesize that lesions removed from K5-Edn3 UV-induced melanoma mouse model will present, but not restrictively, UV signature mutations in some of these genes.

Question \#4: How does the timing of UV exposure affect melanomagenesis?

Epidemiological data suggest that melanoma development results from intense and intermittent UV doses, particularly during childhood (Whiteman et al., 2001). Results obtained from various mouse models support the notion that childhood sunburns constitute a major melanoma risk factor (Hacker et al., 2005; Noonan et al., 2001). Since neonatal murine skin has higher percentage of melanocytic progenitor cells than the skin of adult mice (Hirobe, 1984), when UVirradiated, these cells can acquire DNA photodamage that would lead to DNA mutations, resulting in melanomagenesis later on in life. I hypothesize that a single neonatal UV dose is essential for melanoma development and that a second exposure, during adult stage, will cause an increase in melanoma penetrance and, mainly a decrease in melanoma latency. Further, I expect that mice exposed to UV radiation only at the adult stage will not develop melanoma. 


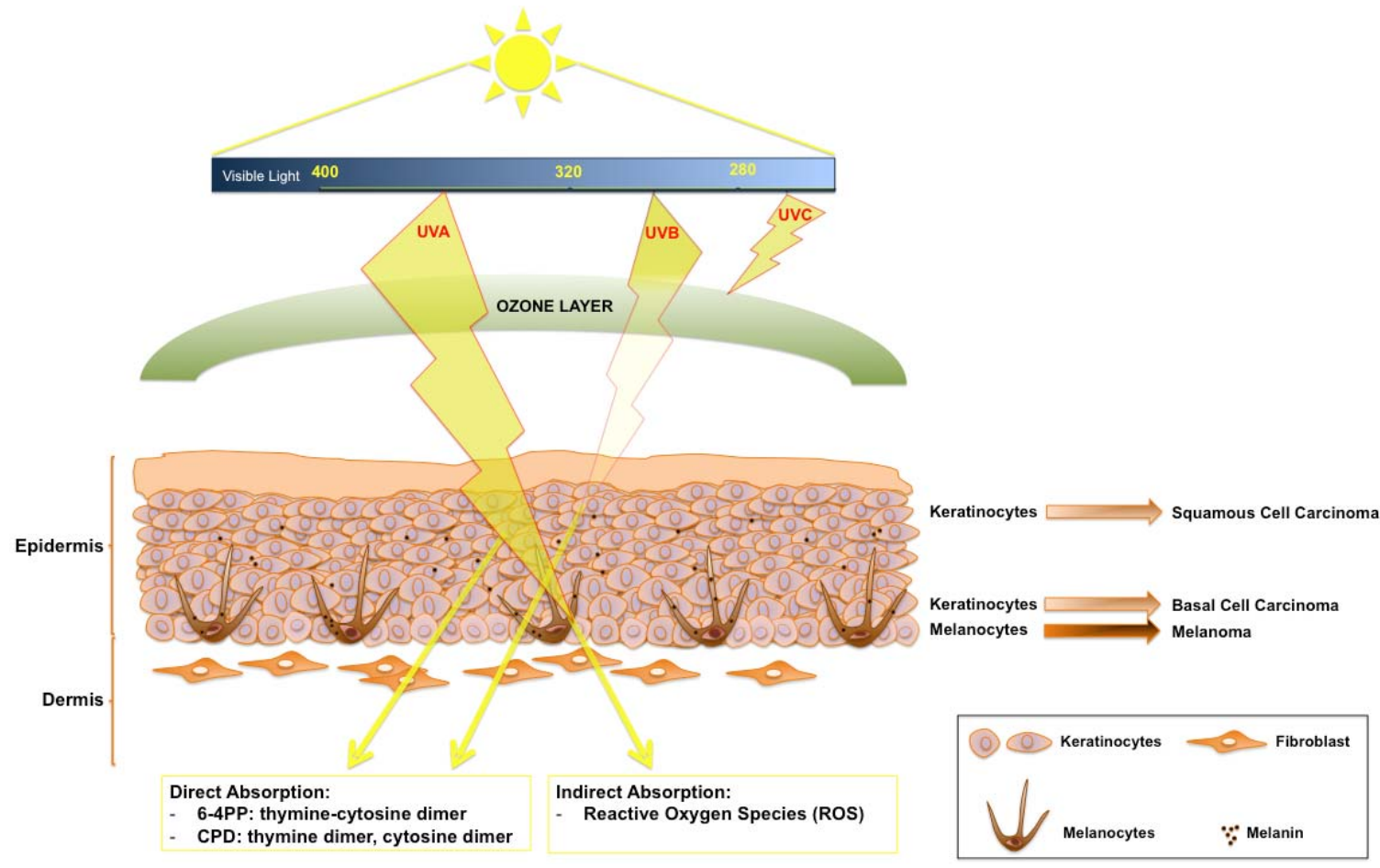

Figure 1.1 The effects of UV radiation on the human skin. Schematic of UV rays passing through the ozone layer and reaching the human skin. Keratinocytes represent $95 \%$ and melanocytes represent $1-2 \%$ of the cells that constitute human epidermis. UV light is subdivided in three wavelengths: UVC, UVB, and UVA. UVC (below $280 \mathrm{~nm}$ ) is completely blocked by the ozone layer. Minimum amounts of UVB (280-320m) are capable of passing through the ozone layer and penetrate the first layers of skin. Most of UVA (320-400nm) is able to reach earth' surface and it can penetrate deeply into the skin. UVA and UVB can directly lead to the formation of pyrimidine dimers, whereas indirect absorption by UVA can lead to reactive oxygen species formation. Localization of different types of cells that give rise to melanoma (melanocytes) SCC and BCC (keratinocytes). 


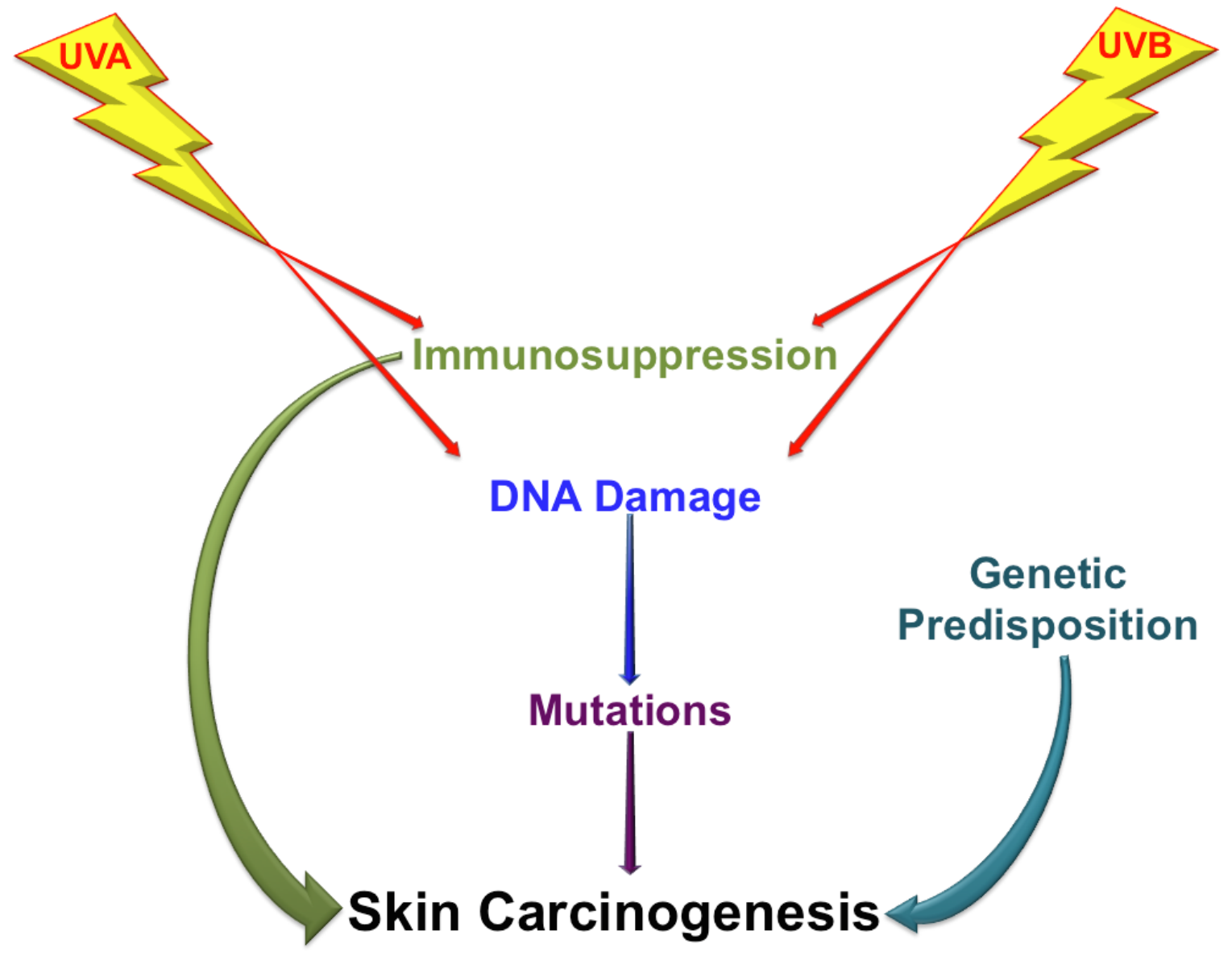

Figure 1.2 Ways in which UV radiation can give rise to skin cancer. Genetic predisposition added to the harmful UV radiation effects enhances the probability of skin carcinogenesis development. 


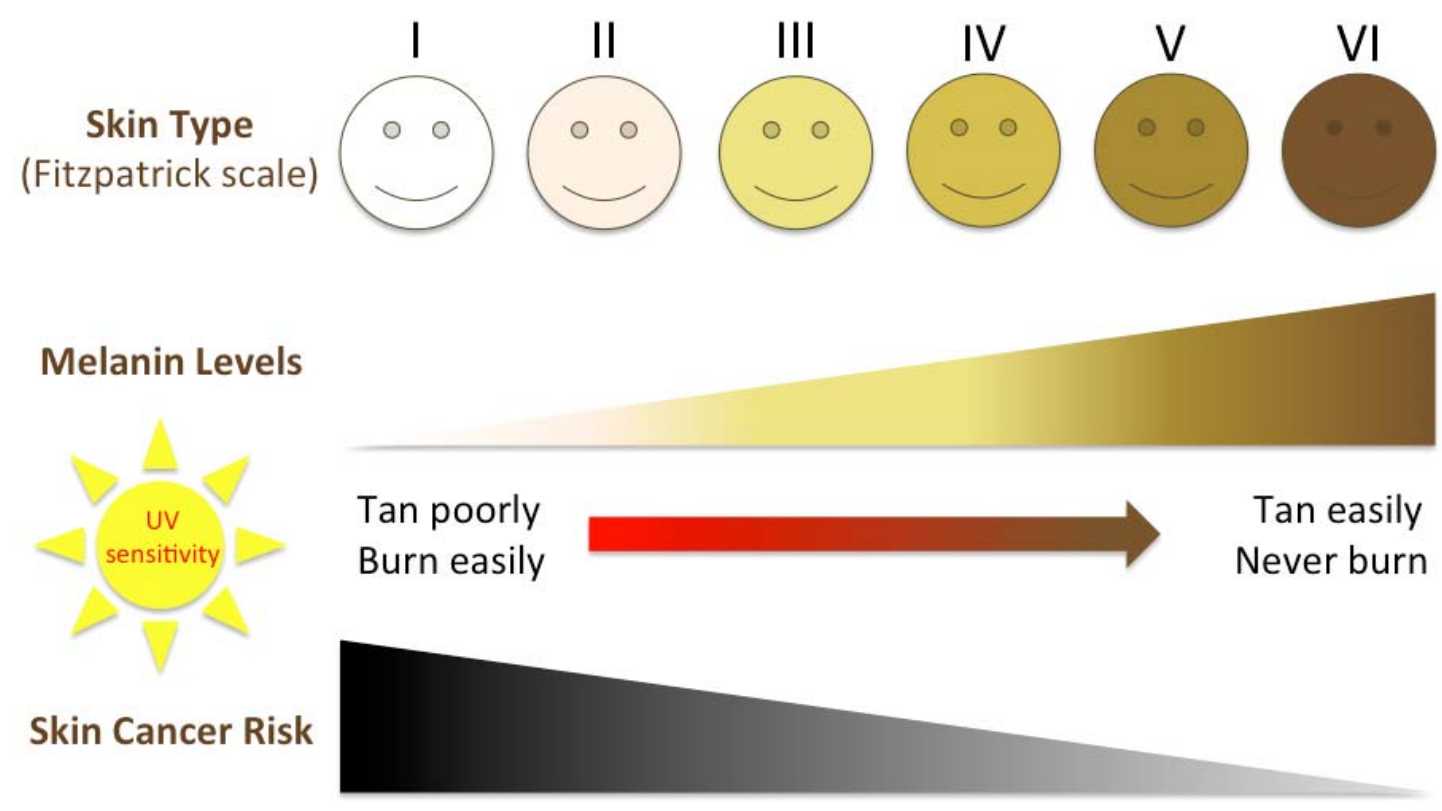

Figure 1.3 Relationship of skin type, UV radiation and skin cancer risk. Individuals with fair skin have low epidermal melanin levels, almost never tan, and burn easily after UV exposure. These phenotypes are associated with high predisposition of skin cancer development. Individuals with darker pigmented skin tend to tan easier rather than burn and are less likely to develop skin carcinogenesis. 


\subsection{References}

Ackermann, J., Frutschi, M., Kaloulis, K., Mckee, T., Trumpp, A., and Beermann, F. (2005). Metastasizing melanoma formation caused by expression of activated N-RasQ61K on an INK4a-deficient background. Cancer Res 65, 4005-11.

Agarwala, S. S. (2009). Current systemic therapy for metastatic melanoma. Expert Rev Anticancer Ther 9, 587-95.

Agbai, O. N., Buster, K., Sanchez, M., Hernandez, C., Kundu, R. V., Chiu, M., Roberts, W. E., Draelos, Z. D., Bhushan, R., Taylor, S. C., et al. (2014). Skin cancer and photoprotection in people of color: a review and recommendations for physicians and the public. J Am Acad Dermatol 70, $748-62$.

American Cancer Society (2014a). Cancer Facts \& Figures 2014. (Atlanta, GA: American Cancer Society).

American Cancer Society (2014b). Skin Cancer Facts. (Atlanta, GA: American Cancer Society).

American Cancer Society (2014c). Skin Cancer: Basal and Squamous Cell. (Atlanta, GA: American Cancer Society).

Antony, G. K., and Dudek, A. Z. (2010). Interleukin 2 in cancer therapy. Current medicinal chemistry $17,3297-302$.

Armstrong, B. K., and Kricker, A. (2001). The epidemiology of UV induced skin cancer. J Photochem Photobiol B 63, 8-18.

Atkins, M. B., Kunkel, L., Sznol, M., and Rosenberg, S. A. (2000). High-dose recombinant interleukin-2 therapy in patients with metastatic melanoma: long-term survival update. The cancer journal from Scientific American 6 Suppl 1, S11-4.

Atkins, M. B., Lotze, M. T., Dutcher, J. P., Fisher, R. I., Weiss, G., Margolin, K., Abrams, J., Sznol, M., Parkinson, D., Hawkins, M., et al. (1999). Highdose recombinant interleukin 2 therapy for patients with metastatic melanoma: analysis of 270 patients treated between 1985 and 1993. J Clin Oncol 17, 2105-16.

Autier, P., and Dore, J. F. (1998). Influence of sun exposures during childhood and during adulthood on melanoma risk. EPIMEL and EORTC Melanoma Cooperative Group. European Organisation for Research and Treatment of Cancer. Int J Cancer 77, 533-7. 
Bagnato, A., and Natali, P. G. (2004). Endothelin receptors as novel targets in tumor therapy. Journal of translational medicine 2, 16.

Bagnato, A., Rosano, L., Spinella, F., Di Castro, V., Tecce, R., and Natali, P. G. (2004). Endothelin B receptor blockade inhibits dynamics of cell interactions and communications in melanoma cell progression. Cancer Res 64, 1436-43.

Balch, C. M., Gershenwald, J. E., Soong, S. J., Thompson, J. F., Atkins, M. B., Byrd, D. R., Buzaid, A. C., Cochran, A. J., Coit, D. G., Ding, S., et al. (2009). Final version of 2009 AJCC melanoma staging and classification. J Clin Oncol 27, 6199-206.

Bald, T., Quast, T., Landsberg, J., Rogava, M., Glodde, N., Lopez-Ramos, D., Kohlmeyer, J., Riesenberg, S., Van Den Boorn-Konijnenberg, D., HomigHolzel, C., et al. (2014). Ultraviolet-radiation-induced inflammation promotes angiotropism and metastasis in melanoma. Nature 507, 109-13.

Ball, N. J., Yohn, J. J., Morelli, J. G., Norris, D. A., Golitz, L. E., and Hoeffler, J. P. (1994). Ras mutations in human melanoma: a marker of malignant progression. J Invest Dermatol 102, 285-90.

Ballantyne, A. D., and Garnock-Jones, K. P. (2013). Dabrafenib: first global approval. Drugs 73, 1367-76.

Barbacid, M. (1987). ras genes. Annu Rev Biochem 56, 779-827.

Barrett, J. H., Taylor, J. C., Bright, C., Harland, M., Dunning, A. M., Akslen, L. A., Andresen, P. A., Avril, M. F., Azizi, E., Bianchi Scarra, G., et al. (2014). Fine mapping of genetic susceptibility loci for melanoma reveals a mixture of single variant and multiple variant regions. Int J Cancer.

Bauer, A., Diepgen, T. L., and Schmitt, J. (2011). Is occupational solar ultraviolet irradiation a relevant risk factor for basal cell carcinoma? A systematic review and meta-analysis of the epidemiological literature. $\mathrm{Br} \mathrm{J}$ Dermatol $165,612-25$.

Berger, M. F., Hodis, E., Heffernan, T. P., Deribe, Y. L., Lawrence, M. S., Protopopov, A., Ivanova, E., Watson, I. R., Nickerson, E., Ghosh, P., et al. (2012). Melanoma genome sequencing reveals frequent PREX2 mutations. Nature 485, 502-6.

Berger, Y., Bernasconi, C. C., and Juillerat-Jeanneret, L. (2006). Targeting the endothelin axis in human melanoma: combination of endothelin receptor antagonism and alkylating agents. Exp Biol Med (Maywood) 231, 1111-9. 
Besaratinia, A., and Pfeifer, G. P. (2008). Sunlight ultraviolet irradiation and BRAF V600 mutagenesis in human melanoma. Human mutation 29, 98391.

Bos, J. L. (1989). ras oncogenes in human cancer: a review. Cancer Res 49, 4682-9.

Brahmer, J. R., Drake, C. G., Wollner, I., Powderly, J. D., Picus, J., Sharfman, W. H., Stankevich, E., Pons, A., Salay, T. M., Mcmiller, T. L., et al. (2010). Phase I study of single-agent anti-programmed death-1 (MDX-1106) in refractory solid tumors: safety, clinical activity, pharmacodynamics, and immunologic correlates. J Clin Oncol 28, 3167-75.

Brash, D. E., and Haseltine, W. A. (1982). UV-induced mutation hotspots occur at DNA damage hotspots. Nature 298, 189-92.

Broome Powell, M., Gause, P. R., Hyman, P., Gregus, J., Lluria-Prevatt, M., Nagle, R., and Bowden, G. T. (1999). Induction of melanoma in TPras transgenic mice. Carcinogenesis 20, 1747-53.

Burke, K. E. (2010). Photoaging: the role of oxidative stress. Giornale italiano di dermatologia e venereologia : organo ufficiale, Societa italiana di dermatologia e sifilografia 145, 445-59.

Byrne, S. N., Ahmed, J., and Halliday, G. M. (2005). Ultraviolet B but not A radiation activates suppressor $B$ cells in draining lymph nodes. Photochem Photobiol 81, 1366-70.

Byrne, S. N., and Halliday, G. M. (2005). B cells activated in lymph nodes in response to ultraviolet irradiation or by interleukin-10 inhibit dendritic cell induction of immunity. J Invest Dermatol 124, 570-8.

Cadet, J., Berger, M., Douki, T., Morin, B., Raoul, S., Ravanat, J. L., and Spinelli, S. (1997). Effects of UV and visible radiation on DNA-final base damage. Biological chemistry 378, 1275-86.

Cadet, J., and Douki, T. (2011). Oxidatively generated damage to DNA by UVA radiation in cells and human skin. $J$ Invest Dermatol 131, 1005-7.

Cadet, J., Douki, T., Ravanat, J. L., and Di Mascio, P. (2009). Sensitized formation of oxidatively generated damage to cellular DNA by UVA radiation. Photochem Photobiol Sci 8, 903-11.

Calonje, E., Brenn, T., Lazar, A., and Mckee, P. H. (2012). Tumors of the surface epithelium. In McKee's Pathology of the skin with clinical correlations. Calonje, E., Brenn, T., Lazar, A. \& Mckee, P. H., eds.: Elsevier Saunders), pp. 1076-1149. 
Castellano, M., and Parmiani, G. (1999). Genes involved in melanoma: an overview of INK4a and other loci. Melanoma Res 9, 421-32.

Chacon-Salinas, R., Chen, L., Chavez-Blanco, A. D., Limon-Flores, A. Y., Ma, Y., and Ullrich, S. E. (2014). An essential role for platelet-activating factor in activating mast cell migration following ultraviolet irradiation. J Leukoc Biol $95,139-48$.

Chapman, P. B., Hauschild, A., Robert, C., Haanen, J. B., Ascierto, P., Larkin, J., Dummer, R., Garbe, C., Testori, A., Maio, M., et al. (2011). Improved survival with vemurafenib in melanoma with BRAF V600E mutation. $\mathrm{N}$ Engl J Med 364, 2507-16.

Chin, L., Pomerantz, J., and Depinho, R. A. (1998). The INK4a/ARF tumor suppressor: one gene--two products--two pathways. Trends Biochem Sci 23, 291-6.

Cleaver, J. E., Lam, E. T., and Revet, I. (2009). Disorders of nucleotide excision repair: the genetic and molecular basis of heterogeneity. Nature reviews. Genetics 10, 756-68.

Clinicaltrials.Gov (2014). Study of BMS-936558 vs. Dacarbazine in Untreated, Unresectable or Metastatic Melanoma (CheckMate 066). ClinicalTrials.gov).

Clozel, M., Breu, V., Gray, G. A., Kalina, B., Loffler, B. M., Burri, K., Cassal, J. M., Hirth, G., Muller, M., Neidhart, W., et al. (1994). Pharmacological characterization of bosentan, a new potent orally active nonpeptide endothelin receptor antagonist. J Pharmacol Exp Ther 270, 228-35.

Cockerell, C. J., Tran, K. T., Carucci, J., Tierney, E., Lang, P., Maize St, J. C., and Rigel, D. S. (2011). Basal Cell Carcinoma. In Cancer of the Skin. Rigel, D. S., Robinson, J., Ross, M., Friedman, R., Cockerell, C., Lim, H. \& Stockfleth, E., eds. (Philadelphia, PA: Elsevier Saunders), pp. 99-123.

Crowson, A. N., Magro, C. M., and Mihm, M. C. (2006). Prognosticators of melanoma, the melanoma report, and the sentinel lymph node. Mod Pathol 19 Suppl 2, S71-87.

D'orazio, J. A., Nobuhisa, T., Cui, R., Arya, M., Spry, M., Wakamatsu, K., Igras, V., Kunisada, T., Granter, S. R., Nishimura, E. K., et al. (2006). Topical drug rescue strategy and skin protection based on the role of Mc1r in UVinduced tanning. Nature 443, 340-4. 
Damian, D. L., Halliday, G. M., Taylor, C. A., and Barnetson, R. S. (1998). Ultraviolet radiation induced suppression of Mantoux reactions in humans. J Invest Dermatol 110, 824-7.

Davies, H., Bignell, G. R., Cox, C., Stephens, P., Edkins, S., Clegg, S., Teague, J., Woffendin, H., Garnett, M. J., Bottomley, W., et al. (2002). Mutations of the BRAF gene in human cancer. Nature 417, 949-54.

Daya-Grosjean, L., and Sarasin, A. (2005). The role of UV induced lesions in skin carcinogenesis: an overview of oncogene and tumor suppressor gene modifications in xeroderma pigmentosum skin tumors. Mutat Res 571, 4356.

De Fabo, E. C., Noonan, F. P., Fears, T., and Merlino, G. (2004). Ultraviolet B but not ultraviolet A radiation initiates melanoma. Cancer Res 64, 6372-6.

De Gruij, F. R., Van Kranen, H. J., and Mullenders, L. H. (2001). UV-induced DNA damage, repair, mutations and oncogenic pathways in skin cancer. J Photochem Photobiol B 63, 19-27.

Del Bino, S., Sok, J., and Bernerd, F. (2013). Assessment of ultraviolet-radiationinduced DNA damage within melanocytes in skin of different constitutive pigmentation. Br J Dermatol 168, 1120-3.

Demunter, A., De Wolf-Peeters, C., Degreef, H., Stas, M., and Van Den Oord, J. J. (2001). Expression of the endothelin-B receptor in pigment cell lesions of the skin. Evidence for its role as tumor progression marker in malignant melanoma. Virchows Arch 438, 485-91.

Diepgen, T. L., and Mahler, V. (2002). The epidemiology of skin cancer. $\mathrm{Br} \mathrm{J}$ Dermatol 146 Suppl 61, 1-6.

Downward, J. (1996). Control of ras activation. Cancer Surv 27, 87-100.

Edge, S. B., and Compton, C. C. (2010). The American Joint Committee on Cancer: the 7th edition of the AJCC cancer staging manual and the future of TNM. Ann Surg Oncol 17, 1471-4.

Eskandarpour, M., Hashemi, J., Kanter, L., Ringborg, U., Platz, A., and Hansson, J. (2003). Frequency of UV-inducible NRAS mutations in melanomas of patients with germline CDKN2A mutations. J Natl Cancer Inst 95, 790-8.

Falchook, G. S., Lewis, K. D., Infante, J. R., Gordon, M. S., Vogelzang, N. J., Demarini, D. J., Sun, P., Moy, C., Szabo, S. A., Roadcap, L. T., et al. (2012). Activity of the oral MEK inhibitor trametinib in patients with advanced melanoma: a phase 1 dose-escalation trial. Lancet Oncol 13, 782-9. 
Feuerstein, I., and Geller, A. C. (2008). Skin cancer education in transplant recipients. Progress in transplantation 18, 232-41; quiz 242.

Fisher, G. J., Kang, S., Varani, J., Bata-Csorgo, Z., Wan, Y., Datta, S., and Voorhees, J. J. (2002). Mechanisms of photoaging and chronological skin aging. Arch Dermatol 138, 1462-70.

Fisher, M. S., and Kripke, M. L. (1977). Systemic alteration induced in mice by ultraviolet light irradiation and its relationship to ultraviolet carcinogenesis. Proc Natl Acad Sci U S A 74, 1688-92.

Fitzpatrick, T. B., Sober, A. J., Pearson, B. J., and Lew, R. (1977). Cutaneous carcinogenic effects of sunlight in humans. In Research in Photobiology. Springer), pp. 485-491.

Flaherty, K. T., Infante, J. R., Daud, A., Gonzalez, R., Kefford, R. F., Sosman, J., Hamid, O., Schuchter, L., Cebon, J., Ibrahim, N., et al. (2012a). Combined BRAF and MEK inhibition in melanoma with BRAF V600 mutations. N Engl J Med 367, 1694-703.

Flaherty, K. T., Robert, C., Hersey, P., Nathan, P., Garbe, C., Milhem, M., Demidov, L. V., Hassel, J. C., Rutkowski, P., Mohr, P., et al. (2012b). Improved survival with MEK inhibition in BRAF-mutated melanoma. N Engl J Med 367, 107-14.

Friedberg, E. C. (2001). How nucleotide excision repair protects against cancer. Nat Rev Cancer 1, 22-33.

Gaffal, E., Landsberg, J., Bald, T., Sporleder, A., Kohlmeyer, J., and Tuting, T. (2011). Neonatal UVB exposure accelerates melanoma growth and enhances distant metastases in Hgf-Cdk4(R24C) C57BL/6 mice. Int J Cancer 129, 285-94.

Gandini, S., Sera, F., Cattaruzza, M. S., Pasquini, P., Zanetti, R., Masini, C., Boyle, P., and Melchi, C. F. (2005). Meta-analysis of risk factors for cutaneous melanoma: III. Family history, actinic damage and phenotypic factors. Eur J Cancer 41, 2040-59.

Garcia, R. J., Ittah, A., Mirabal, S., Figueroa, J., Lopez, L., Glick, A. B., and Kos, L. (2008). Endothelin 3 induces skin pigmentation in a keratin-driven inducible mouse model. J Invest Dermatol 128, 131-42.

Garg, S., Carroll, R. P., Walker, R. G., Ramsay, H. M., and Harden, P. N. (2009). Skin cancer surveillance in renal transplant recipients: re-evaluation of U.K. practice and comparison with Australian experience. $\mathrm{Br} \mathrm{J}$ Dermatol $160,177-9$. 
Geisler, J., Bachmann, I. M., Nyakas, M., Helsing, P., Fjosne, H. E., Maehle, L. O., Aamdal, S., Eide, N. A., Svendsen, H. L., Straume, O., et al. (2013). Malignant melanoma--diagnosis, treatment and follow-up in Norway. Tidsskr Nor Laegeforen 133, 2154-9.

Goldstein, A. M., and Tucker, M. A. (2001). Genetic epidemiology of cutaneous melanoma: a global perspective. Arch Dermatol 137, 1493-6.

Gorman, S., Tan, J. W., Yerkovich, S. T., Finlay-Jones, J. J., and Hart, P. H. (2007). CD4+ T cells in lymph nodes of UVB-irradiated mice suppress immune responses to new antigens both in vitro and in vivo. J Invest Dermatol 127, 915-24.

Grande Sarpa, H., Reinke, K., Shaikh, L., Leong, S. P., Miller, J. R., 3rd, Sagebiel, R. W., and Kashani-Sabet, M. (2006). Prognostic significance of extent of ulceration in primary cutaneous melanoma. Am J Surg Pathol 30, 1396-400.

Hacker, E., Irwin, N., Muller, H. K., Powell, M. B., Kay, G., Hayward, N., and Walker, G. (2005). Neonatal ultraviolet radiation exposure is critical for malignant melanoma induction in pigmented Tpras transgenic mice. J Invest Dermatol 125, 1074-7.

Hacker, E., Muller, H. K., Hayward, N., Fahey, P., and Walker, G. (2010). Enhancement of DNA repair using topical T4 endonuclease $V$ does not inhibit melanoma formation in Cdk4(R24C/R24C)/Tyr-Nras(Q61K) mice following neonatal UVR. Pigment Cell Melanoma Res 23, 121-8.

Hacker, E., Muller, H. K., Irwin, N., Gabrielli, B., Lincoln, D., Pavey, S., Powell, M. B., Malumbres, M., Barbacid, M., Hayward, N., et al. (2006). Spontaneous and UV radiation-induced multiple metastatic melanomas in Cdk4R24C/R24C/TPras mice. Cancer Res 66, 2946-52.

Halliday, G. M., and Cadet, J. (2012). It's all about position: the basal layer of human epidermis is particularly susceptible to different types of sunlightinduced DNA damage. J Invest Dermatol 132, 265-7.

Haluska, F. G., and Hodi, F. S. (1998). Molecular genetics of familial cutaneous melanoma. J Clin Oncol 16, 670-82.

Hauschild, A., Grob, J. J., Demidov, L. V., Jouary, T., Gutzmer, R., Millward, M., Rutkowski, P., Blank, C. U., Miller, W. H., Jr., Kaempgen, E., et al. (2012). Dabrafenib in BRAF-mutated metastatic melanoma: a multicentre, openlabel, phase 3 randomised controlled trial. Lancet 380, 358-65. 
Heakal, Y., Kester, M., and Savage, S. (2011). Vemurafenib (PLX4032): an orally available inhibitor of mutated BRAF for the treatment of metastatic melanoma. Ann Pharmacother 45, 1399-405.

Hemminki, K., Zhang, H., and Czene, K. (2003). Familial and attributable risks in cutaneous melanoma: effects of proband and age. J Invest Dermatol 120, 217-23.

Hill, L. L., Shreedhar, V. K., Kripke, M. L., and Owen-Schaub, L. B. (1999). A critical role for Fas ligand in the active suppression of systemic immune responses by ultraviolet radiation. J Exp Med 189, 1285-94.

Hirano, F., Kaneko, K., Tamura, H., Dong, H., Wang, S., Ichikawa, M., Rietz, C., Flies, D. B., Lau, J. S., Zhu, G., et al. (2005). Blockade of B7-H1 and PD-1 by monoclonal antibodies potentiates cancer therapeutic immunity. Cancer Res 65, 1089-96.

Hirobe, T. (1984). Histochemical survey of the distribution of the epidermal melanoblasts and melanocytes in the mouse during fetal and postnatal periods. The Anatomical record 208, 589-94.

Hocker, T. L., Singh, M. K., and Tsao, H. (2008). Melanoma genetics and therapeutic approaches in the 21st century: moving from the benchside to the bedside. J Invest Dermatol 128, 2575-95.

Hodi, F. S., O'day, S. J., Mcdermott, D. F., Weber, R. W., Sosman, J. A., Haanen, J. B., Gonzalez, R., Robert, C., Schadendorf, D., Hassel, J. C., et al. (2010). Improved survival with ipilimumab in patients with metastatic melanoma. N Engl J Med 363, 711-23.

Hodis, E., Watson, I. R., Kryukov, G. V., Arold, S. T., Imielinski, M., Theurillat, J. P., Nickerson, E., Auclair, D., Li, L., Place, C., et al. (2012). A landscape of driver mutations in melanoma. Cell 150, 251-63.

Hoeijmakers, J. H. (2001). Genome maintenance mechanisms for preventing cancer. Nature 411, 366-74.

Holbrook, K. A., Underwood, R. A., Vogel, A. M., Gown, A. M., and Kimball, H. (1989). The appearance, density and distribution of melanocytes in human embryonic and fetal skin revealed by the anti-melanoma monoclonal antibody, HMB-45. Anatomy and embryology 180, 443-55.

Holzle, E., and Honigsmann, H. (2005). [UV-radiation--sources, wavelength, environment]. J Dtsch Dermatol Ges 3 Suppl 2, S3-10. 
Ichihashi, M., Ueda, M., Budiyanto, A., Bito, T., Oka, M., Fukunaga, M., Tsuru, K., and Horikawa, T. (2003). UV-induced skin damage. Toxicology 189, 21-39.

Ives, N. J., Stowe, R. L., Lorigan, P., and Wheatley, K. (2007). Chemotherapy compared with biochemotherapy for the treatment of metastatic melanoma: a meta-analysis of 18 trials involving 2,621 patients. J Clin Oncol 25, 5426-34.

Jang, S., and Atkins, M. B. (2013). Which drug, and when, for patients with BRAF-mutant melanoma? Lancet Oncol 14, e60-9.

Jarrett, S. G., Novak, M., Harris, N., Merlino, G., Slominski, A., and Kaetzel, D. M. (2013). NM23 deficiency promotes metastasis in a UV radiationinduced mouse model of human melanoma. Clin Exp Metastasis 30, 2536.

Jemec, G. B., and Holm, E. A. (2003). Nonmelanoma skin cancer in organ transplant patients. Transplantation 75, 253-7.

Jhappan, C., Noonan, F. P., and Merlino, G. (2003). Ultraviolet radiation and cutaneous malignant melanoma. Oncogene 22, 3099-112.

Jiang, Y., Rabbi, M., Kim, M., Ke, C., Lee, W., Clark, R. L., Mieczkowski, P. A., and Marszalek, P. E. (2009). UVA generates pyrimidine dimers in DNA directly. Biophys J 96, 1151-8.

Kannan, K., Sharpless, N. E., Xu, J., O'hagan, R. C., Bosenberg, M., and Chin, L. (2003). Components of the $\mathrm{Rb}$ pathway are critical targets of UV mutagenesis in a murine melanoma model. Proc Natl Acad Sci U S A 100, $1221-5$.

Katiyar, S. K., and Mukhtar, H. (2001). Green tea polyphenol (-)-epigallocatechin3-gallate treatment to mouse skin prevents UVB-induced infiltration of leukocytes, depletion of antigen-presenting cells, and oxidative stress. J Leukoc Biol 69, 719-26.

Kauffmann, A., Rosselli, F., Lazar, V., Winnepenninckx, V., Mansuet-Lupo, A., Dessen, P., Van Den Oord, J. J., Spatz, A., and Sarasin, A. (2008). High expression of DNA repair pathways is associated with metastasis in melanoma patients. Oncogene 27, 565-73.

Kefford, R., Beith, J. M., Van Hazel, G. A., Millward, M., Trotter, J. M., Wyld, D. K., Kusic, R., Shreeniwas, R., Morganti, A., and Ballmer, A. (2007). A phase II study of bosentan, a dual endothelin receptor antagonist, as 
monotherapy in patients with stage IV metastatic melanoma. Investigational new drugs 25, 247-252.

Kefford, R. F., Clingan, P. R., Brady, B., Ballmer, A., Morganti, A., and Hersey, P. (2010). A randomized, double-blind, placebo-controlled study of high-dose bosentan in patients with stage IV metastatic melanoma receiving first-line dacarbazine chemotherapy. Mol Cancer 9, 69.

Keir, M. E., Butte, M. J., Freeman, G. J., and Sharpe, A. H. (2008). PD-1 and its ligands in tolerance and immunity. Annual review of immunology 26, 677704.

Kelfkens, G., De Gruijl, F. R., and Van Der Leun, J. C. (1990). Ozone depletion and increase in annual carcinogenic ultraviolet dose. Photochem Photobiol 52, 819-23.

Kelsall, S. R., and Mintz, B. (1998). Metastatic cutaneous melanoma promoted by ultraviolet radiation in mice with transgene-initiated low melanoma susceptibility. Cancer Res 58, 4061-5.

Klein-Szanto, A. J., Silvers, W. K., and Mintz, B. (1994). Ultraviolet radiationinduced malignant skin melanoma in melanoma-susceptible transgenic mice. Cancer Res 54, 4569-72.

Kolk, A., Wolff, K. D., Smeets, R., Kesting, M., Hein, R., and Eckert, A. W. (2014). Melanotic and non-melanotic malignancies of the face and external ear - A review of current treatment concepts and future options. Cancer Treat Rev 40, 819-37.

Kossard, S., Epstein, J., E.H. , Cerio, R., Yu, L. L., and Weedon, D. (2006). Basal Cell Carcinoma. In World Health Organization Classification of Tumours. Pathology and Genetics of Skin Tumours. Leboit, P. E., Burg, G., Weedon, D. \& Sarasin, A., eds. (Lyon, France: IARC Press), pp. 13-19.

Kraemer, K. H., Lee, M. M., Andrews, A. D., and Lambert, W. C. (1994). The role of sunlight and DNA repair in melanoma and nonmelanoma skin cancer. The xeroderma pigmentosum paradigm. Arch Dermatol 130, 1018-21.

Kraemer, K. H., Lee, M. M., and Scotto, J. (1987). Xeroderma pigmentosum. Cutaneous, ocular, and neurologic abnormalities in 830 published cases. Arch Dermatol 123, 241-50.

Kramer, T. R., Powell, M. B., Wilson, M. M., Salvatore, J., and Grossniklaus, H. E. (1998). Pigmented uveal tumours in a transgenic mouse model. The British journal of ophthalmology 82, 953-60. 
Kripke, M. L. (1974). Antigenicity of murine skin tumors induced by ultraviolet light. J Natl Cancer Inst 53, 1333-6.

Kullavanijaya, P., and Lim, H. W. (2005). Photoprotection. J Am Acad Dermatol 52, 937-58; quiz 959-62.

Lahav, R. (2005). Endothelin receptor B is required for the expansion of melanocyte precursors and malignant melanoma. Int J Dev Biol 49, 17380.

Lahav, R., Heffner, G., and Patterson, P. H. (1999). An endothelin receptor B antagonist inhibits growth and induces cell death in human melanoma cells in vitro and in vivo. Proc Natl Acad Sci U S A 96, 11496-500.

Lahav, R., Suva, M. L., Rimoldi, D., Patterson, P. H., and Stamenkovic, I. (2004). Endothelin receptor $B$ inhibition triggers apoptosis and enhances angiogenesis in melanomas. Cancer Res 64, 8945-53.

Lahav, R., Ziller, C., Dupin, E., and Le Douarin, N. M. (1996). Endothelin 3 promotes neural crest cell proliferation and mediates a vast increase in melanocyte number in culture. Proc Natl Acad Sci U S A 93, 3892-7.

Leboit, P. E., Burg, G., Weedon, D., and Sarasain, A., (Eds.) (2006). World Health Organization Classification of Tumours. Pathology and Genetics of Skin Tumours. (Lyon, France: IARC Press), pp. 357.

Lemus-Deschamps, L., and Makin, J. K. (2012). Fifty years of changes in UV Index and implications for skin cancer in Australia. International journal of biometeorology 56, 727-35.

Lowy, D. R., and Willumsen, B. M. (1993). Function and regulation of ras. Annu Rev Biochem 62, 851-91.

Lu, D., Willard, D., Patel, I. R., Kadwell, S., Overton, L., Kost, T., Luther, M., Chen, W., Woychik, R. P., Wilkison, W. O., et al. (1994). Agouti protein is an antagonist of the melanocyte-stimulating-hormone receptor. Nature 371, 799-802.

Luo, C., Sheng, J., Hu, M. G., Haluska, F. G., Cui, R., Xu, Z., Tsichlis, P. N., Hu, G. F., and Hinds, P. W. (2013). Loss of ARF sensitizes transgenic BRAFV600E mice to UV-induced melanoma via suppression of XPC. Cancer Res.

Magro, C. M., Crowson, A. N., and Mihm, M. C. (2006). Unusual variants of malignant melanoma. Mod Pathol 19 Suppl 2, S41-70. 
Mansh, M. (2011). Ipilimumab and cancer immunotherapy: a new hope for advanced stage melanoma. Yale J Biol Med 84, 381-9.

Marais, R., Light, Y., Paterson, H. F., and Marshall, C. J. (1995). Ras recruits Raf-1 to the plasma membrane for activation by tyrosine phosphorylation. EMBO J 14, 3136-45.

Markovic, S. N., Erickson, L. A., Rao, R. D., Weenig, R. H., Pockaj, B. A., Bardia, A., Vachon, C. M., Schild, S. E., Mcwilliams, R. R., Hand, J. L., et al. (2007). Malignant melanoma in the 21st century, part 1: epidemiology, risk factors, screening, prevention, and diagnosis. Mayo Clin Proc 82, 364-80.

Mason, R. S., and Reichrath, J. (2013). Sunlight vitamin D and skin cancer. Anticancer agents in medicinal chemistry 13, 83-97.

Matsumoto, Y., Kim, K., Hurwitz, J., Gary, R., Levin, D. S., Tomkinson, A. E., and Park, M. S. (1999). Reconstitution of proliferating cell nuclear antigendependent repair of apurinic/apyrimidinic sites with purified human proteins. J Biol Chem 274, 33703-8.

Matthews, Y. J., Halliday, G. M., Phan, T. A., and Damian, D. L. (2010a). A UVB wavelength dependency for local suppression of recall immunity in humans demonstrates a peak at $300 \mathrm{~nm}$. J Invest Dermatol 130, 1680-4.

Matthews, Y. J., Halliday, G. M., Phan, T. A., and Damian, D. L. (2010b). Wavelength dependency for UVA-induced suppression of recall immunity in humans. Journal of dermatological science 59, 192-7.

Mckenzie, R. L., Aucamp, P. J., Bais, A. F., Bjorn, L. O., llyas, M., and Madronich, S. (2011). Ozone depletion and climate change: impacts on UV radiation. Photochem Photobiol Sci 10, 182-98.

Meeran, S. M., Punathil, T., and Katiyar, S. K. (2008). IL-12 deficiency exacerbates inflammatory responses in UV-irradiated skin and skin tumors. J Invest Dermatol 128, 2716-27.

Meier, F., Satyamoorthy, K., Nesbit, M., Hsu, M. Y., Schittek, B., Garbe, C., and Herlyn, M. (1998). Molecular events in melanoma development and progression. Front Biosci 3, D1005-10.

Menzies, A. M., and Long, G. V. (2014). Dabrafenib and trametinib, alone and in combination for BRAF-mutant metastatic melanoma. Clin Cancer Res 20, 2035-43.

Middleton, M. R., Grob, J. J., Aaronson, N., Fierlbeck, G., Tilgen, W., Seiter, S., Gore, M., Aamdal, S., Cebon, J., Coates, A., et al. (2000). Randomized phase III study of temozolomide versus dacarbazine in the treatment of 
patients with advanced metastatic malignant melanoma. J Clin Oncol 18, $158-66$.

Milagre, C., Dhomen, N., Geyer, F. C., Hayward, R., Lambros, M., Reis-Filho, J. S., and Marais, R. (2010). A mouse model of melanoma driven by oncogenic KRAS. Cancer Res 70, 5549-57.

Min, W., Liu, X., Qian, Q., Lin, B., Wu, D., Wang, M., Ahmad, I., Yusuf, N., and Luo, D. (2014). The effects of baicalin against UVA-induced photoaging in skin fibroblasts. The American journal of Chinese medicine 42, 709-27.

Mitra, D., Luo, X., Morgan, A., Wang, J., Hoang, M. P., Lo, J., Guerrero, C. R., Lennerz, J. K., Mihm, M. C., Wargo, J. A., et al. (2012). An ultravioletradiation-independent pathway to melanoma carcinogenesis in the red hair/fair skin background. Nature 491, 449-53.

Mocellin, S., Pasquali, S., Rossi, C. R., and Nitti, D. (2010). Interferon alpha adjuvant therapy in patients with high-risk melanoma: a systematic review and meta-analysis. J Natl Cancer Inst 102, 493-501.

Mouret, S., Baudouin, C., Charveron, M., Favier, A., Cadet, J., and Douki, T. (2006). Cyclobutane pyrimidine dimers are predominant DNA lesions in whole human skin exposed to UVA radiation. Proc Natl Acad Sci U S A 103, 13765-70.

Mouret, S., Philippe, C., Gracia-Chantegrel, J., Banyasz, A., Karpati, S., Markovitsi, D., and Douki, T. (2010). UVA-induced cyclobutane pyrimidine dimers in DNA: a direct photochemical mechanism? Org Biomol Chem 8, 1706-11.

Muller, H. K., Malley, R. C., Mcgee, H. M., Scott, D. K., Wozniak, T., and Woods, G. M. (2008). Effect of UV radiation on the neonatal skin immune systemimplications for melanoma. Photochem Photobiol 84, 47-54.

Nakane, H., Takeuchi, S., Yuba, S., Saijo, M., Nakatsu, Y., Murai, H., Nakatsuru, Y., Ishikawa, T., Hirota, S., Kitamura, Y., et al. (1995). High incidence of ultraviolet-B-or chemical-carcinogen-induced skin tumours in mice lacking the xeroderma pigmentosum group A gene. Nature 377, 165-8.

Narbutt, J., Lesiak, A., Skibinska, M., Wozniacka, A., Van Loveren, H., SysaJedrzejowska, A., Lewy-Trenda, I., Omulecka, A., and Norval, M. (2005). Suppression of contact hypersensitivity after repeated exposures of humans to low doses of solar simulated radiation. Photochem Photobiol Sci 4, 517-22. 
Nghiem, D. X., Kazimi, N., Mitchell, D. L., Vink, A. A., Ananthaswamy, H. N., Kripke, M. L., and Ullrich, S. E. (2002). Mechanisms underlying the suppression of established immune responses by ultraviolet radiation. J Invest Dermatol 119, 600-8.

Noonan, F. P., and De Fabo, E. C. (1990). Ultraviolet-B dose-response curves for local and systemic immunosuppression are identical. Photochem Photobiol 52, 801-10.

Noonan, F. P., Otsuka, T., Bang, S., Anver, M. R., and Merlino, G. (2000). Accelerated ultraviolet radiation-induced carcinogenesis in hepatocyte growth factor/scatter factor transgenic mice. Cancer Res 60, 3738-43.

Noonan, F. P., Recio, J. A., Takayama, H., Duray, P., Anver, M. R., Rush, W. L., De Fabo, E. C., and Merlino, G. (2001). Neonatal sunburn and melanoma in mice. Nature 413, 271-2.

Noonan, F. P., Zaidi, M. R., Wolnicka-Glubisz, A., Anver, M. R., Bahn, J., Wielgus, A., Cadet, J., Douki, T., Mouret, S., Tucker, M. A., et al. (2012). Melanoma induction by ultraviolet $A$ but not ultraviolet $B$ radiation requires melanin pigment. Nature communications 3, 884 .

Norval, M., Lucas, R. M., Cullen, A. P., De Gruijl, F. R., Longstreth, J., Takizawa, Y., and Van Der Leun, J. C. (2011). The human health effects of ozone depletion and interactions with climate change. Photochem Photobiol Sci $10,199-225$.

Omholt, K., Karsberg, S., Platz, A., Kanter, L., Ringborg, U., and Hansson, J. (2002). Screening of $\mathrm{N}$-ras codon 61 mutations in paired primary and metastatic cutaneous melanomas: mutations occur early and persist throughout tumor progression. Clin Cancer Res 8, 3468-74.

Opdecamp, K., Kos, L., Arnheiter, H., and Pavan, W. J. (1998). Endothelin signalling in the development of neural crest-derived melanocytes. Biochem Cell Biol 76, 1093-9.

Ortonne, J. P. (2002). From actinic keratosis to squamous cell carcinoma. Br J Dermatol 146 Suppl 61, 20-3.

Ozawa, H., Aiba, S., Nakagawa, and Tagami, H. (1996). Interferon-gamma and interleukin-10 inhibit antigen presentation by Langerhans cells for $\mathrm{T}$ helper type 1 cells by suppressing their CD80 (B7-1) expression. Eur J Immunol $26,648-52$.

Pardoll, D. (2003). Does the immune system see tumors as foreign or self? Annual review of immunology 21, 807-39. 
Park, H., Zhang, K., Ren, Y., Nadji, S., Sinha, N., Taylor, J. S., and Kang, C. (2002). Crystal structure of a DNA decamer containing a cis-syn thymine dimer. Proc Natl Acad Sci U S A 99, 15965-70.

Parrish, J. A., Jaenicke, K. F., and Anderson, R. R. (1982). Erythema and melanogenesis action spectra of normal human skin. Photochem Photobiol 36, 187-91.

Pascucci, B., Stucki, M., Jonsson, Z. O., Dogliotti, E., and Hubscher, U. (1999). Long patch base excision repair with purified human proteins. DNA ligase $\mathrm{I}$ as patch size mediator for DNA polymerases delta and epsilon. J Biol Chem 274, 33696-702.

Pathak, M., Jimbow, K., and Fitzpatrick, T. (1980). Photobiology of pigment cell. Phenotypic Expression in Pigment Cells. University of Tokyo Press, Tokyo, Japan, 655-670.

Patnaik, A., Kang, S. P., Tolcher, A. W., Rasco, D. W., Papadopoulos, K. P., Beeram, M., Drengler, R., Chen, C., Smith, L., and Perez, C. (2012). Phase I study of MK-3475 (anti-PD-1 monoclonal antibody) in patients with advanced solid tumors. J Clin Oncol 30, 2512.

Peak, J. G., and Peak, M. J. (1991). Comparison of initial yields of DNA-toprotein crosslinks and single-strand breaks induced in cultured human cells by far- and near-ultraviolet light, blue light and X-rays. Mutat Res 246, 187-91.

Pennello, G., Devesa, S., and Gail, M. (2000). Association of surface ultraviolet B radiation levels with melanoma and nonmelanoma skin cancer in United States blacks. Cancer Epidemiol Biomarkers Prev 9, 291-7.

Petrella, T., Verma, S., Spithoff, K., Quirt, I., Mccready, D., and Melanoma Disease Site, G. (2012). Adjuvant interferon therapy for patients at high risk for recurrent melanoma: an updated systematic review and practice guideline. Clin Oncol (R Coll Radiol) 24, 413-23.

Pfeifer, G. P., and Besaratinia, A. (2012). UV wavelength-dependent DNA damage and human non-melanoma and melanoma skin cancer. Photochem Photobiol Sci 11, 90-7.

Pleasance, E. D., Cheetham, R. K., Stephens, P. J., Mcbride, D. J., Humphray, S. J., Greenman, C. D., Varela, I., Lin, M. L., Ordonez, G. R., Bignell, G. R., et al. (2010). A comprehensive catalogue of somatic mutations from a human cancer genome. Nature 463, 191-6. 
Poon, T. S., Barnetson, R. S., and Halliday, G. M. (2005). Sunlight-induced immunosuppression in humans is initially because of UVB, then UVA, followed by interactive effects. J Invest Dermatol 125, 840-6.

Powell, M. B., Hyman, P., Bell, O. D., Balmain, A., Brown, K., Alberts, D., and Bowden, G. T. (1995). Hyperpigmentation and melanocytic hyperplasia in transgenic mice expressing the human T24 Ha-ras gene regulated by a mouse tyrosinase promoter. Mol Carcinog 12, 82-90.

Ranadive, N. S., Shirwadkar, S., Persad, S., and Menon, I. A. (1986). Effects of melanin-induced free radicals on the isolated rat peritoneal mast cells. $\mathrm{J}$ Invest Dermatol 86, 303-7.

Rane, S. G., Dubus, P., Mettus, R. V., Galbreath, E. J., Boden, G., Reddy, E. P., and Barbacid, M. (1999). Loss of Cdk4 expression causes insulin-deficient diabetes and Cdk4 activation results in beta-islet cell hyperplasia. Nat Genet 22, 44-52.

Rastogi, R. P., Richa, Kumar, A., Tyagi, M. B., and Sinha, R. P. (2010). Molecular mechanisms of ultraviolet radiation-induced DNA damage and repair. Journal of nucleic acids 2010, 592980.

Recio, J. A., Noonan, F. P., Takayama, H., Anver, M. R., Duray, P., Rush, W. L., Lindner, G., De Fabo, E. C., Depinho, R. A., and Merlino, G. (2002). Ink4a/arf deficiency promotes ultraviolet radiation-induced melanomagenesis. Cancer Res 62, 6724-30.

Reeve, V. E., Bosnic, M., and Nishimura, N. (1999). Interferon-gamma is involved in photoimmunoprotection by UVA $(320-400 \mathrm{~nm})$ radiation in mice. J Invest Dermatol 112, 945-50.

Reeve, V. E., and Tyrrell, R. M. (1999). Heme oxygenase induction mediates the photoimmunoprotective activity of UVA radiation in the mouse. Proc Natl Acad Sci U S A 96, 9317-21.

Reid, K., Turnley, A. M., Maxwell, G. D., Kurihara, Y., Kurihara, H., Bartlett, P. F., and Murphy, M. (1996). Multiple roles for endothelin in melanocyte development: regulation of progenitor number and stimulation of differentiation. Development 122, 3911-9.

Rigel, D. S. (2010). Epidemiology of melanoma. Seminars in cutaneous medicine and surgery 29, 204-9.

Rigel, D. S., and Carucci, J. A. (2000). Malignant melanoma: prevention, early detection, and treatment in the 21st century. CA: a cancer journal for clinicians 50, 215-36; quiz 237-40. 
Rigel, D. S., Friedman, R. J., Kopf, A. W., and Polsky, D. (2005). ABCDE--an evolving concept in the early detection of melanoma. Arch Dermatol 141, $1032-4$.

Rippey, J. J. (1998). Why classify basal cell carcinomas? Histopathology 32, 393-8.

Rodriguez-Viciana, P., Warne, P. H., Dhand, R., Vanhaesebroeck, B., Gout, I., Fry, M. J., Waterfield, M. D., and Downward, J. (1994). Phosphatidylinositol-3-OH kinase as a direct target of Ras. Nature 370, 527-32.

Rogers, H. W., Weinstock, M. A., Harris, A. R., Hinckley, M. R., Feldman, S. R., Fleischer, A. B., and Coldiron, B. M. (2010). Incidence estimate of nonmelanoma skin cancer in the United States, 2006. Arch Dermatol 146, 283-7.

Rosano, L., Spinella, F., Genovesi, G., Di Castro, V., Natali, P. G., and Bagnato, A. (2004). Endothelin-B receptor blockade inhibits molecular effectors of melanoma cell progression. J Cardiovasc Pharmacol 44 Suppl 1, S136-9.

Rosso, S., Zanetti, R., Martinez, C., Tormo, M. J., Schraub, S., Sancho-Garnier, H., Franceschi, S., Gafa, L., Perea, E., Navarro, C., et al. (1996). The multicentre south European study 'Helios'. II: Different sun exposure patterns in the aetiology of basal cell and squamous cell carcinomas of the skin. Br J Cancer 73, 1447-54.

Russo, A., Piovano, M., Lombardo, L., Garbarino, J., and Cardile, V. (2008). Lichen metabolites prevent UV light and nitric oxide-mediated plasmid DNA damage and induce apoptosis in human melanoma cells. Life Sci 83, 468-74.

Sahin, S., Rao, B., Kopf, A. W., Lee, E., Rigel, D. S., Nossa, R., Rahman, I. J., Wortzel, H., Marghoob, A. A., and Bart, R. S. (1997). Predicting ten-year survival of patients with primary cutaneous melanoma: corroboration of a prognostic model. Cancer 80, 1426-31.

Saldana-Caboverde, A., and Kos, L. (2010). Roles of endothelin signaling in melanocyte development and melanoma. Pigment Cell Melanoma Res 23, 160-70.

Samarasinghe, V., Madan, V., and Lear, J. T. (2011). Focus on Basal cell carcinoma. Journal of skin cancer 2011, 328615.

Schaefer, H., Moyal, D., and Fourtanier, A. (1998). Recent advances in sun protection. Seminars in cutaneous medicine and surgery 17, 266-75. 
Schmitt, J., Seidler, A., Diepgen, T. L., and Bauer, A. (2011). Occupational ultraviolet light exposure increases the risk for the development of cutaneous squamous cell carcinoma: a systematic review and metaanalysis. Br J Dermatol 164, 291-307.

Serrone, L., Zeuli, M., Sega, F. M., and Cognetti, F. (2000). Dacarbazine-based chemotherapy for metastatic melanoma: thirty-year experience overview. Journal of experimental \& clinical cancer research : CR 19, 21-34.

Setlow, R. B., and Carrier, W. L. (1964). The Disappearance of Thymine Dimers from DNA: An Error-Correcting Mechanism. Proc Natl Acad Sci U S A 51, 226-31.

Sharpless, N. E. (2005). INK4a/ARF: a multifunctional tumor suppressor locus. Mutat Res 576, 22-38.

Sharpless, N. E., Kannan, K., Xu, J., Bosenberg, M. W., and Chin, L. (2003). Both products of the mouse Ink4a/Arf locus suppress melanoma formation in vivo. Oncogene 22, 5055-9.

Shibutani, S., Takeshita, M., and Grollman, A. P. (1991). Insertion of specific bases during DNA synthesis past the oxidation-damaged base 8-oxodG. Nature 349, 431-4.

Sirisinha, S. (2014). Evolutionary insights into the origin of innate and adaptive immune systems: different shades of grey. Asian Pacific journal of allergy and immunology / launched by the Allergy and Immunology Society of Thailand 32, 3-15.

Smoller, B. R. (2006). Histologic criteria for diagnosing primary cutaneous malignant melanoma. Mod Pathol 19 Suppl 2, S34-40.

Soufir, N., Lacapere, J. J., Bertrand, G., Matichard, E., Meziani, R., Mirebeau, D., Descamps, V., Gerard, B., Archimbaud, A., Ollivaud, L., et al. (2004). Germline mutations of the INK4a-ARF gene in patients with suspected genetic predisposition to melanoma. Br J Cancer 90, 503-9.

Soyer, H., Rigel, D., and Wurm, E. (2012). Actinic keratosis, basal cell carcinoma and squamous cell carcinoma. In Dermatology. Bolognia, J., Jorizzo, J. \& Schaffer, J., eds. (Philadelphia, PA: Elsevier Saunders), pp. 1773-1794.

Stapelberg, M. P., Williams, R. B., Byrne, S. N., and Halliday, G. M. (2009). The alternative complement pathway seems to be a UVA sensor that leads to systemic immunosuppression. J Invest Dermatol 129, 2694-701.

Stary, A., and Sarasin, A. (2002). The genetics of the hereditary xeroderma pigmentosum syndrome. Biochimie 84, 49-60. 
Stone, J. G., Spirling, L. I., and Richardson, M. K. (1997). The neural crest population responding to endothelin-3 in vitro includes multipotent cells. J Cell Sci 110 ( Pt 14), 1673-82.

Sturm, R. A. (2002). Skin colour and skin cancer - MC1R, the genetic link. Melanoma Res 12, 405-16.

Swaika, A., Crozier, J. A., and Joseph, R. W. (2014). Vemurafenib: an evidencebased review of its clinical utility in the treatment of metastatic melanoma. Drug design, development and therapy 8,775-87.

Sznol, M., Kluger, H. M., Hodi, F. S., Mcdermott, D. F., Carvajal, R. D., Lawrence, D. P., Topalian, S. L., Atkins, M. B., Powderly, J. D., and Sharfman, W. H. (2013). Survival and long-term follow-up of safety and response in patients (pts) with advanced melanoma (MEL) in a phase I trial of nivolumab (anti-PD-1; BMS-936558; ONO-4538). J Clin Oncol 31.

Takayama, H., La Rochelle, W. J., Anver, M., Bockman, D. E., and Merlino, G. (1996). Scatter factor/hepatocyte growth factor as a regulator of skeletal muscle and neural crest development. Proc Natl Acad Sci U S A 93, 586671.

Tamura, D., Digiovanna, J. J., Khan, S. G., and Kraemer, K. H. (2014). Living with xeroderma pigmentosum: comprehensive photoprotection for highly photosensitive patients. Photodermatol Photoimmunol Photomed 30, 14652 .

Tang, L., Su, M., Zhang, Y., Ip, W., Martinka, M., Huang, C., and Zhou, Y. (2008). Endothelin-3 is produced by metastatic melanoma cells and promotes melanoma cell survival. Journal of cutaneous medicine and surgery $12,64-70$.

Tas, F. (2012). Metastatic behavior in melanoma: timing, pattern, survival, and influencing factors. J Oncol 2012, 647684.

Tessari, G., and Girolomoni, G. (2012). Nonmelanoma skin cancer in solid organ transplant recipients: update on epidemiology, risk factors, and management. Dermatol Surg 38, 1622-30.

The Jackson Laboratory (2014). Guidelines for Nomenclature of Genes, Genetic Markers, Alleles, and Mutations in Mouse and Rat (Bar Harbor, Maine: The Jackson Laboratory).

Trahey, M., and Mccormick, F. (1987). A cytoplasmic protein stimulates normal N-ras p21 GTPase, but does not affect oncogenic mutants. Science 238, 542-5. 
Traynor, K. (2011). Ipilimumab approved for metastatic melanoma. American journal of health-system pharmacy : AJHP : official journal of the American Society of Health-System Pharmacists 68, 768.

Tsai, J., Lee, J. T., Wang, W., Zhang, J., Cho, H., Mamo, S., Bremer, R., Gillette, S., Kong, J., Haass, N. K., et al. (2008). Discovery of a selective inhibitor of oncogenic B-Raf kinase with potent antimelanoma activity. Proc Natl Acad Sci U S A 105, 3041-6.

Tsao, H., Bevona, C., Goggins, W., and Quinn, T. (2003). The transformation rate of moles (melanocytic nevi) into cutaneous melanoma: a populationbased estimate. Arch Dermatol 139, 282-8.

Tucker, M. A., Halpern, A., Holly, E. A., Hartge, P., Elder, D. E., Sagebiel, R. W., Guerry, D. T., and Clark, W. H., Jr. (1997). Clinically recognized dysplastic nevi. A central risk factor for cutaneous melanoma. JAMA 277, 1439-44.

Ullrich, S. E. (2002). Photoimmune suppression and photocarcinogenesis. Front Biosci 7, d684-703.

Ulrich, C., Schmook, T., Sachse, M. M., Sterry, W., and Stockfleth, E. (2004). Comparative epidemiology and pathogenic factors for nonmelanoma skin cancer in organ transplant patients. Dermatol Surg 30, 622-7.

United Nations Environment Programme, E. E. a. P., Andrady, A. L., Aucamp, P. J., Austin, A. T., Bais, A. F., Ballare, C. L., Bjorn, L. O., Bornman, J. F., Caldwell, M., Cullen, A. P., et al. (2012). Environmental effects of ozone depletion and its interactions with climate change: progress report, 2011. Photochem Photobiol Sci 11, 13-27.

Valverde, P., Healy, E., Jackson, I., Rees, J. L., and Thody, A. J. (1995). Variants of the melanocyte-stimulating hormone receptor gene are associated with red hair and fair skin in humans. Nat Genet 11, 328-30.

Van Schanke, A., Van Venrooij, G. M., Jongsma, M. J., Banus, H. A., Mullenders, L. H., Van Kranen, H. J., and De Gruijl, F. R. (2006). Induction of nevi and skin tumors in Ink4a/Arf Xpa knockout mice by neonatal, intermittent, or chronic UVB exposures. Cancer Res 66, 2608-15.

Vantuchova, Y., and Curik, R. (2006). Histological types of basal cell carcinoma. Scripta Medica (BRNO) 79, 261-70.

Varghese, A. J., and Patrick, M. H. (1969). Cytosine derived heteroadduct formation in ultraviolet-irradiated DNA. Nature 223, 299-300. 
Viros, A., Sanchez-Laorden, B., Pedersen, M., Furney, S. J., Rae, J., Hogan, K., Ejiama, S., Girotti, M. R., Cook, M., Dhomen, N., et al. (2014). Ultraviolet radiation accelerates BRAF-driven melanomagenesis by targeting TP53. Nature 511, 478-82.

Vogel, R. I., Ahmed, R. L., Nelson, H. H., Berwick, M., Weinstock, M. A., and Lazovich, D. (2014). Exposure to indoor tanning without burning and melanoma risk by sunburn history. J Natl Cancer Inst 106, dju112.

Wagle, N., Emery, C., Berger, M. F., Davis, M. J., Sawyer, A., Pochanard, P., Kehoe, S. M., Johannessen, C. M., Macconaill, L. E., Hahn, W. C., et al. (2011). Dissecting therapeutic resistance to RAF inhibition in melanoma by tumor genomic profiling. J Clin Oncol 29, 3085-96.

Wain, H. M., Bruford, E. A., Lovering, R. C., Lush, M. J., Wright, M. W., and Povey, S. (2002). Guidelines for human gene nomenclature. Genomics $79,464-70$.

Wang, L., Toda, M., Saito, K., Hori, T., Horii, T., Shiku, H., Kuribayashi, K., and Kato, T. (2008). Post-immune UV irradiation induces Tr1-like regulatory T cells that suppress humoral immune responses. International immunology 20, 57-70.

Weedon, D., Morgan, M. B., Gross, C., Nagore, E., and Yu, L. L. (2006). Squamous cell carcinoma. In World Health Organization Classification of Tumours. Pathology and Genetics of Skin Tumours. Leboit, P. E., Burg, G., Weedon, D. \& Sarasin, A., eds. (Lyon, France: IARC Press), pp. 2025.

Weinberg, A. S., Ogle, C. A., and Shim, E. K. (2007). Metastatic cutaneous squamous cell carcinoma: an update. Dermatol Surg 33, 885-99.

Welsh, M. M., Karagas, M. R., Applebaum, K. M., Spencer, S. K., Perry, A. E., and Nelson, H. H. (2008). A role for ultraviolet radiation immunosuppression in non-melanoma skin cancer as evidenced by geneenvironment interactions. Carcinogenesis 29, 1950-4.

Wenczl, E., Pool, S., Timmerman, A. J., Van Der Schans, G. P., Roza, L., and Schothorst, A. A. (1997). Physiological doses of ultraviolet irradiation induce DNA strand breaks in cultured human melanocytes, as detected by means of an immunochemical assay. Photochem Photobiol 66, 826-30.

Wenczl, E., Van Der Schans, G. P., Roza, L., Kolb, R. M., Timmerman, A. J., Smit, N. P., Pavel, S., and Schothorst, A. A. (1998). (Pheo)melanin photosensitizes UVA-induced DNA damage in cultured human melanocytes. J Invest Dermatol 111, 678-82. 
Whiteman, D. C., Whiteman, C. A., and Green, A. C. (2001). Childhood sun exposure as a risk factor for melanoma: a systematic review of epidemiologic studies. Cancer Causes Control 12, 69-82.

Wood, R. D., Mitchell, M., and Lindahl, T. (2005). Human DNA repair genes, 2005. Mutat Res 577, 275-83.

Wood, R. D., Mitchell, M., Sgouros, J., and Lindahl, T. (2001). Human DNA repair genes. Science 291, 1284-9.

Yaar, M., and Gilchrest, B. A. (2001). Ageing and photoageing of keratinocytes and melanocytes. Clin Exp Dermatol 26, 583-91.

Yamaguchi, Y., Beer, J. Z., and Hearing, V. J. (2008). Melanin mediated apoptosis of epidermal cells damaged by ultraviolet radiation: factors influencing the incidence of skin cancer. Arch Dermatol Res 300 Suppl 1, S43-50.

Yamazaki, F., Okamoto, H., Matsumura, Y., Tanaka, K., Kunisada, T., and Horio, T. (2005). Development of a new mouse model (xeroderma pigmentosum a-deficient, stem cell factor-transgenic) of ultraviolet B-induced melanoma. J Invest Dermatol 125, 521-5.

Yang, F. C., Merlino, G., and Chin, L. (2001). Genetic dissection of melanoma pathways in the mouse. Semin Cancer Biol 11, 261-8.

Yang, G., Curley, D., Bosenberg, M. W., and Tsao, H. (2007). Loss of xeroderma pigmentosum C (Xpc) enhances melanoma photocarcinogenesis in Ink4aArf-deficient mice. Cancer Res 67, 5649-57.

Yarosh, D. B., Canning, M. T., Teicher, D., and Brown, D. A. (2005). After sun reversal of DNA damage: enhancing skin repair. Mutat Res 571, 57-64.

Young, A. R. (1997). Chromophores in human skin. Phys Med Biol 42, 789-802.

Zaidi, M. R., Davis, S., Noonan, F. P., Graff-Cherry, C., Hawley, T. S., Walker, R. L., Feigenbaum, L., Fuchs, E., Lyakh, L., Young, H. A., et al. (2011). Interferon-gamma links ultraviolet radiation to melanomagenesis in mice. Nature 469, 548-53.

Zaidi, M. R., and Merlino, G. (2011). The two faces of interferon-gamma in cancer. Clin Cancer Res 17, 6118-24.

Zhang, Y., Xiong, Y., and Yarbrough, W. G. (1998). ARF promotes MDM2 degradation and stabilizes p53: ARF-INK4a locus deletion impairs both the $\mathrm{Rb}$ and p53 tumor suppression pathways. Cell 92, 725-34. 


\section{CHAPTER II.}

NOVEL UV-INDUCED MELANOMA MOUSE MODEL DEPENDENT ON ENDOTHELIN 3 SIGNALING 
II. NOVEL UV-INDUCED MELANOMA MOUSE MODEL DEPENDENT ON ENDOTHELIN 3 SIGNALING

\subsection{Published Paper Information}

This chapter has been published as a Letter to the Editor in the Pigment Cell and Melanoma Research Journal volume 27 issue 5, pages 839-842.

\subsection{Letter to the Editor}

Dear Editor,

Melanomagenesis is closely associated with early exposure to ultraviolet (UV) radiation and the development of UV-responsive animal models has contributed to the elucidation of UV radiation effects on carcinogenesis. To our knowledge, all previously established mouse models of neonatal UV-induced melanoma, carry loss or gain of function mutations in the melanocytes, and develop lesions spontaneously that are enhanced by UV exposure (Kannan et al., 2003; Noonan et al., 2001). Hence, it is important to generate a mouse model that develops lesions exclusively upon neonatal UV exposure, and whose melanocytes are not transformed a priori.

Here we report the development of a melanoma mouse model dependent solely on the presence of Endothelin3 (Edn3) in the tumor microenvironment and neonatal UV radiation.

The Endothelin 3 (Edn3) - Endothelin receptor B (EdnrB) pathway is essential for melanocyte development, and has been associated with increased risk of different types of cancers including melanoma (Bagnato et al., 2004). Previously, our laboratory reported the generation of the K5-tTA; TRE-Edn3-lacZ 
(for simplicity, K5-Edn3) mice (Garcia et al., 2008). The skin of newborn and adults K5-Edn3 mice is extremely dark when compared to non-transgenic littermates. This hyperpigmentation is due to the over-activation of Edn3 under the control of the K5 promoter, which consequently led to the accumulation of large numbers of melanocytes in the dermis and dermal-epidermal junction of the skin where they are not normally found.

Photoproducts induced by UV radiation are, in normal cells, repaired by the nucleotide excision repair (NER) pathway. Malfunction of this pathway is an important factor in UV-induced skin cancer. Xeroderma Pigmentosum (XP) patients have a defective NER and are at a much higher risk, up to 1,000 times, of developing skin cancers, including melanoma (Kraemer et al., 1994). This disease results from mutations in the components of the NER pathway, such as XPA. Interestingly, mice lacking the Xpa gene were highly sensitive to UVinduced nevi and exhibited a high incidence of squamous cell carcinoma after exposure to UVB, however UVB exposure alone did not lead to melanomagenesis (Nakane et al., 1995; van Schanke et al., 2006).

To determine if neonatal UV-exposure would lead to melanomagenesis in mice that have over-activation of Edn3 and Xpa deficiency, a total of 76 mice, 39 experimental $\left(\mathrm{Xpa}^{-/-} ; \mathrm{K} 5-E d n 3, \mathrm{Xpa}^{+/-} ; \mathrm{K} 5-E d n 3, \mathrm{Xpa}^{+/+} ; \mathrm{K} 5-E d n 3\right)$, and 37 controls $\left(\mathrm{Xpa}^{-/-}, \mathrm{Xpa}^{+/-}, \mathrm{Xpa}^{+/+}\right)($Table 1$)$, were exposed to UV radiation (see Supporting Information 2.3). Melanocytic lesions were not observed in the control group. Animals carrying the K5-Edn3 transgene developed lesions that were diagnosed by histopathology and immunofluorescence as melanoma (Figure 1B- 
D) or blue nevi (Figure 1F-H). Grossly, melanoma lesions appeared as hyperpigmented spots that began to grow and often became ulcerated (Figure 1A). These lesions were found on the ventral (46.7\%) and dorsal $(33.3 \%)$ aspects of the torso, as well as on the face $(20 \%)$ of the mice, and their localization was independent of the genotype. Similarly, blue nevus-like lesions (Figure 1E) were found on the ventral (33.3\%) and dorsal (50.0\%) torso, and face $(16.7 \%)$ of the mice.

The histopathological analysis of the lesions revealed that melanomas appeared to have arisen from blue nevus-like lesions. The foci of most melanomas were comprised of atypical cells in clusters extending into the subcutis. The cells were crowded, with overlapping large nuclei and one to few nucleoli. The melanocytes contained fine melanin granules and there were several associated melanophages. One case showed a nevoid melanoma, fairly well circumscribed, and composed of a cluster of melanocytes in nests. The cells were uniform and bland and did not show maturation. Pigment was present in the deep aspect of the lesion and several mitotic figures were found. Blue nevus-like lesions were broad based and comprised of horizontally oriented dendritic melanocytes predominantly confined to the dermis. Frequently they wrapped around appendages. The melanocytes contained fine melanin granules and small bland nuclei. Most cases were comprised predominantly of melanophages, which were polygonal in shape and contained coarse melanin granules.

Immunostaining analysis using antibody against $S 100$ revealed that melanoma lesions were heavily stained in comparison to blue nevus-like lesions 
(Figure 1C, G). Since proliferation rates are frequently used as a cancer prognosis marker, we verified if there was a quantitative difference between the melanoma and the blue nevus-like lesions. The mean proliferation rate, assessed by quantification of Ki67 positive cells out of the total number of cells, was significantly higher $(p=0.034)$ in melanoma lesions $(1.31 \pm 0.37)$ than in blue nevus-like lesions $(0.22 \pm 0.05)$ (Figure 1D, $\mathrm{H}, \mathrm{J})$.

Exposure of neonatal $\mathrm{Xpa}^{+/+} ; \mathrm{K} 5-\mathrm{Edn} 3$ transgenic mice to UV radiation was sufficient to induce melanomagenesis. However, the percentage of $X \mathrm{pa}^{-/}$; K5-Edn3 melanoma-bearing animals was remarkably higher $(60 \%)$ than the $\mathrm{Xpa}^{+/} ; \mathrm{K} 5-\mathrm{Edn3}(46.2 \%)$ and $\mathrm{Xpa}^{+/+} ; \mathrm{K} 5-E d n 3$ (18.75\%) (Table 1). Additionally, the average time of melanoma appearance was significantly different $(p=0.013)$ between $\mathrm{Xpa}^{-/}$; K5-Edn3 $(29.62 \pm 5.47)$ and $\mathrm{Xpa}^{+/-}$; K5-Edn3 (43.81 \pm 10.08$)$, although a significant difference was not observed in comparison to $\mathrm{Xpa}^{+/+} ; \mathrm{K} 5$ Edn3 $(56.57 \pm 31.64)$.

The melanoma free-survival period of $\mathrm{Xpa}^{--}$; K5-Edn3 mice was significantly shorter ( $p=0.029$, Kaplan-Meier with log-rank test) than that of $\mathrm{Xpa}^{+/+}$; K5-Edn3. However, the melanoma free-survival period for $\mathrm{Xpa}^{+/} ; \mathrm{K} 5$ Edn3 was not significantly different from that of $X p a^{-/-} ; \mathrm{K} 5-E d n 3$ or $\mathrm{Xpa}^{+/+} ; \mathrm{K} 5-$ Edn3 ( $p=0.231$ and $p=0.358$, respectively) (Figure 1I). Blue nevus like lesions, bearing a striking similarity to human blue nevi, were observed in $10 \%$ of $\mathrm{Xpa}^{-/}$; $\mathrm{K} 5-E d n 3,30.8 \%$ of $\mathrm{Xpa}^{+/-}$; K5-Edn3 and $43.75 \%$ of the $\mathrm{Xpa}^{+/+}$; K5-Edn3 (Table 1). Nodal nevi were observed in $58.33 \%$ of the mice with blue nevi (Figure S1C, D). All mice that developed melanoma also presented enlarged and 
hyperpigmented lymph nodes that contained several clusters of Trp1 positive cells (Figure S1A, B). These findings indicate that the combination of UV, Xpa deficiency and over-expression of Edn3 in the skin lead to the formation of melanomas that have the capacity of local metastasis.

The impact of UV radiation on the development of nevi and melanoma lesions has also been studied in mice lacking Xpa in combination with Ink4a/Arf deficiency. Pigmented hairless $X \mathrm{~Pa}^{-/-}$; Ink4a/Arf ${ }^{--}$mice developed many blue nevi but rarely melanoma even after neonatal or repetitive adult UVB exposure (van Schanke et al., 2006). In another study, pigmented $\mathrm{Xpa}^{-/-}$; SCF-Tg mice were found to develop melanoma after repetitive exposure to high doses of UV radiation during adulthood; however, melanomas infrequently metastasized to lymph nodes (Yamazaki et al., 2005). In our study, after one neonatal dose of UV radiation, $\mathrm{K} 5-E d n 3$ with and without $\mathrm{Xpa}$ deficiency developed melanoma and fully penetrant lymph node metastasis. Although Xpa deficiency was not essential for melanomagenesis, it did have a major impact on the frequency and time of appearance of melanoma lesions.

In order to better understand the relationship between DNA repair deficiency, apoptosis, and cancer susceptibility, we analyzed UV-induced apoptosis in $\mathrm{Xpa^{-- }}$; K5-Edn3 and $\mathrm{Xpa}^{+/}$; K5-Edn3 mice. Neonatal mice (3.5 days of age) were exposed to UV radiation and their dorsal skin was removed after 24 hours. Cleaved Caspase-3 positive cells were quantified in the epidermis and dermis (Figure S2A, B.). Results revealed that the total numbers of epidermal apoptotic cells in $\mathrm{Xpa}^{-/} ; \mathrm{K} 5-\mathrm{Edn3}$ were significantly greater $(p=0.00032)$ than 
those of $\mathrm{Xpa}^{+/}$; K5-Edn3; however, this difference was not significant when the dermal numbers of apoptotic cells were compared. Interestingly, the dermal number of apoptotic melanocytes, and more dramatically the epidermal numbers, were significantly higher $\left(p=0.02675\right.$ and $p=0.00429$, respectively) in $X p a^{-/-}$; K5Edn3 than in $\mathrm{Xpa}^{+/}$; K5-Edn3 mice (Figure S3C). The unexpected large number of apoptotic cells in the animals carrying the K5-Edn3 transgene may result from the phototoxic and photosensitizing effects of melanin (Noonan et al., 2012; Wood et al., 2006). Our findings suggest that in our heavily pigmented mouse model, melanin did not act as a protective factor; instead it acted in a harmful way accelerating melanoma development and progression.

Higher penetrance and decreased latency of melanomas were observed in the mice carrying heterozygous or homozygous mutations in Xpa, despite of the fact that the numbers of apoptotic melanocytes were also larger in these animals. These results suggest that the apoptotic differentiated melanocytes may not be the cell of origin of the melanomas. One possibility is that these tumors arise from undifferentiated cells residing in the skin or hair follicles and follow the stem cell hypothesis of tumorigenesis (Grichnik, 2008). Furthermore, undifferentiated melanocyte precursors present in the skin or hair follicles may respond to the higher levels of apoptosis by increasing their proliferation rate to compensate for dying cells. This would in turn lead to a higher frequency of mutations in these highly proliferative Xpa deficient cells and result in earlier melanoma appearance (Queille et al., 2001). 
This new model of melanomagenesis will serve as a useful tool to further explore the deleterious effects of UV radiation in tumorigenesis and for the evaluation of possible therapeutic agents.

\subsection{Acknowledgments}

We thank Dr. Vincent Hearing (National Institute of Health, Bethesda, MD) for generously providing a-PEP1 antibody; Dr. Friedberg (University of Texas Southwestern Medical Center, Dallas, TX) for the kind gift of Xpa knockout mice; Alberto Delgado for setting up the UV exposure apparatus. This work was partly supported by NIH 5 SC2 CA138175-03. APB was fully supported by NIH/NIGMS R25 GM061347. 
Table 1. Lesions observed in UV-irradiated neonatal mice of different genotypes

H\&E/ IHC Diagnosed

Genotype

\begin{tabular}{cccccccccc}
$n$ & & & Melanoma & Lymph Node & Blue & Nodal & \multicolumn{3}{c}{ Others } \\
\cline { 6 - 9 } & & Metastasis & Nevus & Nevus & A & B & C & D \\
10 & 6 & 6 & 1 & 1 & 0 & 1 & 0 & 0 \\
13 & 6 & 6 & 4 & 2 & 0 & 0 & 1 & 0 \\
16 & 3 & 3 & 7 & 4 & 0 & 0 & 0 & 0 \\
37 & 0 & 0 & 0 & 0 & 1 & 0 & 0 & 2 \\
\hline
\end{tabular}

$\mathrm{Xpa}^{-/-}$K5-Edn3 $\quad 10 \quad 6$

$\mathrm{Xpa}^{+/-} ; \mathrm{K} 5-\mathrm{Edn3} \quad 13$

$\mathrm{Xpa}^{+/+} ; \mathrm{K} 5-\mathrm{Edn} 3 \quad 16 \quad 3$

Controls 37

A- Squamous cell carcinoma; B- Sarcoma; C- Fibroma; D- Fibrohistiocytic Tumor 


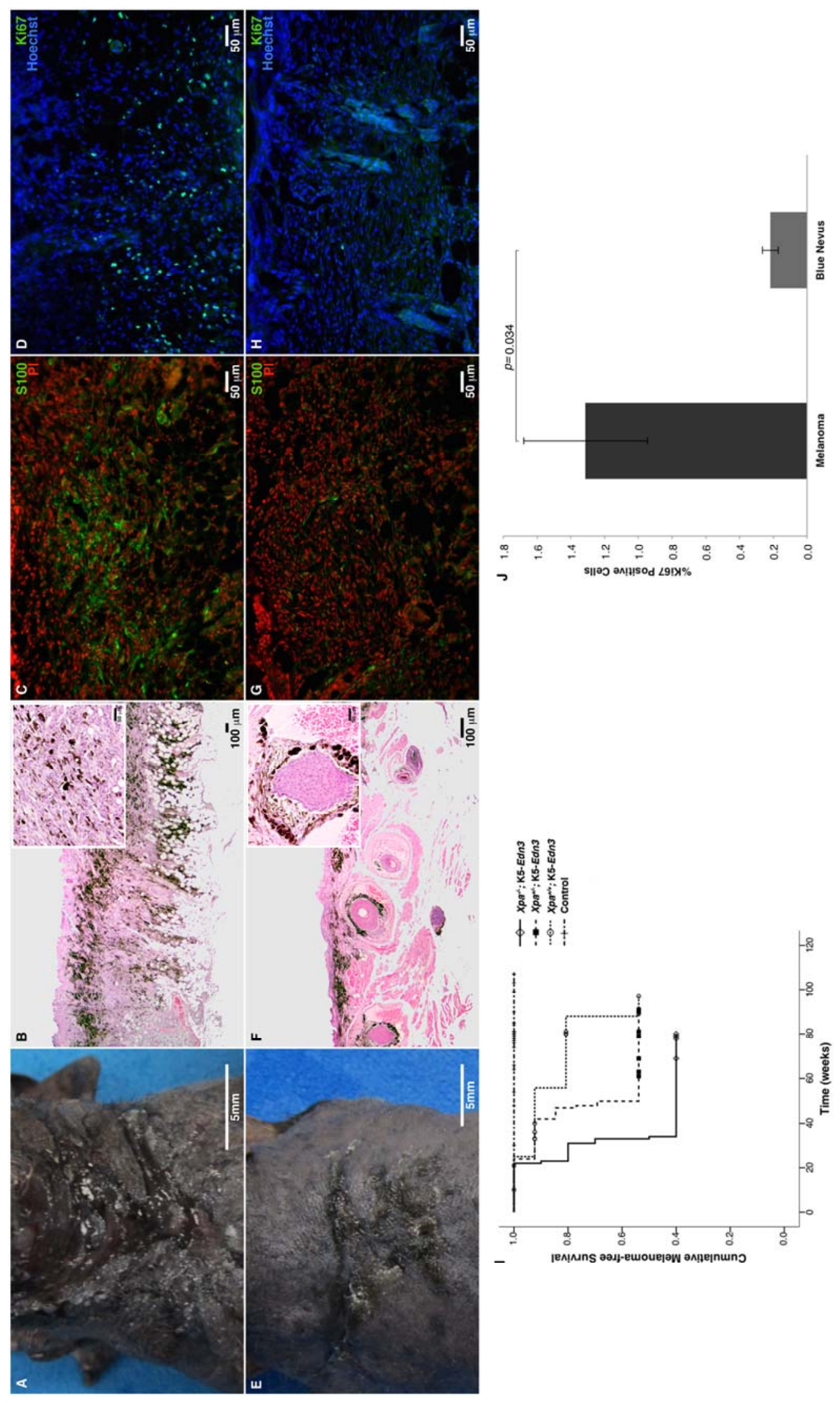


Figure 2.1 Lesions in UV-irradiated K5-Edn3 transgenic mice. (A) Representative melanoma skin lesion found in the ventral torso of a 12 month-old $\mathrm{Xpa}^{+-}$; K5-Edn3 mouse. (E) Representative blue nevus lesion found in the dorsal torso of an 18 month-old $X \mathrm{pa}^{-/} ; \mathrm{K} 5-E d n 3$ mouse. Hematoxylin and eosin staining of a $5 \mu \mathrm{m}$ paraffin section of a melanoma (B) and blue nevus lesion (F) (higher magnification in insets). Immunofluorescence staining of melanoma (C, D) and blue nevus $(\mathrm{G}, \mathrm{H}) 10 \mu \mathrm{m}$ cryosections with $\mathrm{S} 100$ (1:200, Dako, Carpinteria, CA) and Ki67 (1:100, Abcam, MA), respectively. Propidium iodide (PI) $(C, G)$ and Hoechst $(D, H)$ were used as counterstain. (I) Cumulative survival of melanomafree mice as a function of age (Kaplan-Meier analysis) in UV-irradiated K5-Edn3 and non-K5-Edn3 mice with and without $X p a$ deficiency. The melanoma freesurvival period of $X p a^{-/} ; \mathrm{K} 5-E d n 3(n=10)$ mice was significantly shorter $(p=0.029$, Kaplan-Meier with log-rank test) than that of $X_{p a}^{+/+} ; \mathrm{K} 5-E d n 3(n=16)$. The melanoma free-survival period for $\mathrm{Xpa}^{+/-} ; \mathrm{K} 5-E d n 3(\mathrm{n}=13)$ was not significantly different than that of $X p a^{-/} ; \mathrm{K} 5-E d n 3$ or $X p a^{+/+} ; \mathrm{K} 5-E d n 3$ ( $p=0.231$ and $p=0.358$, respectively, Kaplan-Meier with log-rank test). In the absence of K5-Edn3 transgene $(n=37)$, mice failed to develop melanoma. (J) Quantification of Ki67 positive cells in melanoma $(n=3)$ and blue nevus-like $(n=3)$ lesions. Bars represent means \pm SD. Statistical differences were calculated by one-way ANOVA ( $p<0.05, \mathrm{n}=3$ per melanocytic lesion). 


\subsection{References}

Bagnato, A., Rosano, L., Spinella, F., Di Castro, V., Tecce, R., and Natali, P. G. (2004). Endothelin B receptor blockade inhibits dynamics of cell interactions and communications in melanoma cell progression. Cancer Res 64, 1436-43.

Garcia, R. J., Ittah, A., Mirabal, S., Figueroa, J., Lopez, L., Glick, A. B., and Kos, L. (2008). Endothelin 3 induces skin pigmentation in a keratin-driven inducible mouse model. J Invest Dermatol 128, 131-42.

Grichnik, J. M. (2008). Melanoma, nevogenesis, and stem cell biology. J Invest Dermatol 128, 2365-80.

Kannan, K., Sharpless, N. E., Xu, J., O'hagan, R. C., Bosenberg, M., and Chin, L. (2003). Components of the $\mathrm{Rb}$ pathway are critical targets of UV mutagenesis in a murine melanoma model. Proc Natl Acad Sci U S A 100, $1221-5$.

Kraemer, K. H., Lee, M. M., Andrews, A. D., and Lambert, W. C. (1994). The role of sunlight and DNA repair in melanoma and nonmelanoma skin cancer. The xeroderma pigmentosum paradigm. Arch Dermatol 130, 1018-21.

Nakane, H., Takeuchi, S., Yuba, S., Saijo, M., Nakatsu, Y., Murai, H., Nakatsuru, Y., Ishikawa, T., Hirota, S., Kitamura, Y., et al. (1995). High incidence of ultraviolet-B-or chemical-carcinogen-induced skin tumours in mice lacking the xeroderma pigmentosum group A gene. Nature 377, 165-8.

Noonan, F. P., Recio, J. A., Takayama, H., Duray, P., Anver, M. R., Rush, W. L., De Fabo, E. C., and Merlino, G. (2001). Neonatal sunburn and melanoma in mice. Nature 413, 271-2.

Noonan, F. P., Zaidi, M. R., Wolnicka-Glubisz, A., Anver, M. R., Bahn, J., Wielgus, A., Cadet, J., Douki, T., Mouret, S., Tucker, M. A., et al. (2012). Melanoma induction by ultraviolet $A$ but not ultraviolet $B$ radiation requires melanin pigment. Nature communications 3, 884 .

Queille, S., Drougard, C., Sarasin, A., and Daya-Grosjean, L. (2001). Effects of XPD mutations on ultraviolet-induced apoptosis in relation to skin cancerproneness in repair-deficient syndromes. J Invest Dermatol 117, 1162-70.

Van Schanke, A., Van Venrooij, G. M., Jongsma, M. J., Banus, H. A., Mullenders, L. H., Van Kranen, H. J., and De Gruijl, F. R. (2006). Induction of nevi and skin tumors in Ink4a/Arf Xpa knockout mice by neonatal, intermittent, or chronic UVB exposures. Cancer Res 66, 2608-15. 
Wood, S. R., Berwick, M., Ley, R. D., Walter, R. B., Setlow, R. B., and Timmins, G. S. (2006). UV causation of melanoma in Xiphophorus is dominated by melanin photosensitized oxidant production. Proc Natl Acad Sci U S A 103, 4111-5.

Yamazaki, F., Okamoto, H., Matsumura, Y., Tanaka, K., Kunisada, T., and Horio, T. (2005). Development of a new mouse model (xeroderma pigmentosum a-deficient, stem cell factor-transgenic) of ultraviolet B-induced melanoma. J Invest Dermatol 125, 521-5.

\subsection{Supporting information}

\subsubsection{Materials and Methods}

\subsubsection{Mice}

K5-tTA; TRE-Edn3-lacZ (for simplicity, K5-Edn3) mice were generated in our laboratory (Garcia et al., 2008). The skin of newborn K5-Edn3 mice is extremely dark when compared to non-transgenic littermates, and remains hyperpigmented into adulthood. This hyperpigmentation is due to the accumulation of large numbers of melanocytes in the epidermis, dermis and junction of the skin where they are not normally found.

Xpa knockout mice (courtesy of Dr. Friedberg, University of Texas Southwestern Medical Center, Dallas, Texas) were crossed with K5-Edn3 double-transgenic mice to generate $\mathrm{Xpa}^{+/} ; \mathrm{K} 5-\mathrm{Edn} 3$ mice. Treatment and control mice were produced from $\mathrm{Xpa}^{+/} ; \mathrm{K} 5-E d n 3$ intercrosses. Genotyping was carried out according to previously published protocols (de Vries et al., 1995; Garcia et al., 2008). All mice used in this study were housed in the Animal Care Facility at Florida International University (Miami, FL). All animal studies were carried out in accordance with Institutional Animal Care and Use Committee (IACUC) regulations. 


\subsubsection{Induction of Skin Tumors by UV Radiation}

A bank of six Phillips F40 UV lamps (Q Panel Lab Products, Cleveland, $\mathrm{OH}$ ) was used. The UV dose was continuously monitored with a IL1700 radiometer (UV Process Supply, Inc., Chicago, IL). Neonatal mice (3.5 days old) were subjected to a single erythematous dose of UV radiation in single wells of a 6-well Falcon plastic tissue culture plate (Becton-Dickinson, $\mathrm{NJ}$ ) without the lid (Noonan et al., 2001). Following UV exposure, animals were monitored weekly for skin lesions and tumor development during a period of 18 months. The time of appearance of the first skin lesion that subsequently became melanoma was recorded for each mouse and used in a Kaplan-Meier survival analysis.

\subsubsection{Histological and Immunostaining Analysis of Tumors}

At the time of necropsy, mice were grossly assessed for the presence of metastases. Melanomas and melanoma metastases were diagnosed based on a combination of histomorphology and immunostaining. For histomorphology, tissues were fixed in $10 \%$ buffered formalin, paraffin-embedded, sectioned at 5 microns, and stained with hematoxylin and eosin. For immunostaining analyses, tissues were fixed in $4 \%$ paraformaldehyde, embedded in freezing medium (OCT Compound for Cryostat Sectioning, Ted-pella, USA), and cryosectioned longitudinally at 10 microns. Cryosections of skin lesions were stained with antibodies against S100 (1:200 dilution, Dako, Carpinteria, CA) and Trp1 (1:50 dilution, $\alpha$-PEP1 antibody, Dr. Vincent Hearing - NIH) whereas lymph nodes were only stained with antibody against Trp1. Sections were visualized on a Leica Leitz DMRB fluorescent microscope. Digital pictures were captured with a Leica 
DC 500 camera. Pathological analysis was carried out blind with respect to the animals' genotype.

\subsubsection{Proliferating Cells}

Melanoma and blue nevus-like skin biopsies were cryosectioned longitudinally $(10 \mu \mathrm{m})$ and immunostained with the antibody against Ki67 (dilution 1:100, Abcam, MA). Ki67 positive cells were counted in 25 sections of each skin biopsy ( $\mathrm{n}=3$ per melanocytic lesion type).

\subsubsection{Apoptotic Cells}

Neonatal mice (3.5 days old) were UV-irradiated for 15 minutes, as previously described, and sacrificed 24 hours later. Dorsal skin biopsies were cryosectioned longitudinally $(10 \mu \mathrm{m})$ and immunostained with the antibody against cleaved Caspase-3 (dilution 1:100, Cell Signaling, Boston, MA). Apoptotic cells in the epidermis and dermis were counted in 30 sections for each genotype $(n=3$ per genotype).

\subsubsection{Statistical Analysis}

Kaplan-Meier curves were generated for the analyses of tumor incidence between genotypes. Statistical differences were calculated by log-rank test and one-way ANOVA. Sunburn cells results were analyzed using a one-way ANOVA. Values of $p<0.05$ were considered statistically significant. 


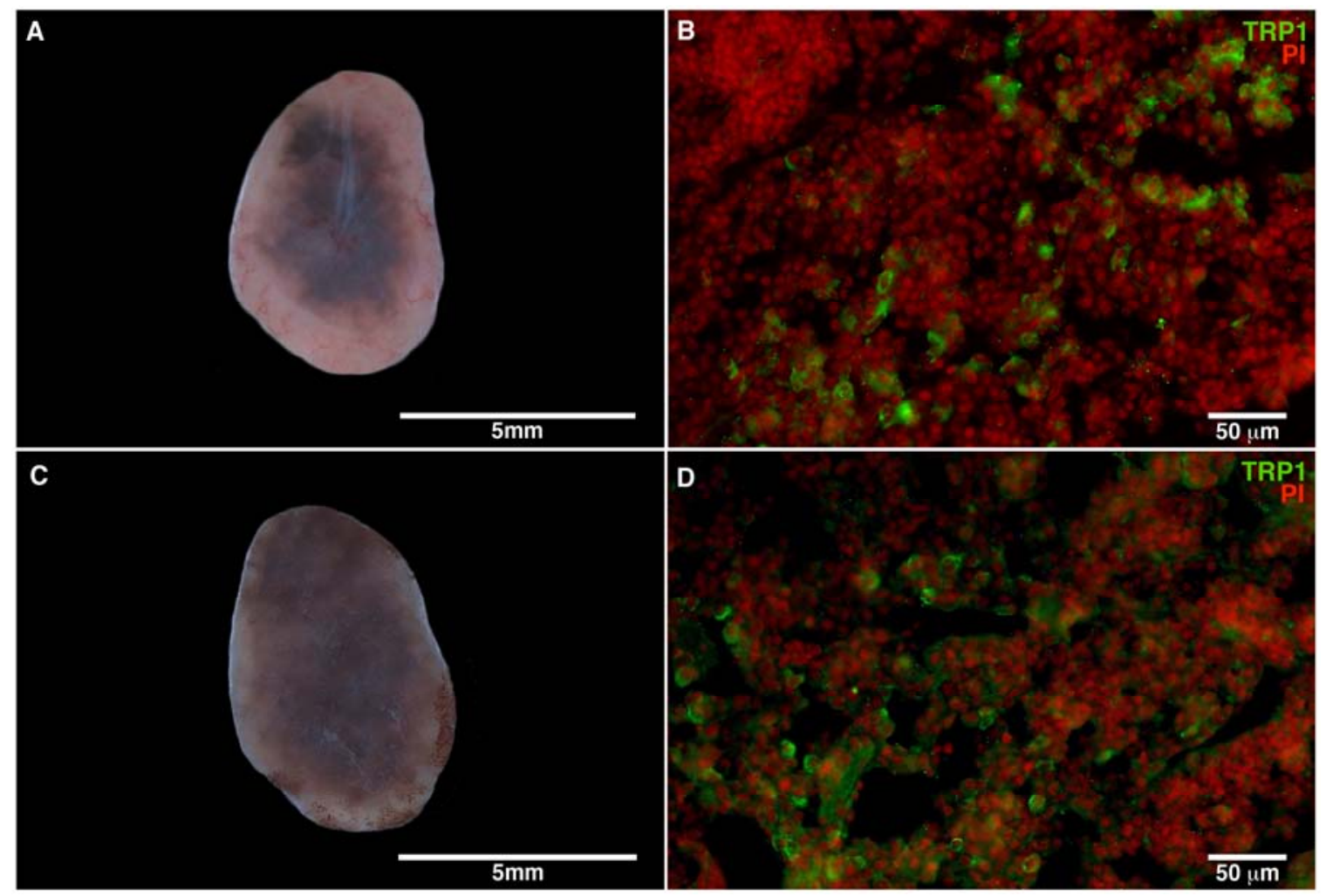

Figure S1. Lymph nodes in UV-irradiated K5-Edn3 transgenic mice. (A) Hyperpigmented and enlarged cervical lymph node diagnosed as local metastasis removed from $\mathrm{Xpa}^{+-}$; K5-Edn3 mouse showed in Figure 1A. (C) Hyperpigmented and enlarged brachial lymph node diagnosed as nodal nevus removed from $X \mathrm{~Pa}^{-/-} ; \mathrm{K} 5-\mathrm{Edn} 3$ mouse showed in Figure 1E. Immunofluorescence staining of lymph nodes cryosections with antibody against TRP1 (B, D). Propidium iodide (PI) was used as counterstain. 


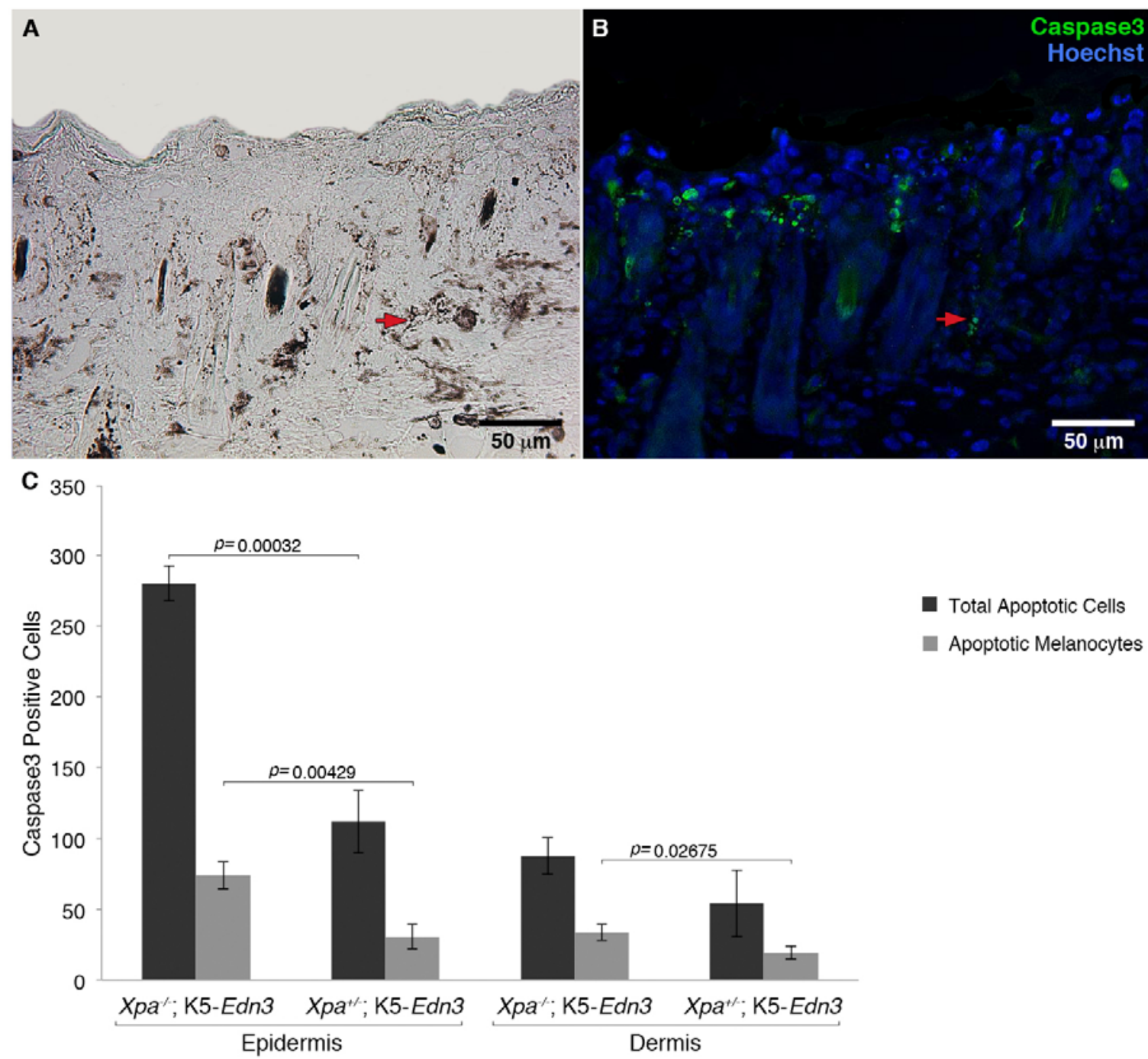

Figure S2. Distribution of melanin and quantification cleaved Caspase-3 positive cells in neonatal UV-irradiated dorsal skin. Newborns (3.5 days old) were exposed to 15 minutes of UV radiation and sacrificed 24 hours later for dorsal skin removal. Melanin ( $A$, dark) and cleaved Caspase-3 (B, green) distribution in a dorsal skin cryosection of an $\mathrm{Xpa}^{-/-}$; K5-Edn3 mouse. Hoechst was used as counterstaining. Double labeled cells (arrows) were counted as apoptotic melanocytes. (C) Quantification of cleaved Caspase-3 positive cells in epidermis and dermis of $X \mathrm{pa}^{-/} ; \mathrm{K} 5-E n d 3(\mathrm{n}=3)$ and $\mathrm{Xpa}{ }^{+-}$; K5-End3 $(\mathrm{n}=3)$. Bars represent means \pm SD. Statistical differences were calculated by one-way ANOVA $(p<0.05$, $n=3$ per genotype). 


\subsubsection{References}

De Vries, A., Van Oostrom, C. T., Hofhuis, F. M., Dortant, P. M., Berg, R. J., De Gruijl, F. R., Wester, P. W., Van Kreijl, C. F., Capel, P. J., Van Steeg, H., et al. (1995). Increased susceptibility to ultraviolet-B and carcinogens of mice lacking the DNA excision repair gene XPA. Nature 377, 169-73.

Garcia, R. J., Ittah, A., Mirabal, S., Figueroa, J., Lopez, L., Glick, A. B., and Kos, L. (2008). Endothelin 3 induces skin pigmentation in a keratin-driven inducible mouse model. J Invest Dermatol 128, 131-42.

Noonan, F. P., Recio, J. A., Takayama, H., Duray, P., Anver, M. R., Rush, W. L., De Fabo, E. C., and Merlino, G. (2001). Neonatal sunburn and melanoma in mice. Nature 413, 271-2. 


\section{CHAPTER III.}

NUCLEOTIDE EXCISION REPAIR DEFFICIENCY ENHANCES MELANOMA PHOTOCARCINOGENESIS IN TRANSGENIC K5-EDN3 MICE 


\section{NUCLEOTIDE EXCISION REPAIR DEFFICIENCY ENHANCES MELANOMA PHOTOCARCINOGENESIS IN TRANSGENIC K5-EDN3 MICE}

\subsection{Abstract}

Melanomagenesis is influenced by the interaction of environmental and genetic factors, as well as, tumor-host interactions. Mice with $X p c$ deficiency show high sensitivity to ultraviolet (UV) light, leading to skin cancer development, except melanoma. The Endothelin 3 (Edn3) signaling pathway is essential for the development of melanocyte precursor cells. In humans, this pathway has also been implicated in melanoma progression and its metastatic potential. The purpose of the present study was the development of a UV-induced melanoma mouse model that combines Xpc deficiency with the over-activation of the Edn3 pathway. To this end, transgenic mice over-expressing Edn3 under the control of the Keratin 5 promoter (K5-Edn3) and carrying a targeted mutation in Xpc were exposed to a single suberythemal neonatal dose of UV radiation. A subgroup of mice was additionally exposed to a second dose of UV radiation at 6 weeks of age. One more group of animals was exposed to a single dose of UV only at 6 weeks of age. Animals were monitored weekly for skin lesion development during the period of at least 18 months. Histomorphology and immunostaining were used to confirm the melanocytic origin of primary skin tumors. Melanoma was only found in animals with the K5-Edn3 transgene. Increased penetrance and decreased latency were observed in animals exposed to one dose of UV radiation that were $X p c$ null in comparison to $X p c$ heterozygous or $X p c$ wild type. Animals exposed to two doses of UV radiation (at 3.5 days and 6 weeks of age) 
did not reveal significant differences in melanoma penetrance or average time for melanoma appearance between $X p c$ null, $X p c$ heterozygous or $X p c$ wild type. Mice exposed to UV radiation only at 6 weeks of age did not develop melanoma. Quantification of UV-induced photodamage in the dorsal skin of 3.5 days old UVirradiated mice revealed a decreased number of thymine-dimer positive cells in the K5-Edn3 skin in comparison to the skin of non K5-Edn3. Next generation sequencing of two melanoma skin lesions revealed several mutations in Braf, Nras, Kras and Hras amplicons. These results indicate that combination of neonatal UV exposure with over-activation of the Edn3 pathway is sufficient to lead for melanomagenesis in mice, and lack of $X p c$ enhances its development.

\subsection{Introduction}

Melanoma is the most aggressive form of skin cancer, notorious for its high propensity to metastasize and poor response to current treatment modalities. The incidence rates of melanoma have considerably increased for the past several decades and it is estimated that approximately $65 \%$ of the worldwide and $90 \%$ of North America cutaneous malignant melanoma are linked to ultraviolet (UV) radiation as a causal agent (Armstrong and Kricker, 1993).

Development of UV-responsive animal models has contributed to the elucidation of the interactions between UV effects and melanoma formation and progression. Transgenic mice expressing either activated $\mathrm{H}$-ras (Broome Powell et al., 1999) or SV40 T-antigen (Kelsall and Mintz, 1998; Klein-Szanto et al., 1994) under the regulation of a melanocyte specific promoter (TPras or TyrSV4OTag) capable of developing melanocytic hyperplasia or spontaneous 
melanoma, respectively, showed an increased melanoma penetrance when submitted to chronic UV exposures. These transgenic mice were hyperpigmented with accumulation of melanocytes in the skin. This seems to be a requirement for UV-induced melanomagenesis in mice, most likely because in adult skin, melanocytes are normally restricted to hair follicles where they are protected from the damaging effects of UV.

One of the most successful UV-induced melanoma mouse models is the transgenic mouse that over-expresses the tyrosine kinase receptor Met ligand, Hepatocyte Growth Factor/Scatter Factor (HGF/SF), ubiquitously under the control of the metallothionein promoter. These mice are hyperpigmented with large numbers of melanocytes found at or near the dermal-epidermal junction, similar to their distribution in human skin. They develop metastatic melanomas spontaneously, but at very low incidence and long latency (Takayama et al., 1997). Chronic suberythemal UV exposure of these mice did not alter the kinetics of melanomagenesis (Noonan et al., 2000). However, a single neonatal dose of suberythemal UV was sufficient to induce melanomas with high penetrance, short latency, and histopathological features that resembled those of human melanomas (Noonan et al., 2001). Additionally, other studies using the same neonatal UV exposure regimen showed that TPras (Hacker et al., 2005) and TyrHras: Arf $^{\prime-}$ (Kannan et al., 2003) mice have a dramatic increase in melanoma penetrance in comparison to chronic UV treatments or unexposed adult mice with the same genotype, respectively. These studies validated retrospective epidemiological data suggesting that in contrast to other skin cancers that are 
linked with cumulative lifetime UV exposure, cutaneous malignant melanoma is caused by intense intermittent UV exposure, especially during childhood (Whiteman et al., 2001). A recent study addressing the role of UV radiation in a mouse model in which melanocytes express $\mathrm{BRAF}^{\mathrm{V} 600 \mathrm{E}}$ demonstrated that UV protection, such as sunscreen and UVR-proof cloth, does help against UVinduced melanoma. The use of sunscreen was shown to delay the onset age and to reduce the number of melanomas in UV-exposed $B R A F^{V 600 E}$ transgenic mice. Furthermore, p53 gene was identified as a UV-targeted gene in melanoma lesions removed from these mice, and p53 mutations were often linked to faster melanoma formation (Viros et al., 2014).

The DNA damage caused by UV radiation can lead to mutations in critical genes encoding for proteins related to DNA repair, apoptosis and cell cycle control. Malfunction of these important proteins are strongly connected with early stages of skin cancer (Ortonne, 2002). Photoproducts induced by UV radiation are, in normal cells, repaired by the nucleotide excision repair (NER) pathway, highlighting its essential role in the maintenance of integrity of genomic DNA after it has been exposed to environmental damage (Friedberg et al., 1995). Indeed, NER malfunction is an important factor in UV-induced skin cancer (Yarosh et al., 2005). The prominent role of NER in cancer resistance is well exemplified by patients with Xeroderma Pigmentosum (XP). The XP disease is an autosomal recessive disease where patients have a defective NER and a much higher risk, up to 1,000 times, of developing skin cancers, including melanoma (Kraemer et al., 1994). This disease results from mutations in the components of the NER 
pathway, such as Xpa and Xpc. Mice lacking the Xpa gene were highly sensitive to UV-induced nevi and exhibited a high incidence of squamous cell carcinoma after exposure to UVB (Nakane et al., 1995; van Schanke et al., 2006). However, melanomas only developed when the skin of $\mathrm{Xpa}^{-/-}$mice was topically treated with DMBA and chronically exposed to UV (van Schanke et al., 2006). Mice lacking the $X p c$ gene are likely to develop esophageal, bladder and lung cancer when exposed to chemical carcinogens (Hollander et al., 2005). They are also very susceptible to UV-induced basal and squamous cell carcinomas (Friedberg et al., 1999; Sands et al., 1995; Venema et al., 1991).

Several human cancers, including melanoma, present mutations in the three human RAS genes (NRAS, KRAS, HRAS) (Ball et al., 1994; Omholt et al., 2002). Additionally, mutations in the RAS effector protein BRAF have also been identified in $66 \%$ of melanoma patients (Davies et al., 2002). Disrupted NER pathway allows UV radiation to trigger gene mutations. Studies carried out in XP patients showed that approximately $50 \%$ of the patients present RAS mutations in skin cancers. This is twice of the percentage observed in skin cancer patients that do not have XP disease (Daya-Grosjean et al., 1993).

The Endothelin 3 (Edn3) cytokine and its seven-transmembrane receptor Endothelin receptor $b(E d n r b)$ are essential for melanocyte development, and have been associated with increased risk of different types of cancers such as breast cancer, prostate cancer, and malignant melanoma (Bagnato et al., 2004). Experiments using the Ednrb specific antagonist, BQ788, showed that decreasing Ednrb levels in malignant melanoma can inhibit the growth of 
melanoma cell lines both in vitro and in vivo by enhancing apoptosis and stimulating angiogenesis via upregulation of Vascular Endothelial Growth Factor (Lahav et al., 1999; Lahav et al., 2004). The activation of Ednrb by Endothelin 1 (Edn1) and Edn3 in melanoma cell lines led to changes in cadherins, connexins, integrins and matrix metalloproteinases that are associated with the disruption of normal host-tumor interactions and progression of cutaneous melanoma (Bagnato and Natali, 2004; Rosano et al., 2004).

In order to further understand the relationship among UV radiation, genetic factors and tumor microenvironment, we established a novel UV-induced melanoma mouse model that depends exclusively on the presence of Edn3 in the tumor microenvironment and it is exacerbated by Xpa deficiency (Benaduce et al., 2014). In this study we describe how Xpc deficiency affects melanoma initiation and progression and how important the timing of UV radiation exposure is to melanomagenesis.

\subsection{Materials and Methods}

\subsubsection{Mice}

K5-tTA; TRE-Edn3-lacZ (for simplicity, K5-Edn3) mice were originally developed in our laboratory (Garcia et al., 2008). The K5-Edn3 newborn skin is extremely dark when compared to non-transgenic littermates, and remains hyperpigmented into adulthood. This hyperpigmentation is the result of the accumulation of large numbers of melanocytes in the epidermis, dermis and epidermal-dermal junction of the skin where they are not normally found. 
The Xpa and Xpc knockout mice (courtesy of Dr. Friedberg, University of Texas Southwestern Medical Center, Dallas, TX) were crossed with K5-Edn3 transgenic mice to generate $\mathrm{Xpa}^{+/-} ; \mathrm{K} 5-E d n 3$ and $\mathrm{Xpc}^{+/-} ; \mathrm{K} 5-\mathrm{Edn} 3$ mice, respectively. Treatment and control mice were produced from intercrosses of

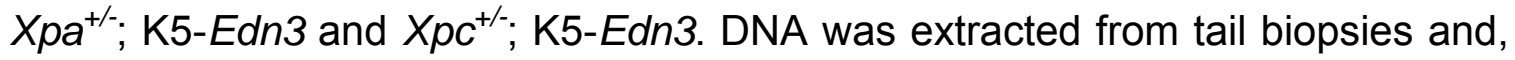
genotyping was performed according to previously published protocols (Cheo et al., 1997; de Vries et al., 1995; Garcia et al., 2008). All mice used in this study were housed in the Animal Care Facility at Florida International University (Miami, FL). All animal experiments were carried out in accordance with Institutional Animal Care and Use Committee (IACUC) regulations.

\subsubsection{Induction of Skin Tumors by UV Radiation}

A bank of six Phillips F40 UV lamps (Q Panel Lab Products, Cleveland, $\mathrm{OH}$ ) was used in the experiments. The UV radiation dosage was continuously monitored with a IL1700 radiometer (UV Process Supply, Inc., Chicago, IL). Neonatal mice ( 3.5 days old) were exposed to a single erythematous dose of UV radiation in single wells of a 6-well Falcon plastic tissue culture plate (Becton-

Dickinson, NJ) without the lid (Noonan et al., 2001). A group of mice was further exposed to a second dose of UV radiation of 30 minutes at 6 weeks of age; whereas another group of mice was exclusively exposed to a 30 minutes dose of UV radiation at 6 weeks of age. Twenty-four hours prior to the 6 weeks of age exposure, the dorsal aspect of the animals were gently depilated with Veet (Reckitt Benckiser Inc., Parsippany, NJ). Following UV exposure, animals were monitored weekly for skin lesions and tumor development for at least 18 months. 
The time of appearance of the first skin lesion that subsequently became melanoma was recorded for each mouse and used in a Kaplan-Meier survival analysis.

\subsubsection{Histological and Immunostaining Analysis of Tumors}

At the time of necropsy, mice were meticulously evaluated for the presence of melanoma metastases. Melanoma was diagnosed based on a combination of histomorphology and immunostaining. For histomorphology, tissues were fixed in $10 \%$ buffered formalin, paraffin-embedded, sectioned at 5 microns, and stained with hematoxylin and eosin. For immunostaining analyses, tissues were fixed in $4 \%$ paraformaldehyde, embedded in freezing medium (OCT Compound for Cryostat Sectioning, Ted-pella, USA), and cryosectioned longitudinally at 10 microns. Cryosections of skin lesions were washed with PBS pH 7.4, incubated $10 \%$ goat serum (Life Technologies, NY), $0.1 \%$ Triton $\mathrm{X}-100$

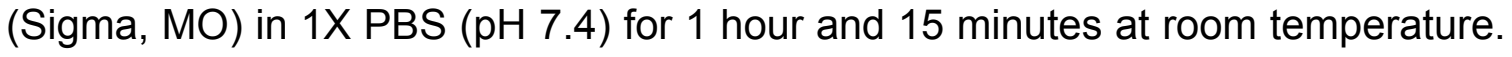
Sections were then incubated overnight, at $4^{\circ} \mathrm{C}$, with antibody against $\mathrm{S} 100$ (1:200 dilution) (Dako, CA; cat\#Z0311). Cryosections were then washed three times with PBS $(\mathrm{pH} 7.4)$ and incubated for 1 hour, at room temperature, with Alexa Flour 488 Goat Anti-Rabbit (1:200, Invitrogen, NY; cat\#A11008) and counterstained with Propidium lodide. Sections were visualized on a Leica Leitz DMRB fluorescent microscope. Digital pictures were taken with a Leica DC 500 camera. Pathological analysis was carried out blind with respect to the animals' genotype. 


\subsubsection{Thymine-Dimer Detection}

Neonatal mice (3.5 days old) were UV-irradiated for 15 minutes, as previously described, and sacrificed 24 hours later. Dorsal skin biopsies were fixed in $4 \%$ paraformaldehyde, embedded in freezing medium (OCT Compound for Cryostat Sectioning, Ted-pella, USA), and cryosectioned longitudinally at 10 microns. Antigen-retrieval was performed by heating $5 \mathrm{mM}$ Tris - 1mM EDTA buffer solution ( $\mathrm{pH} 8.0$ ) for two minutes in the microwave, followed by addition of slides to the boiling buffer and cooking them for 20 minutes in a $100^{\circ} \mathrm{C}$ water bath. After cooling down for 60 minutes at room temperature, slides were washed with PBS and incubated with 10\% fetal bovine serum, 10\% goat serum, 5\% BSA and $0.1 \%$ Triton $\mathrm{X}-100$ in PBS $(\mathrm{pH} 7.4)$ for 1 hour and 15 minutes. Subsequently, cryosections were incubated overnight, at $4^{\circ} \mathrm{C}$, with anti-thymine dimer monoclonal antibody (dilution 1:50) (Kamiya Biomedical, Seattle, WA; cat\#MC062) and washed three times with PBS (pH7.4). Following 1 hour incubation with Alexa Flour 488 Goat Anti-mouse (1:1000, Invitrogen, NY; cat\#A011001) and counterstained with Hoechst. Sections were visualized on a Leica Leitz DMRB fluorescent microscope. Digital pictures were taken with a Leica DC 500 camera. Thymine-dimer positive cells were counted in 10 different sections, 5 fields of view (magnification of 200X) per section, for each genotype ( $n=3$ per genotype). ImageJ software (Schneider et al., 2012) was used to count thymine dimer positive cells and also the total number of cells identified by Hoechst. 


\subsubsection{Detection and Analyses of Melanoma Mutations}

Two skin lesions diagnosed as melanomas removed from two different K5Edn3 transgenic mice exposed to two doses of UV radiation were sequenced. RNA was extracted from frozen biopsies using TRlzol Reagent (Life Technology, NY). Concentration and purity of RNA was assessed using a nanodrop spectrophotometer (ND-3000, NanoDrop, Thermo Scientific, IL). RNA samples were subjected to reverse transcription'-PCR (Maxima First Strand cDNA Synthesis Kit for RT-qPCR, Thermo Scientific, IL), following the manufacturer's protocols. Bovine serum albumin $(500 \mu \mathrm{g} / \mathrm{mL}$, New England BioLabs, MA) was added to the reaction to counteract possible melanin PCR inhibition effects. Polymerase chain reaction was used to amplify regions of Braf, Kras, Nras, Hras genes, using the following primers: Braf (369bp) (forward 5'-TCATGGGCTATTCTACAAAGCCACA AC-3'; reverse 5'-CGTCTGACTGAAAGCTATACGGGTTTTTA-3'), Kras (432bp) (forward 5'-CGCGGCGCGGAGAGAG-3'; reverse 5'-CCTTGCTAACTCCTGAGC CTGTTTC-3'), Nras (428 bp) (forward 5'-GGAGTTTGAGGTTTTTGCTGGTGTG3'; reverse 5'-GCCAGTTCGTGGGCTTGCTTT-3'), Hras (420 bp) (forward 5'GATTGGCAGCCGCTGTAGAAGCT-3'; reverse 5'-GGTCCTGGGCCTGCCGA3 '). The correct sizes of the amplicons were confirmed on $2 \%$ agarose gels with DNA visualized with Ethidium Bromide (Fisher Scientific, MA; cat\#BP1302). DNA concentration and quality was determined using a nanodrop spectrophotometer (ND-3000, NanoDrop, Thermo Scientific, IL). Braf, Kras, Nras, Hras gene mutations were detected by lon-Torrent next generation (Ion Torren Personal Genome Machine, Life Technology, NY) sequencing of the PCR products. 
Data were analyzed using NextGENe ${ }^{\mathrm{TM}}$ software (v2.3.4, SoftGenetics LLC, State College, PA). The raw data from lon Torrent were quality-filtered and trimmed to remove bad-quality reads and adaptors. The high-quality sequence reads were aligned to reference sequences of the PCR amplified regions used in Ion panel. The alignment was then performed using a parameter of a $85 \%$ minimum read match to reference sequence with $30 \mathrm{bp}$ seed size. $A>=5 \%$ mutant read coverage was selected for variant identification. NextGENe ${ }^{T M}$ assigns a Phred-like confidence score to each variant. This score takes into account multiple variables to calculate the likelihood of a given variant being true instead of being caused by sequencing or alignment error. A minimum confidence score of 10 , which corresponds to an accuracy of $90 \%$ that the variant is true, was applied as a threshold for the mutations in this study.

\subsubsection{Statistical Analysis}

Kaplan-Meier curves were generated for the analyses of tumor incidence between genotypes. Statistical differences were calculated by log-rank test and one-way ANOVA. Thymine-dimer cells results were analyzed using a one-way ANOVA. Values of $p<0.05$ were considered statistically significant.

\subsection{Results}

\subsubsection{NER Deficiency Exacerbates UV-Induce Melanomagenesis in Neonatal}

\section{K5-Edn3 Transgenic Mice}

In accordance with previously published data, exposure of neonatal K5-

Edn3 transgenic mice to one erythemal dose of UV radiation was sufficient for 
melanoma development (Benaduce et al., 2014). Additionally, melanomagenesis was independent of the subsequent erythemal dose at 6 weeks of age (Table 1).

Diagnosis of melanocytic lesions as melanoma (Figure 1) was carried out via histopathology and confirmed by immunofluorescence using the $\mathbf{S 1 0 0}$ marker. Mice in the control group, that did not carry the K5-Edn3 transgene, did not present any type of melanocytic lesion (Table 1).

At the gross anatomical level, melanoma lesions on mice exposed to a single neonatal erythemal dose of UV radiation, started as hyperpigmented spots that kept growing overtime and frequently became ulcerated. These lesions were situated on the dorsal (64.29\%) and ventral (35.71\%) aspects of the torso. Body localization of lesions was genotype-independent.

The histopathologic analysis revealed three patterns. There were two cases of in-situ melanomas, two nevoid melanomas and the vast majority appeared to have originated from blue nevus like dermal lesions. As a result of extensive ulceration, the epidermis and dermal epidermal junction was not available for evaluation in most cases. In one case of invasive melanoma, the dermal epidermal junction was preserved. There were foci of confluent melanocytes at the dermal epidermal junction with upward migration, pagetoid spread, of the melanocytes. The invasive component showed atypical cells extending into the subcutis (Figure $1 \mathrm{~N}, \mathrm{O}$ ). Other cases of invasive melanoma showed extension to the underlying skeletal muscle. The cells were crowded with overlapping large nuclei and few nucleoli. Fine melanin granules were present and mitoses were infrequently found (Figure 1B, C). The nevoid melanomas 
were composed of nests of melanocytes in a cluster. The cells were deceptively bland with abundant amphopilic cytoplasm, centrally located nuclei with small nucleoli. Features favoring the malignant nature of the lesions were lack of maturation, mitotic figures and pigment at the base (Figure 1F, G). The two cases of in situ melanoma showed clusters of atypical melanocytes, some of which showed pigmentation, along the junction of the hair follicle and dermis, which is comparable to the same phenomenon at the dermal epidermal junction (Figure 1J, K).

In animals exposed to two doses of UV radiation, melanocytic lesions also started as hyperpigmented spots that began to grow; however these lesions ulcerated much faster and were more severe. Because most of the melanocytic lesions removed from these animals were extremely excoriated, it was not possible to accurately diagnose these lesions as melanoma or not. As a result, melanoma penetrance was remarkably reduced in animals exposed to two doses of UV radiation and did not show any significant differences between treatments (Table 1).

In 3.5 day old mice exposed to a single UV radiation dose, the percentage of $\mathrm{Xpc}^{-/}$; K5-Edn3 melanoma-bearing animals was extremely higher (66.67\%) than the $X p c^{+/-}$; K5-Edn3 (31.58\%) and $X p c^{+/+} ; \mathrm{K} 5-E d n 3$ (15.38\%) (Table 1). Yet, the average time of melanoma appearance was not significantly different between treatments, $\mathrm{Xpc}^{-/-}$; K5-Edn3 (19.40 \pm 12.57), $\mathrm{Xpc}^{+/}$; K5-Edn3 (23.33 \pm 7.44), $X p c^{+/+} ; \mathrm{K} 5-E d n 3(41.07 \pm 24.95)$. 
The melanoma free-survival period of $X p c^{-/} ; \mathrm{K} 5-E d n 3$ mice exposed to a single neonatal dose of UV radiation was significantly shorter than that of $\mathrm{Xpc}^{+/-}$; $\mathrm{K} 5-E d n 3(p=0.020)$ and $X p c^{+/+} ; \mathrm{K} 5-E d n 3(p=0.001)$ exposed to one single dose (Kaplan-Meier with log-rank test). Furthermore, the melanoma free-survival period of the neonatal exposed $X p c^{---} ; \mathrm{K} 5-E d n 3$ was significantly shorter than that for $\mathrm{Xpc}^{+/} ; \mathrm{K} 5-E d n 3(p=0.029)$ and for $\mathrm{Xpc}^{+/+} ; \mathrm{K} 5-E d n 3(p=0.018)$ exposed to two doses of UV radiation (3.5 days and at 6 weeks of age) (Kaplan-Meier with logrank test). Melanoma free-survival period for $\mathrm{Xpc}^{-/} ; \mathrm{K} 5-\mathrm{Edn} 3$ exposed to a single neonatal dose or to two doses of UV radiation was not significantly different $(p=0.058$, Kaplan-Meier with log-rank test) (Figure 2). The average time of melanoma appearance on mice exposed to two doses of UV radiation was also not significantly different among $X p c^{-/-}$; K5-Edn3 (16.48 \pm 10.97$), \mathrm{Xpc}^{+/-}$; K5-Edn3 (20.05 \pm 10.00$), X p c^{+/+} ; \mathrm{K} 5-E d n 3$ (27.85, just one case was observed).

Similar to the trend observed in our previously published data (Benaduce et al., 2014), the average time of melanoma appearance on mice exposed to two doses of UV radiation was significantly shorter in $\mathrm{Xpa}^{--}$; K5-Edn3 $(19.52 \pm 6.97)$ in comparison to $\mathrm{Xpa}^{+/}$; K5-Edn3 $(35.19 \pm 3.07)$ and $X \mathrm{Xa}^{++-}$; K5-Edn3 $(74.19 \pm$ 0.54 ) ( $p=0.023$ and $p=0.005$, respectively). Additionally, a significant difference was also found between $\mathrm{Xpa}^{+/} ; \mathrm{K} 5-\mathrm{Edn} 3$ and $\mathrm{Xpa}^{+/+} ; \mathrm{K} 5-\mathrm{Edn} 3 \quad(p=2.69 \mathrm{E}-05)$. On the other hand, the melanoma free-survival period was not significantly different between these treatments (Figure 3).

Melanoma development was not observed in any of $X p a^{--} ; \mathrm{K} 5-E d n 3(\mathrm{n}=4)$, $\mathrm{Xpa}^{+/} ; \mathrm{K} 5-\mathrm{Edn3}(\mathrm{n}=4)$ or $\mathrm{Xpa}^{+/+} ; \mathrm{K} 5-\mathrm{Edn3}(\mathrm{n}=5)$ mice exposed to UV radiation 
just at 6 weeks of age. This result confirms the importance of neonatal UV radiation exposure for melanoma initiation.

Our data suggest that the combination of neonatal UV radiation with Xpc deficiency intensifies melanoma development in mice over-expressing Edn3 in the skin.

\subsubsection{K5-Edn3 Transgenic Mice Skin Shows Decreased Levels of Direct DNA Photodamage}

Given that only mice carrying the K5-End3 transgene with the hyperpigmentation phenotype developed melanoma, we decided to compare the amount of DNA photodamage in the skin by comparing the levels of the thyminedimer formation in K5-Edn3 and non K5-Edn3 UV-exposed mice. Neonatal mice (3.5 days of age) were exposed to a single erythemal dose of UV radiation and their dorsal skin was removed after 24 hours. Quantification of thymine-dimer positive cells revealed that the total numbers of photodamaged cells in K5-Edn3 newborn skin were significantly smaller $(p=0.00084)$ than those of non K5-Edn3 skin (Figure 4I). In K5-Edn3 dorsal skin the majority of CPDs were found in areas with low melanin levels and mostly concentrated in the epidermis with few positive cells found in upper layers of the dermis (Figure 4A, C, E, G). Non K5Edn3 skin showed CPD formation throughout the epidermis and dermis (Figure $4 B, D, F, H)$.

\subsubsection{Melanoma Mutations Screening}

We screened two melanoma lesions removed from two distinct K5-Edn3 mice exposed to two doses of UV radiation, for mutations in Braf, Kras, Nras and 
Hras genes. Twenty-eight mutations, with mutation score above 25 , were found (Table 2). Increased amount of mutations were observed in Hras gene $(60.71 \%)$ in comparison to Braf (14.29\%), Kras (14.29\%) and Nras (10.71\%). Kras gene presented the only UV-signature mutation found; however this mutation did not lead to an amino acid modification. Insertion $(71.43 \%)$ or deletion $(25 \%)$ of a single nucleotide was the most frequent form of mutation found. All of these mutations led to early stop codons and, possibly, to non-functional proteins.

\subsection{Discussion}

Over the past two decades, the influence of UV radiation on melanoma development has been assessed using different light sources and protocols to promote the malignant transformation of melanocytes in organisms carrying different genetic modifications. Previous studies using the same neonatal UV exposure used in this study showed a dramatic increase in melanoma penetrance of exposed mice in comparison to unexposed mice of the same genotype (Hacker et al., 2005; Kannan et al., 2003; Noonan et al., 2001; Recio et al., 2002). The K5-Edn3 mouse model differs greatly from previous published models because it neither carries oncogenic Ras-related genes in their melanocytes nor spontaneously develops melanoma. Most importantly, it develops cutaneous melanoma exclusively upon neonatal UV radiation.

The results obtained with the K5-Edn3 mouse model further corroborates epidemiological data which suggest a link between childhood sunburn and the development of malignant melanocytic lesions later on in life (Whiteman et al., 2001). 
Epidemiological studies also indicate that dark human skin is less sensitive to UV-induced carcinogenesis, including melanoma, when compared to fairer skin (Del Bino and Bernerd, 2013; Del Bino et al., 2013; Diepgen and Mahler, 2002). The K5-Edn3 mice are highly pigmented and still capable of developing melanoma. At first this would seem to contradict the epidemiological data but it is possible that K5-Edn3 mice on an albino (no melanin) or lethal yellow background (low levels of eumelanin) will be more prone to developing melanoma than the ones used for this study.

Consistent with the epidemiological studies demonstrating that NER deficiency leads to significant higher levels of skin carcinogenesis (DiGiovanna and Kraemer, 2012), the K5-Edn3 mice with Xpc deficiency exposed to a single neonatal dose of UV radiation showed enhanced melanoma penetrance and decreased latency in comparison to animals that had partial $\left(X^{++/}\right)$or completely functional $\left(X p c^{+/+}\right)$NER pathway. The impact of $X p c$ loss on melanoma development was studied in mice carrying Ink4a/ARF deficiency. In these neonatal UV-exposed mice, $X p c$ loss lead to a significant increase in melanomagenesis rates in comparison to the wild type equivalent (Yang et al., 2007). A recent study reported that loss of $A R F$ sensitizes $B R A F^{V 600 E}$ mice to neonatal UVB-induced melanomagenesis by reducing NER due to the inhibition of XPC expression (Luo et al., 2013). In the UV-induced K5-Edn3, Xpc deficiency was not a requirement for melanomagenesis after neonatal UV exposure; however it did influence the melanoma penetrance and age of onset. 
Ultraviolet-exposure of adult K5-Edn3 (6 weeks) did not lead to melanomagenesis and, unexpectedly, when it was associated with previous neonatal exposure, higher melanoma penetrance was not observed. We believe that there might have actually been a decrease in melanoma latency but the speed and level of tumor ulceration was so high that proper diagnosis was jeopardized. It is also important to point out that animals exposed to two doses of UV radiation, at 3.5 days and at 6 weeks, presented more severe inflammation than animals exposed with a single neonatal dose. Recent published results have demonstrated how inflammatory response may underlie melanoma initiation and progression (Bald et al., 2014; Zaidi et al., 2011). Inflammatory environment was linked to angiotropism stimulation, promotion of melanomagenesis via interferon- $\gamma$ secretion by macrophages and the migration of melanoma cells, which results in metastasis (Bald et al., 2014; Zaidi et al., 2011).

Ultraviolet radiation induces the formation of di-pyrimidine lesions, such as cyclobutane pyrimidine dimers (CPDs: thymine-dimer, cytosine-dimer) (Setlow and Carrier, 1964), and this type of DNA damage is repaired by the NER pathway (Rastogi et al., 2010). The dorsal skin of K5-Edn3 newborn mice exposed to UV had markedly reduced number of thymine-dimer positive cells when compared to non K5-Edn3 skin. There are two possible explanations for this result: (1) overexpression of Edn3 in the skin stimulates DNA repair and/or (2) the protective effects of melanin. Previous studies demonstrated an association between the Endothelin axis and DNA repair. Endothelin 1 (Edn1), another EdnrB ligand such as Edn3, is believed to reduce UV-induced DNA 
photoproducts, thus implying an involvement of this cytokine in enhancement of NER (Vlachostergios and Papandreou, 2013). Experiments carried out in mice revealed that upon UV exposure, numbers of CPD positive cells were greatly inhibited in Xpa null; SCF-Tg in comparison to Xpa null mice. No significant differences were observed between these mice when chemically treated with DMBA, instead of exposed to UV radiation. These results showed that epidermal melanin has a protective effect against UVB-induced DNA damage but not against chemical damage (Yamazaki et al., 2004). It appears tough that the amounts or types of melanin may modulate its protective role and even change it into a harmful factor (Cadet and Douki, 2011; Cadet et al., 2009). Recent studies analyzing the effects of UV radiation in albino and pigmented HGF/SF transgenic mice revealed that the presence of melanin is a requirement for UVA-induction of oxidative DNA damage and this indirect DNA damage is the cause of melanoma development in pigmented HGF/SF mice (Noonan et al., 2012). No differences were observed in the amount of DNA damage between these two groups of mice when exposed to UVB radiation (Noonan et al., 2012). These results revealed that melanin presence could be the cause for melanoma initiation upon UVA exposure, but not UVB (Noonan et al., 2012).

Ultraviolet-induced DNA damage causes typical genetic mutations, C to T and CC to TT transitions, called UV-signature mutations. These types of mutations are prominently found in human cutaneous melanoma (Berger et al., 2012; Pleasance et al., 2010). Next generation sequencing of melanoma lesion biopsies removed from K5-Edn3 exposed to two doses of UV radiation revealed one UV-signature mutation 
in the Kras gene. This mutation did not lead to amino acid modification and, consequently, did not affect protein structure. All other mutations found were either insertions or deletions and led to early stop codon formation. A more extensive mutational analysis of the lesions in the K5-Edn3 by whole exome sequencing is necessary. We expect that such analysis may reveal mutations in other well known melanoma related genes such as Pten, p53 and Cdkn2a, and possibly, in genes that have not previously been associated with melanoma. The K5-Edn3 neonatal model will serve as an excellent tool to guide the identification of molecular UV targets and further our understanding of the role played by UV in the process of tumorigenesis. It will also be a useful platform for testing the efficacy of new compounds against melanoma in pre-clinical studies. 
Table 1. Lesions observed in UV-irradiated neonatal mice of different genotypes

\begin{tabular}{|c|c|c|c|c|c|c|c|c|c|}
\hline \multirow{3}{*}{ UV } & \multirow{3}{*}{ Genotype } & \multicolumn{8}{|c|}{ H\&E/ IHC Diagnosed } \\
\hline & & \multirow{2}{*}{$\mathrm{n}$} & \multirow{2}{*}{ Melanoma } & \multirow{2}{*}{ Melanoma \% } & \multicolumn{5}{|c|}{ Others } \\
\hline & & & & & $A$ & $B$ & $\mathrm{C}$ & $\mathrm{D}$ & $\mathrm{E}$ \\
\hline $1 X$ & $X p c^{-/-} ; \mathrm{K} 5-E d n 3$ & 9 & 6 & 66.67 & 0 & 1 & 0 & 0 & 0 \\
\hline $1 X$ & $X p c^{+/-} ; \mathrm{K} 5-E d n 3$ & 19 & 6 & 31.58 & 0 & 0 & 0 & 0 & 0 \\
\hline $1 X$ & $X p c^{+/+} ; \mathrm{K} 5-E d n 3$ & 13 & 2 & 15.38 & 0 & 0 & 0 & 0 & 0 \\
\hline $1 \mathrm{X}$ & Controls & 34 & 0 & 0 & 0 & 0 & 0 & 0 & 2 \\
\hline $2 X$ & $X p c^{-/-} ; \mathrm{K} 5-E d n 3$ & 12 & 3 & 25 & 0 & 0 & 0 & 0 & 0 \\
\hline $2 x$ & $X p c^{+/-} ; \mathrm{K} 5-E d n 3$ & 13 & 3 & 23.08 & 0 & 0 & 0 & 0 & 0 \\
\hline $2 X$ & $X p c^{+/+} ; \mathrm{K} 5-E d n 3$ & 8 & 1 & 12.50 & 0 & 0 & 0 & 0 & 0 \\
\hline $2 x$ & Controls & 22 & 0 & 0 & 1 & 0 & 1 & 0 & 0 \\
\hline $2 x$ & Xpa ${ }^{-/-} ; \mathrm{K} 5-E d n 3$ & 14 & 3 & 21.43 & 1 & 0 & 0 & 0 & 0 \\
\hline $2 X$ & $\mathrm{Xpa}^{+-} ; \mathrm{K} 5-\mathrm{Edn} 3$ & 14 & 3 & 21.43 & 0 & 0 & 0 & 0 & 0 \\
\hline $2 x$ & $\mathrm{Xpa}^{+/+} ; \mathrm{K} 5-\mathrm{Edn} 3$ & 15 & 3 & 20 & 0 & 0 & 0 & 0 & 0 \\
\hline $2 X$ & Controls & 25 & 0 & 0 & 1 & 0 & 0 & 0 & 0 \\
\hline
\end{tabular}

A- Squamous Cell Carcinoma; B- Sarcoma; C- Fibroma; D- Fibrohistiocytic Tumor; E- Pilomatrichoma 


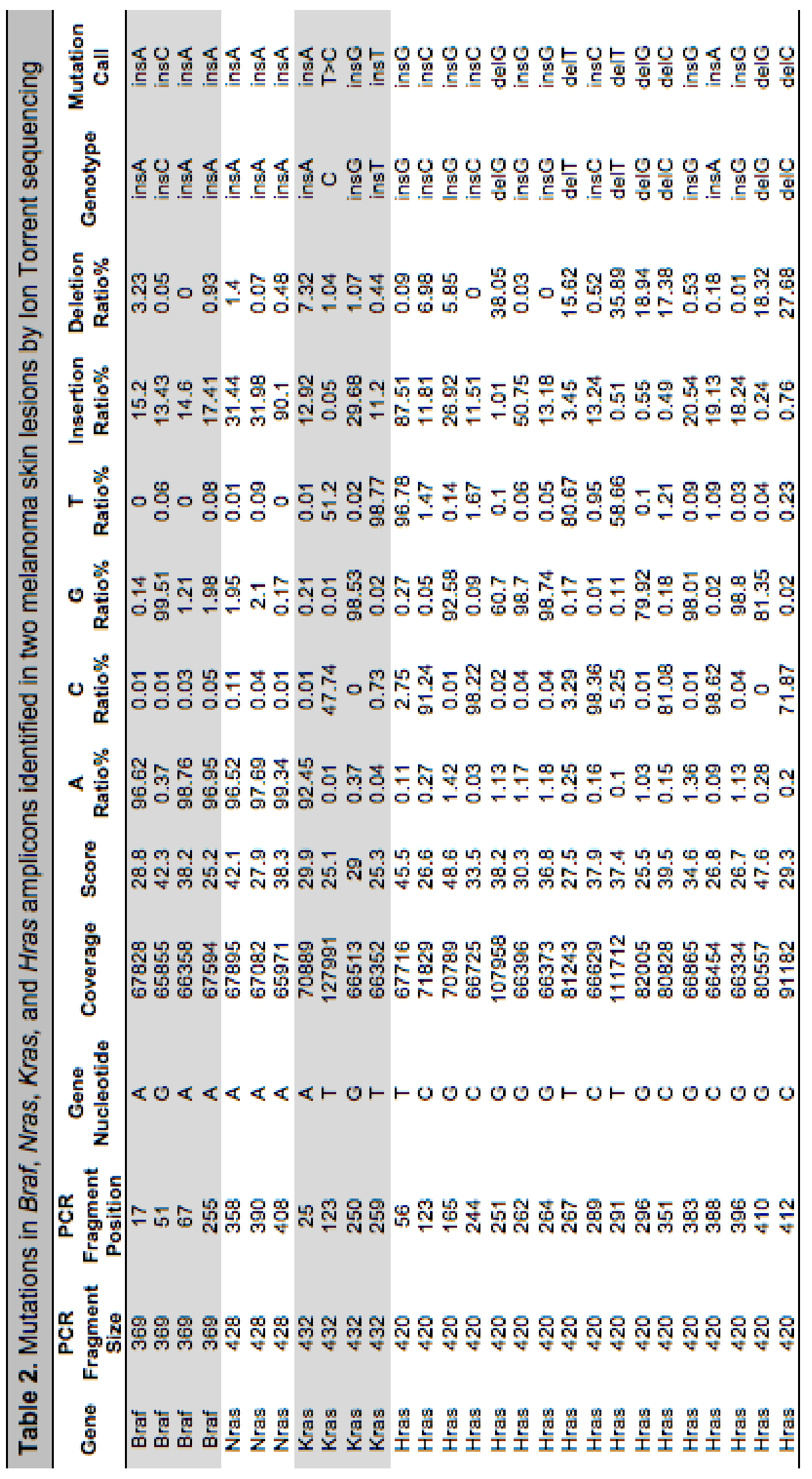


Figure 3.1 Melanoma lesions in UV-irradiated K5-Edn3 transgenic mice. (A) Representative melanoma skin lesion found in the dorsal torso of a 7 month-old $X p c^{--} ; \mathrm{K} 5-E d n 3$ mouse exposed to a single neonatal dose of UV radiation. (B) Hematoxylin and eosin staining of a $5 \mu \mathrm{m}$ paraffin section of the lesion showing eroded epidermis, dermis with a dense collection of pigmented melanocytes extending beyond the subcutis into the underlying skeletal muscle. (C) Higher magnification of $B$ showing melanoma invading between muscle bundles. (D) Substantial amount of immunofluorescence staining observed in the melanoma cryosection stained for the S100 melanoma marker (green). Propidium iodide (PI) (red) was used as counterstain. (E) Representative melanoma skin lesions found in the dorsal torso of a 4 month-old $X p c^{--}$; K5-Edn3 mouse (I) and in the face of 9 month-old $X p c^{+++} ; \mathrm{K} 5-E d n 3$ a mouse exposed to UV radiation at 3.5 days of age and at 6 weeks of age. $(F, G$ and $H)$ Hematoxylin and eosin staining, and S100 immunofluorescence staining displaying the nevoid melanoma found in $\mathrm{E}$ and the $(\mathrm{J}, \mathrm{K}, \mathrm{L}$ and $\mathrm{P})$ in situ melanoma found in $\mathrm{I}$. $(\mathrm{F})$ Beneath an ulcerated epidermis is a nodule composed of nests of deceptively bland melanocytes 
extending into the subcutis. Cells have abundant cytoplasm with small centrally located nuclei. There is lack of maturation. (G) Higher magnification of $F$ displays nuclei with nucleoli and mitotic figure (black arrow). (H) $\quad$ S100 immunofluorescence staining of the melanoma cryosection showing heavy $\mathrm{S} 100$ staining. $(\mathrm{J})$ The epidermis overlying the hair follicle is eroded. Confluent clusters of atypical melanocytes, many of them heavily pigmented, at the junction between the hair follicle and dermis; atypical cells are morphologically similar to those in $\mathrm{B}$. (K) Higher magnification of $\mathrm{J}$ showing overlapping and crowded melanocytes with prominent nucleoli. ( $L$ and P) S100 immunofluorescence staining of the melanoma cryosection showing $S 100$ positive cells at the junction between the hair follicle and dermis. (M) Representative melanoma skin lesions found in the left lateral of a 15 month-old $\mathrm{Xpa}^{+/} ; \mathrm{K} 5-\mathrm{Edn} 3$ mouse exposed to UV radiation at 3.5 days of age and at 6 weeks of age. (N) Hematoxilin and eosin staining confluence of melanocytes with pagetoid spread (yellow arrow). The dermis shows a blue nevus like lesion. (O) Higher magnification of $\mathrm{N}$ shows dermis replaced by atypical melanocytes which extend into the subcutis. Pigmented cells are present at the base of the lesion. 


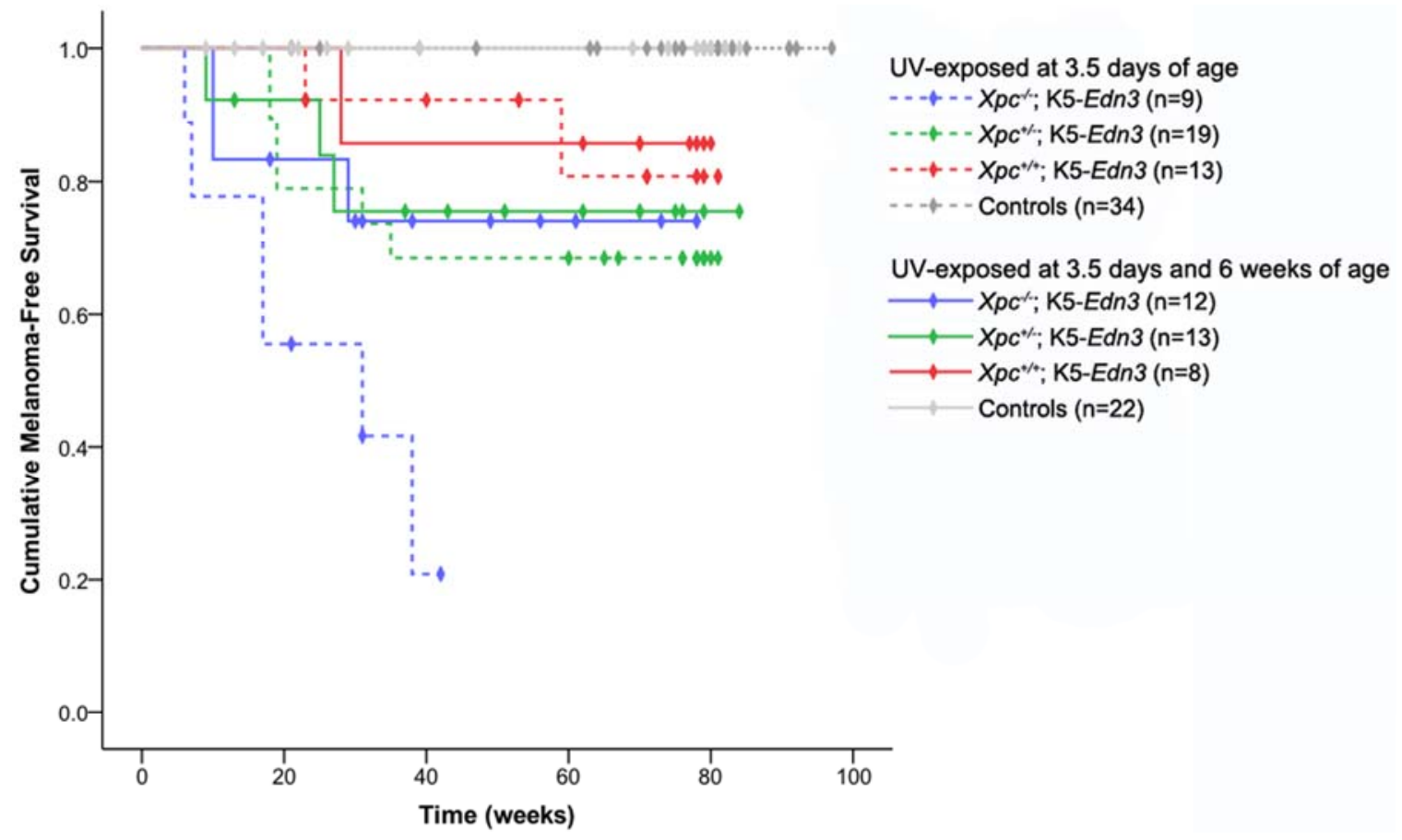

Figure 3.2 Cumulative survival of melanoma-free mice as a function of age (Kaplan-Meier analysis) in UV-irradiated K5-Edn3 and non-K5-Edn3 mice with and without $X p c$ deficiency. The melanoma free-survival period of $\mathrm{Xpc}^{--}$; $\mathrm{K} 5$ Edn3 mice exposed to a single neonatal UV dose was significantly shorter than that of $X p c^{+/} ; \mathrm{K} 5-E d n 3(p=0.020)$ and $X p c^{+/+} ; \mathrm{K} 5-E d n 3(p=0.001)$ (Kaplan-Meier with log-rank test). The melanoma free-survival period for $X p c^{-/-} ; \mathrm{K} 5-E d n 3$ was also significantly different than that of $\mathrm{Xpc}^{+/}$; K5-Edn3 or $X p c^{+++} ; \mathrm{K} 5-E d n 3$ that were exposed to UV radiation at 3.5 days and at 6 weeks of age $(p=0.029$ and $p=0.018$, respectively, Kaplan-Meier with log-rank test). In the absence of K5Edn3 transgene, mice failed to develop melanoma. 


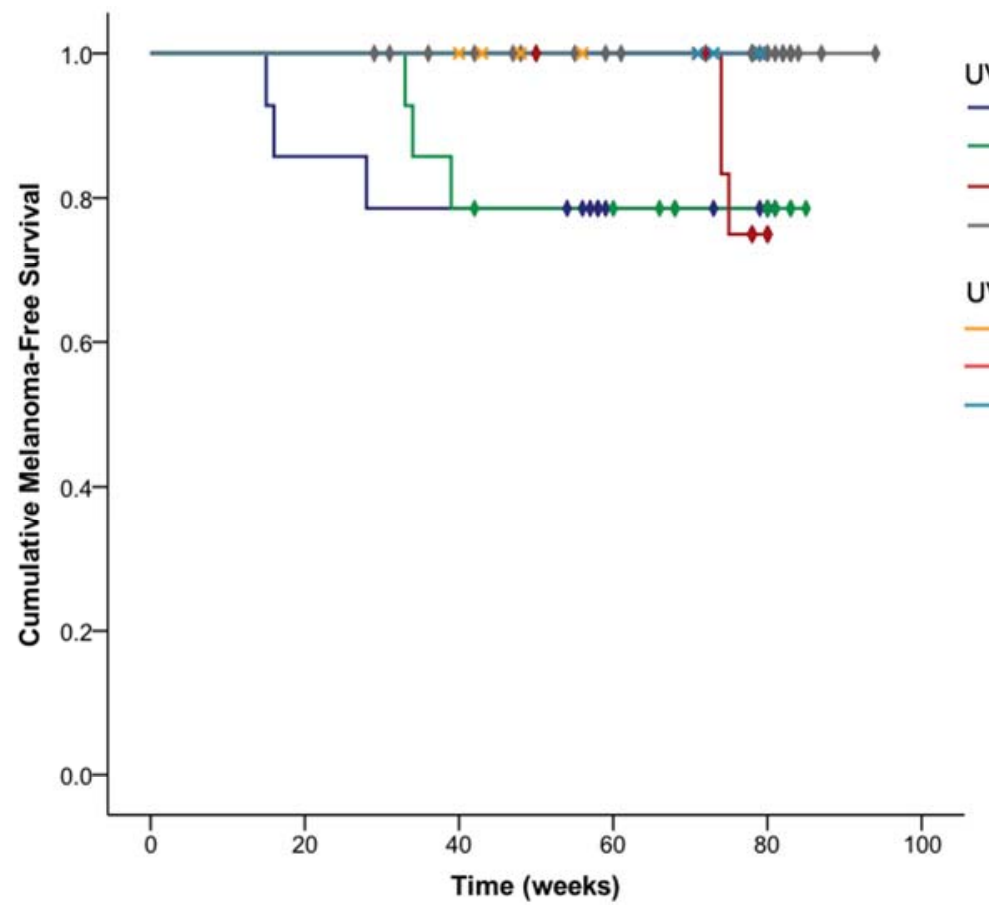

UV-exposed at 3.5 days and 6 weeks of age $\longrightarrow$ Xpar; K5-Edn3 ( $\mathrm{n}=14)$

$\longrightarrow X p a^{* / \%}, K 5-E d n 3(n=14)$

$\longrightarrow X p a^{* * *} ; \mathrm{K} 5-E d n 3(\mathrm{n}=15)$

$\longrightarrow$ Controls $(n=25)$

UV-exposed at 6 weeks of age

$\ldots-X p a^{\prime} ; \mathrm{K} 5-E d n 3(n=4)$

- ${ }^{*} a^{*} \%$ K5-Edn3 $(n=4)$

$\longrightarrow \times \mathrm{pa}^{* / *} ; \mathrm{K} 5-\mathrm{Edn} 3(\mathrm{n}=5)$

Figure 3.3 Cumulative survival of melanoma-free mice as a function of age (Kaplan-Meier analysis) in UV-irradiated K5-Edn3 and non-K5-Edn3 mice with and without $\mathrm{Xpa}$ deficiency. The melanoma free-survival period for $\mathrm{Xpa}^{--}$; K5Edn3 exposed to two doses of UV radiation ( 3.5 days and 6 weeks of age) was not significantly different than that of $\mathrm{Xpa}^{+/-}$; K5-Edn3 or $\mathrm{Xpa}^{+/+}$; K5-Edn3 $\left(p=0.883\right.$ and $p=0.470$, respectively, Kaplan-Meier with log-rank test); $X p a^{+/} ; \mathrm{K} 5$ Edn3 was also not significantly different from Xpa ${ }^{+/+} ; \mathrm{K} 5-E d n 3(p=0.632$, KaplanMeier with log-rank test). In the absence of K5-Edn3 transgene, mice did not develop melanoma. K5-Edn3 mice with and without Xpa deficiency exposed to an UV erythemal dose at adult stage ( 6 weeks of age), also failed to develop melanoma. 


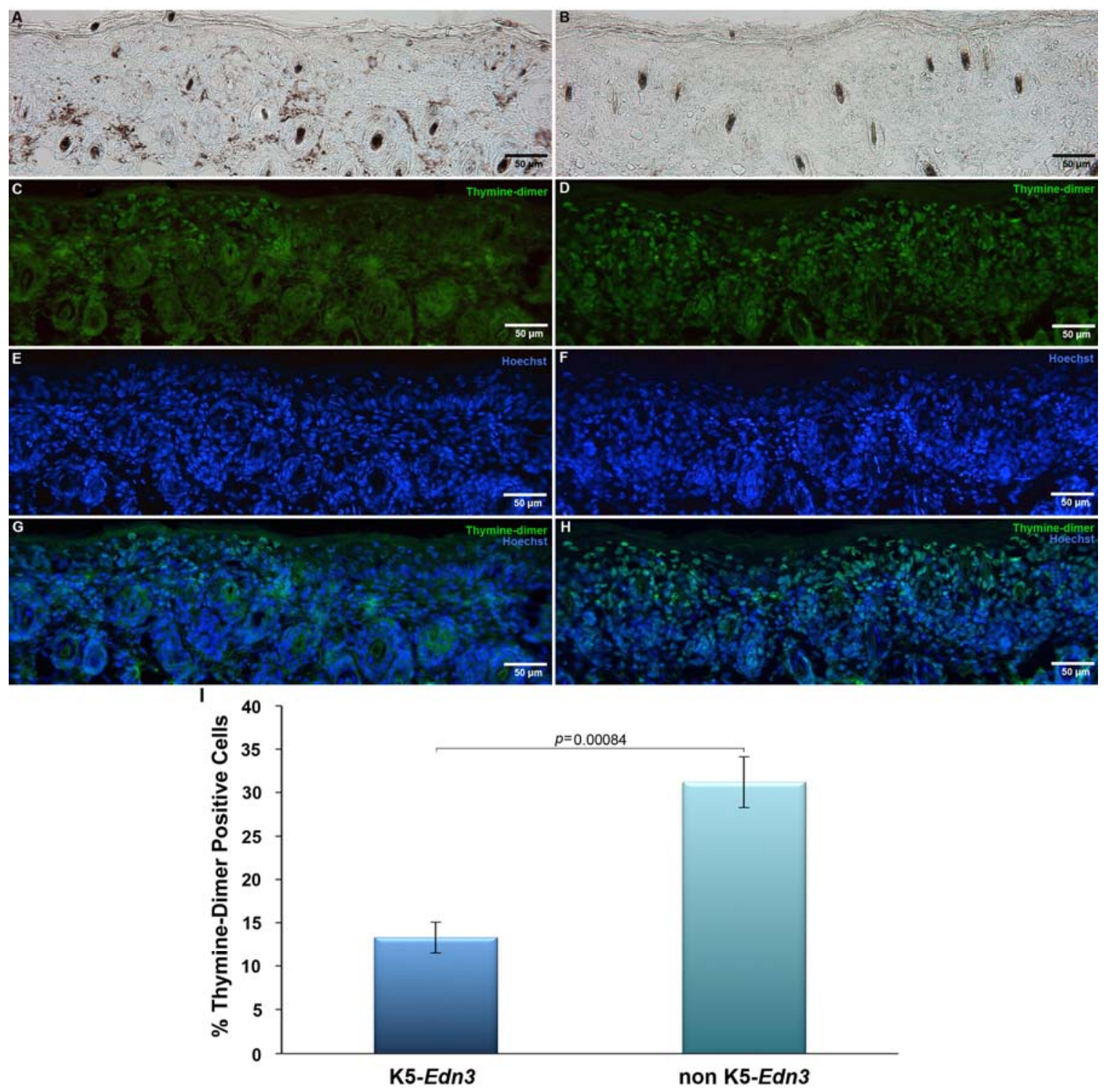

Figure 3.4 Distribution and quantification of melanin and thymine-dimer positive cells in neonatal UV-irradiated dorsal skin. Newborns (3.5 days old) were exposed to 15 minutes of UV radiation and sacrificed 24 hours later for dorsal skin removal. Melanin (A, B dark brown) and thimine-dimers (C, D green) distribution in a dorsal skin cryosection of K5-Edn3 and non K5-Edn3 mice. (G, $H)$ overlapped pictures of thymine-dimer $(C, D)$ staining and Hoechst $(E, F)$ used as countersating. (I) Quantification of thymine-dimer positive cells in the skin of K5-End3 $(n=3)$ and non K5-End3 $(n=3)$. Bars represent means \pm SD. Statistical differences were calculated by one-way ANOVA $(p<0.05, n=3$ per genotype). 


\subsection{References}

Armstrong, B. K., and Kricker, A. (1993). How much melanoma is caused by sun exposure? Melanoma Res 3, 395-401.

Bagnato, A., and Natali, P. G. (2004). Endothelin receptors as novel targets in tumor therapy. J Transl Med 2.

Bagnato, A., Rosano, L., Spinella, F., Di Castro, V., Tecce, R., and Natali, P. G. (2004). Endothelin B receptor blockade inhibits dynamics of cell interactions and communications in melanoma cell progression. Cancer research $64,1436-43$.

Bald, T., Quast, T., Landsberg, J., Rogava, M., Glodde, N., Lopez-Ramos, D., Kohlmeyer, J., Riesenberg, S., Van Den Boorn-Konijnenberg, D., HomigHolzel, C., et al. (2014). Ultraviolet-radiation-induced inflammation promotes angiotropism and metastasis in melanoma. Nature 507, 109-13.

Ball, N. J., Yohn, J. J., Morelli, J. G., Norris, D. A., Golitz, L. E., and Hoeffler, J. P. (1994). Ras mutations in human melanoma: a marker of malignant progression. J Invest Dermatol 102, 285-90.

Benaduce, A. P., Batista, D., Grilo, G., Jorge, K., Cardero, D., Milikowski, C., and Kos, L. (2014). Novel UV-induced melanoma mouse model dependent on Endothelin3 signaling. Pigment Cell Melanoma Res 27, 839-42.

Berger, M. F., Hodis, E., Heffernan, T. P., Deribe, Y. L., Lawrence, M. S., Protopopov, A., Ivanova, E., Watson, I. R., Nickerson, E., Ghosh, P., et al. (2012). Melanoma genome sequencing reveals frequent PREX2 mutations. Nature 485, 502-6.

Broome Powell, M., Gause, P. R., Hyman, P., Gregus, J., Lluria-Prevatt, M., Nagle, R., and Bowden, G. T. (1999). Induction of melanoma in TPras transgenic mice. Carcinogenesis 20, 1747-53.

Cadet, J., and Douki, T. (2011). Oxidatively generated damage to DNA by UVA radiation in cells and human skin. $J$ Invest Dermatol 131, 1005-7.

Cadet, J., Douki, T., Ravanat, J. L., and Di Mascio, P. (2009). Sensitized formation of oxidatively generated damage to cellular DNA by UVA radiation. Photochem Photobiol Sci 8, 903-11.

Cheo, D. L., Ruven, H. J., Meira, L. B., Hammer, R. E., Burns, D. K., Tappe, N. J., Van Zeeland, A. A., Mullenders, L. H., and Friedberg, E. C. (1997). Characterization of defective nucleotide excision repair in XPC mutant mice. Mutat Res 374, 1-9. 
Davies, H., Bignell, G. R., Cox, C., Stephens, P., Edkins, S., Clegg, S., Teague, J., Woffendin, H., Garnett, M. J., Bottomley, W., et al. (2002). Mutations of the BRAF gene in human cancer. Nature 417, 949-54.

Daya-Grosjean, L., Robert, C., Drougard, C., Suarez, H., and Sarasin, A. (1993). High mutation frequency in ras genes of skin tumors isolated from DNA repair deficient xeroderma pigmentosum patients. Cancer Res 53, 1625-9.

De Vries, A., Van Oostrom, C. T., Hofhuis, F. M., Dortant, P. M., Berg, R. J., De Gruijl, F. R., Wester, P. W., Van Kreijl, C. F., Capel, P. J., Van Steeg, H., et al. (1995). Increased susceptibility to ultraviolet-B and carcinogens of mice lacking the DNA excision repair gene XPA. Nature 377, 169-73.

Del Bino, S., and Bernerd, F. (2013). Variations in skin colour and the biological consequences of ultraviolet radiation exposure. Br J Dermatol 169 Suppl $3,33-40$.

Del Bino, S., Sok, J., and Bernerd, F. (2013). Assessment of ultraviolet-radiationinduced DNA damage within melanocytes in skin of different constitutive pigmentation. Br J Dermatol 168, 1120-3.

Diepgen, T. L., and Mahler, V. (2002). The epidemiology of skin cancer. Br J Dermatol 146 Suppl 61, 1-6.

Digiovanna, J. J., and Kraemer, K. H. (2012). Shining a light on xeroderma pigmentosum. J Invest Dermatol 132, 785-96.

Friedberg, E., Walker, G., and Siede, W. (1995). DNA Repair and Mutagenesis, Washington DC: American Society for Microbiology.).

Friedberg, E. C., Cheo, D. L., Meira, L. B., and Reis, A. M. (1999). Cancer predisposition in mutant mice defective in the XPC DNA repair gene. Prog Exp Tumor Res 35, 37-52.

Garcia, R. J., Ittah, A., Mirabal, S., Figueroa, J., Lopez, L., Glick, A. B., and Kos, L. (2008). Endothelin 3 induces skin pigmentation in a keratin-driven inducible mouse model. The Journal of investigative dermatology 128, $131-42$.

Hacker, E., Irwin, N., Muller, H. K., Powell, M. B., Kay, G., Hayward, N., and Walker, G. (2005). Neonatal ultraviolet radiation exposure is critical for malignant melanoma induction in pigmented Tpras transgenic mice. J Invest Dermatol 125, 1074-7.

Hollander, M. C., Philburn, R. T., Patterson, A. D., Velasco-Miguel, S., Friedberg, E. C., Linnoila, R. I., and Fornace, A. J., Jr. (2005). Deletion of XPC leads 
to lung tumors in mice and is associated with early events in human lung carcinogenesis. Proc Natl Acad Sci U S A 102, 13200-5.

Kannan, K., Sharpless, N. E., Xu, J., O'hagan, R. C., Bosenberg, M., and Chin, L. (2003). Components of the $\mathrm{Rb}$ pathway are critical targets of UV mutagenesis in a murine melanoma model. Proc Natl Acad Sci U S A 100, $1221-5$.

Kelsall, S. R., and Mintz, B. (1998). Metastatic cutaneous melanoma promoted by ultraviolet radiation in mice with transgene-initiated low melanoma susceptibility. Cancer Res 58, 4061-5.

Klein-Szanto, A. J., Silvers, W. K., and Mintz, B. (1994). Ultraviolet radiationinduced malignant skin melanoma in melanoma-susceptible transgenic mice. Cancer Res 54, 4569-72.

Kraemer, K. H., Lee, M. M., Andrews, A. D., and Lambert, W. C. (1994). The role of sunlight and DNA repair in melanoma and nonmelanoma skin cancer. The xeroderma pigmentosum paradigm. Arch Dermatol 130, 1018-21.

Lahav, R., Heffner, G., and Patterson, P. H. (1999). An endothelin receptor B antagonist inhibits growth and induces cell death in human melanoma cells in vitro and in vivo. Proc Natl Acad Sci U S A 96, 11496-500.

Lahav, R., Suva, M. L., Rimoldi, D., Patterson, P. H., and Stamenkovic, I. (2004). Endothelin receptor $B$ inhibition triggers apoptosis and enhances angiogenesis in melanomas. Cancer research 64, 8945-53.

Luo, C., Sheng, J., Hu, M. G., Haluska, F. G., Cui, R., Xu, Z., Tsichlis, P. N., Hu, G. F., and Hinds, P. W. (2013). Loss of ARF sensitizes transgenic BRAFV600E mice to UV-induced melanoma via suppression of XPC. Cancer Res.

Nakane, H., Takeuchi, S., Yuba, S., Saijo, M., Nakatsu, Y., Murai, H., Nakatsuru, Y., Ishikawa, T., Hirota, S., Kitamura, Y., et al. (1995). High incidence of ultraviolet-B-or chemical-carcinogen-induced skin tumours in mice lacking the xeroderma pigmentosum group A gene. Nature 377, 165-8.

Noonan, F. P., Otsuka, T., Bang, S., Anver, M. R., and Merlino, G. (2000). Accelerated ultraviolet radiation-induced carcinogenesis in hepatocyte growth factor/scatter factor transgenic mice. Cancer Res 60, 3738-43.

Noonan, F. P., Recio, J. A., Takayama, H., Duray, P., Anver, M. R., Rush, W. L., De Fabo, E. C., and Merlino, G. (2001). Neonatal sunburn and melanoma in mice. Nature 413, 271-2. 
Noonan, F. P., Zaidi, M. R., Wolnicka-Glubisz, A., Anver, M. R., Bahn, J., Wielgus, A., Cadet, J., Douki, T., Mouret, S., Tucker, M. A., et al. (2012). Melanoma induction by ultraviolet $A$ but not ultraviolet $B$ radiation requires melanin pigment. Nature communications 3,884 .

Omholt, K., Karsberg, S., Platz, A., Kanter, L., Ringborg, U., and Hansson, J. (2002). Screening of $\mathrm{N}$-ras codon 61 mutations in paired primary and metastatic cutaneous melanomas: mutations occur early and persist throughout tumor progression. Clin Cancer Res 8, 3468-74.

Ortonne, J. P. (2002). From actinic keratosis to squamous cell carcinoma. $\mathrm{Br} \mathrm{J}$ Dermatol 146 Suppl 61, 20-3.

Pleasance, E. D., Cheetham, R. K., Stephens, P. J., Mcbride, D. J., Humphray, S. J., Greenman, C. D., Varela, I., Lin, M. L., Ordonez, G. R., Bignell, G. R., et al. (2010). A comprehensive catalogue of somatic mutations from a human cancer genome. Nature 463, 191-6.

Rastogi, R. P., Richa, Kumar, A., Tyagi, M. B., and Sinha, R. P. (2010). Molecular mechanisms of ultraviolet radiation-induced DNA damage and repair. Journal of nucleic acids 2010, 592980.

Recio, J. A., Noonan, F. P., Takayama, H., Anver, M. R., Duray, P., Rush, W. L., Lindner, G., De Fabo, E. C., Depinho, R. A., and Merlino, G. (2002). Ink4a/arf deficiency promotes ultraviolet radiation-induced melanomagenesis. Cancer Res 62, 6724-30.

Rosano, L., Spinella, F., Genovesi, G., Di Castro, V., Natali, P. G., and Bagnato, A. (2004). Endothelin-B receptor blockade inhibits molecular effectors of melanoma cell progression. J Cardiovasc Pharmacol 44 Suppl 1, S136-9.

Sands, A. T., Abuin, A., Sanchez, A., Conti, C. J., and Bradley, A. (1995). High susceptibility to ultraviolet-induced carcinogenesis in mice lacking XPC. Nature 377, 162-5.

Schneider, C. A., Rasband, W. S., and Eliceiri, K. W. (2012). NIH Image to ImageJ: 25 years of image analysis. Nature methods 9, 671-5.

Setlow, R. B., and Carrier, W. L. (1964). The Disappearance of Thymine Dimers from DNA: An Error-Correcting Mechanism. Proc Natl Acad Sci U S A 51, 226-31.

Takayama, H., Larochelle, W. J., Sharp, R., Otsuka, T., Kriebel, P., Anver, M., Aaronson, S. A., and Merlino, G. (1997). Diverse tumorigenesis associated with aberrant development in mice overexpressing hepatocyte growth factor/scatter factor. Proc Natl Acad Sci U S A 94, 701-6. 
Van Schanke, A., Van Venrooij, G. M., Jongsma, M. J., Banus, H. A., Mullenders, L. H., Van Kranen, H. J., and De Gruijl, F. R. (2006). Induction of nevi and skin tumors in Ink4a/Arf Xpa knockout mice by neonatal, intermittent, or chronic UVB exposures. Cancer Res 66, 2608-15.

Venema, J., Van Hoffen, A., Karcagi, V., Natarajan, A. T., Van Zeeland, A. A., and Mullenders, L. H. (1991). Xeroderma pigmentosum complementation group $\mathrm{C}$ cells remove pyrimidine dimers selectively from the transcribed strand of active genes. Mol Cell Biol 11, 4128-34.

Viros, A., Sanchez-Laorden, B., Pedersen, M., Furney, S. J., Rae, J., Hogan, K., Ejiama, S., Girotti, M. R., Cook, M., Dhomen, N., et al. (2014). Ultraviolet radiation accelerates BRAF-driven melanomagenesis by targeting TP53. Nature 511, 478-82.

Vlachostergios, P. J., and Papandreou, C. N. (2013). The Endothelin Axis in DNA Damage and Repair: The Cancer Paradigm.

Whiteman, D. C., Whiteman, C. A., and Green, A. C. (2001). Childhood sun exposure as a risk factor for melanoma: a systematic review of epidemiologic studies. Cancer Causes Control 12, 69-82.

Yamazaki, F., Okamoto, H., Miyauchi-Hashimoto, H., Matsumura, Y., Itoh, T., Tanaka, K., Kunisada, T., and Horio, T. (2004). XPA gene-deficient, SCFtransgenic mice with epidermal melanin are resistant to UV-induced carcinogenesis. J Invest Dermatol 123, 220-8.

Yang, G., Curley, D., Bosenberg, M. W., and Tsao, H. (2007). Loss of xeroderma pigmentosum $\mathrm{C}(\mathrm{Xpc})$ enhances melanoma photocarcinogenesis in Ink4aArf-deficient mice. Cancer Res 67, 5649-57.

Yarosh, D. B., Canning, M. T., Teicher, D., and Brown, D. A. (2005). After sun reversal of DNA damage: enhancing skin repair. Mutat Res 571, 57-64.

Zaidi, M. R., Davis, S., Noonan, F. P., Graff-Cherry, C., Hawley, T. S., Walker, R. L., Feigenbaum, L., Fuchs, E., Lyakh, L., Young, H. A., et al. (2011). Interferon-gamma links ultraviolet radiation to melanomagenesis in mice. Nature 469, 548-53. 


\section{CHAPTER IV.}

CONCLUSIONS, FUTURE DIRECTIONS AND IMPLICATIONS 


\section{CONCLUSIONS, FUTURE DIRECTIONS AND IMPLICATIONS}

\subsection{Conclusions and Future Directions}

Unlike many other cancers, melanoma affects people of all ages. Melanoma incidence increases with age. Although pediatric cases are very rare, melanoma is recognized as one of the most common cancers affecting a relative young population. As in all cancers, melanoma initiation, progression and metastasis is influenced by genetic and environmental factors as well as by tumor-host interactions. Melanoma is notorious for its propensity to metastasize and for its poor response to therapeutic regimens. In spite of all the efforts aimed at elucidating the initiation and progression of this malignancy, it continues being the most deadly form of skin cancer and its occurrence does not seem to be decreasing anytime soon.

Mice are commonly used as disease models, however because of structural differences between mice and human skin, in many of the attempts to establish UV responsive mouse models, UV alone did not seem to be sufficient to trigger melanoma development. In human skin, melanocytes are localized in the basal layer of the epidermis. They make dendritic connections with neighboring keratinocytes and transfer melanin to these cells, which provides skin pigmentation and sunlight protection. In mouse skin, melanocytes predominantly reside at the base of the hair follicles inside the dermis and are only found in the epidermis in hairless areas, such as ears and tails (Fitch et al., 2003; Hirobe, 1988). However, at specific periods, such as embryonic and neonatal stages, melanocytes can be found in the epidermal-dermal junction 
(Hirobe, 1984). One possible explanation for wild type mice being highly resistant to melanoma induction by UV irradiation is the protected location of melanocytes inside the hair follicle deep into the mouse skin dermis rather than the epidermis as in humans.

The K5-Edn3 double transgenic mice have a more "humanized" skin. The production of excess Edn3 by epidermal keratinocytes leads to the accumulation of large numbers of melanocytes in the skin, more specifically in the dermis and epidermal-dermal junction, throughout their lifetime. As a consequence of the presence of extra-follicular melanocytes, K5-Edn3 mice display a hyperpigmented skin phenotype (Garcia et al., 2008). Because of the resemblance with the human skin, we hypothesized that K5-Edn3 mice would develop melanomagenesis upon UV radiation. I showed that, even though K5Edn3 mice do not develop spontaneous melanoma, a single neonatal UV erythemal dose was capable of inducing melanomagenesis and its metastasis. Unexpectedly, when K5-Edn3 mice were exposed to UV radiation neonatally as well as during adulthood, a significant increase in melanoma penetrance was not observed. One possible explanation for this surprising outcome is that the majority of the lesions removed from $\mathrm{K} 5-E d n 3$ mice exposed to both neonatal and adult UV erythemal doses were very ulcerated. These lesions were very excoriated with no residual epidermis, therefore only the dermal component could be evaluated making it impossible to accurately diagnose them. Interestingly, when adult mice (6 weeks of age) were exposed to a single erythemal dose of UV radiation, they did not develop melanoma. This result 
underscored the importance of neonatal UV exposure in order for K5-Edn3 mice to develop melanoma. Furthermore, it provided further support to the epidemiological data indicating that early sun exposure is critical and sufficient for melanomagenesis (Whiteman et al., 2001).

The reason for the neonatal sensitivity and lack of adult sensitivity to UV radiation is not clear but it could be related to (1)- the fact that neonatal mice have immune response distinct from adult mice, which can result in tolerance in adults to antigens produced by UV exposure (Muller et al., 2008); and/or (2)- the acquisition and retention of DNA damage by melanocyte progenitor cells found in higher amounts in post-natal skin than in adult skin, resulting in melanomagenesis later on in life (Wolnicka-Glubisz and Noonan, 2006).

Given that only K5-Edn3 mice develop melanoma upon neonatal UV exposure, it is possible that Edn3 overexpression not only allows for the survival of melanocytes in the extra-follicular skin but also affects the skin microenvironment making it more susceptible to the development and progression of melanoma. The latter is based on in vitro studies that showed that, in melanoma cell lines, Edn3 alters the expression of cell adhesion proteins and metalloproteinases that are associated with the disruption of normal tumorhost interactions and progression of cutaneous melanoma (Bagnato et al., 2004; Rosano et al., 2004).

The K5-Edn3 mouse uses the tetracycline regulatory system to drive the overexpression of Edn3 under the control of Keratin 5 promoter (Garcia et al., 2008). Taking advantage of this system, it would be interesting to determine if 
overexpression of Edn3 in the skin of adult mice is a requirement for UV-induced melanomagenesis and metastasis. The simple addition of doxycycline to the drinking water of these mice, leads to the blockage of the Edn3 transgene. Since overexpression of Edn3 in the skin is a requirement for extra-follicular melanocyte persistence, K5-Edn3 transgenic mice would initially undergo the same UV exposure regimen at 3.5 days of age, before the K5-Edn3 transgene was turned off beginning at 21 days after birth. Doxycycline treatment would be continued for 18 months and mice would be weekly checked for melanoma appearance.

The Nucleotide Excision Repair (NER) pathway repairs photoproducts induced by UV radiation; Xpa and Xpc proteins have important roles in this pathway. Xpa deficiency and, in a higher magnitude Xpc deficiency, enhanced melanoma penetrance and decreased melanoma latency in the neonatal K5Edn3 UV-induced mouse model. This result was expected and it is in accordance with previously published data in humans and also in mouse models which links NER pathway disruption to high indices of skin cancer, including melanoma (Kraemer et al., 1987; Luo et al., 2013; Nakane et al., 1995; van Schanke et al., 2006; Yamazaki et al., 2005; Yang et al., 2007).

Neonatal K5-Edn3 dorsal skin exposed to UV-radiation revealed a decrease in thymine-dimer formation and a larger number of apoptotic cells in comparison to neonatal non K5-Edn3 dorsal skin exposed to the same dose of UV radiation. These observations can result from the effects caused by the higher levels of Edn3 and/or larger amounts of melanin present in the skin of the 
K5-Edn3 mice. In order to isolate the contributions of Edn3 and melanin, K5Edn3 transgenic mice could be placed in an albino background, exposed to the same regimen of UV radiation at 3.5 days of age, and monitored for a period of 18 months for melanoma development and metastasis. Wood et al. (2006) reported on the possible involvement of melanin in phototoxic reactions responsible for UV-dependent causation of melanoma in Xiphophorus (Wood et al., 2006). A recent study showed that the presence of melanin is a requirement for melanoma induction by UVA, but not UVB, in HGF/SC transgenic mice (Noonan et al., 2012). Taking these results into account, I would expect that K5Edn3 on the albino background mice would not develop or would have a lower incidence of melanomagenesis upon neonatal UV exposure.

Next generation sequencing of Braf, Kras, Hras and Nras PCR amplicons did not reveal any mutations that would lead to constitutive activation of these oncogenes in UV-induced K5-Edn3 melanoma lesions. In a recent published paper, UV-induced p53 gene mutation was found to be the cause of melanomagenesis acceleration in $B R A F^{V 600 E}$ mice (Viros et al., 2014). In light of this, it would be of great interest to perform whole exome sequencing of K5-Edn3 melanoma lesions to find out which genes, if any, are the UV-targeted genes in the K5-Edn3 model. This would help to further understand the molecular basis for melanoma development in the UV-exposed K5-Edn3 mice.

Previously established neonatal, UV-induced melanoma mouse models carried loss or gain of function mutations in the melanocytes and spontaneously developed skin lesions that were enhanced by UV exposure. Most of the existing 
models are based on disruption of tyrosine kinase receptor mediated signaling pathways. The K5-Edn3 UV-induced melanoma mouse model is the first model based on the over-activation of a G-coupled receptor. Additionally, the K5-Edn3 model has two very distinguishable features: (1)- melanocytes are not transformed a priori and, (2)- the tumorigenic process depends exclusively on neonatal UV radiation. Therefore, testing new chemical compounds, as well as current and new melanoma therapies in this model would be of great relevance. It will provide a very different platform for the evaluation of the efficacy of novel drugs and, as such, be considered a new standard for pre-clinical studies.

\subsection{Implications}

Ultraviolet radiation is known to be the major environmental risk factor for melanoma, but it is still unclear exactly how UV affects melanoma initiation, progression and metastasis. The effects of UV radiation on organisms are very broad making the solution to this puzzle particularly complex. Recently, with the use of experimental animal models, some progress towards elucidating the mechanisms at work in UV-induced melanomagenesis has been made.

The UV-induced K5-Edn3 melanoma mouse model developed in this project establishes a new paradigm for the role of Edn3 in melanoma risk. Further understanding of the precise cellular, biochemical and molecular mechanisms employed by this pathway in the K5-Edn3 melanoma model will substantially help in the advance of our understanding of the interactions between UV radiation and skin carcinogenesis. In the near future, this model may 
serve as a useful tool in the identification of new molecular targets for intervention and also in the assessment of the efficacy of therapeutic agents.

\subsection{References}

Bagnato, A., Rosano, L., Spinella, F., Di Castro, V., Tecce, R., and Natali, P. G. (2004). Endothelin B receptor blockade inhibits dynamics of cell interactions and communications in melanoma cell progression. Cancer Res 64, 1436-43.

Fitch, K. R., Mcgowan, K. A., Van Raamsdonk, C. D., Fuchs, H., Lee, D., Puech, A., Herault, Y., Threadgill, D. W., Hrabe De Angelis, M., and Barsh, G. S. (2003). Genetics of dark skin in mice. Genes Dev 17, 214-28.

Garcia, R. J., Ittah, A., Mirabal, S., Figueroa, J., Lopez, L., Glick, A. B., and Kos, L. (2008). Endothelin 3 induces skin pigmentation in a keratin-driven inducible mouse model. J Invest Dermatol 128, 131-42.

Hirobe, T. (1984). Histochemical survey of the distribution of the epidermal melanoblasts and melanocytes in the mouse during fetal and postnatal periods. The Anatomical record 208, 589-94.

Hirobe, T. (1988). Developmental changes of the proliferative response of mouse epidermal melanocytes to skin wounding. Development 102, 567-74.

Kraemer, K. H., Lee, M. M., and Scotto, J. (1987). Xeroderma pigmentosum. Cutaneous, ocular, and neurologic abnormalities in 830 published cases. Arch Dermatol 123, 241-50.

Luo, C., Sheng, J., Hu, M. G., Haluska, F. G., Cui, R., Xu, Z., Tsichlis, P. N., Hu, G. F., and Hinds, P. W. (2013). Loss of ARF sensitizes transgenic BRAFV600E mice to UV-induced melanoma via suppression of XPC. Cancer Res 73, 4337-48.

Muller, H. K., Malley, R. C., Mcgee, H. M., Scott, D. K., Wozniak, T., and Woods, G. M. (2008). Effect of UV radiation on the neonatal skin immune systemimplications for melanoma. Photochem Photobiol 84, 47-54.

Nakane, H., Takeuchi, S., Yuba, S., Saijo, M., Nakatsu, Y., Murai, H., Nakatsuru, Y., Ishikawa, T., Hirota, S., Kitamura, Y., et al. (1995). High incidence of ultraviolet-B-or chemical-carcinogen-induced skin tumours in mice lacking the xeroderma pigmentosum group A gene. Nature 377, 165-8.

Noonan, F. P., Zaidi, M. R., Wolnicka-Glubisz, A., Anver, M. R., Bahn, J., Wielgus, A., Cadet, J., Douki, T., Mouret, S., Tucker, M. A., et al. (2012). 
Melanoma induction by ultraviolet $A$ but not ultraviolet $B$ radiation requires melanin pigment. Nature communications 3,884 .

Rosano, L., Spinella, F., Genovesi, G., Di Castro, V., Natali, P. G., and Bagnato, A. (2004). Endothelin-B receptor blockade inhibits molecular effectors of melanoma cell progression. J Cardiovasc Pharmacol 44 Suppl 1, S136-9.

Van Schanke, A., Van Venrooij, G. M., Jongsma, M. J., Banus, H. A., Mullenders, L. H., Van Kranen, H. J., and De Gruijl, F. R. (2006). Induction of nevi and skin tumors in Ink4a/Arf Xpa knockout mice by neonatal, intermittent, or chronic UVB exposures. Cancer Res 66, 2608-15.

Viros, A., Sanchez-Laorden, B., Pedersen, M., Furney, S. J., Rae, J., Hogan, K., Ejiama, S., Girotti, M. R., Cook, M., Dhomen, N., et al. (2014). Ultraviolet radiation accelerates BRAF-driven melanomagenesis by targeting TP53. Nature 511, 478-82.

Whiteman, D. C., Whiteman, C. A., and Green, A. C. (2001). Childhood sun exposure as a risk factor for melanoma: a systematic review of epidemiologic studies. Cancer Causes Control 12, 69-82.

Wolnicka-Glubisz, A., and Noonan, F. P. (2006). Neonatal susceptibility to UV induced cutaneous malignant melanoma in a mouse model. Photochem Photobiol Sci 5, 254-60.

Wood, S. R., Berwick, M., Ley, R. D., Walter, R. B., Setlow, R. B., and Timmins, G. S. (2006). UV causation of melanoma in Xiphophorus is dominated by melanin photosensitized oxidant production. Proc Natl Acad Sci U S A 103, 4111-5.

Yamazaki, F., Okamoto, H., Matsumura, Y., Tanaka, K., Kunisada, T., and Horio, T. (2005). Development of a new mouse model (xeroderma pigmentosum a-deficient, stem cell factor-transgenic) of ultraviolet B-induced melanoma. J Invest Dermatol 125, 521-5.

Yang, G., Curley, D., Bosenberg, M. W., and Tsao, H. (2007). Loss of xeroderma pigmentosum $\mathrm{C}(\mathrm{Xpc})$ enhances melanoma photocarcinogenesis in Ink4aArf-deficient mice. Cancer Res 67, 5649-57. 
VITA

ANA PAULA DA SILVA BENADUCE

EDUCATION:

2014

Ph.D. Candidate

Florida International University - Miami, FL, USA.

$2005 \quad$ Master of Animal Biodiversity

Federal University of Santa Maria - Santa Maria, RS, Brazil.

2003 Bachelor of Biology

Federal University of Santa Maria - Santa Maria, RS, Brazil.

PUBLICATIONS AND PRESENTATIONS:

Benaduce, A.P., Batista, D., Grilo, G., Jorge, K., Cardero, D., Milikowski, C., Kos, L. XPC deficiency enhances melanoma photocarcinogenesis in transgenic K5Edn3 mice. In: XXII International Pigment Cell Conference. Singapore, 2014.

Benaduce, A.P., Batista, D., Grilo, G., Jorge, K., Cardero, D., Milikowski, C., Kos, L. Novel UV-induced melanoma mouse model dependent on Endothelin3 signaling. Pigment Cell and Melanoma Research, v.27(5), p.839-842, 2014.

Benaduce, A.P., Batista, D., Grilo, G., Jorge, K., Cardero, D., Milikowski, C., Kos, L. Ultraviolet radiation induces carcinogenesis in a novel transgenic mouse model of melanoma. In: American Association for Cancer Research Annual Meeting 2014. San Diego, CA, USA, 2014.

Benaduce, A.P., Batista, D., Grilo, G., Jorge, K., Cardero, D., Milikowski, C., Kos, L. Loss of nucleotide excision repair pathway increases sensitivity of transgenic K5-Edn3 mice to UV-induced melanoma. In: Sixteenth Annual Biology Research Symposium. Miami, FL, USA, 2014.

Benaduce, A.P., Batista, D., Grilo, G., Jorge, K., Kos, L. UV radiation interacts with Endothelin 3 and loss of nucleotide excision repair pathway to promote melanomagenesis. In: American Association for Cancer Research Annual Meeting 2013. Washington, DC, USA, 2013.

Benaduce, A.P., Batista, D., Grilo, G., Jorge, K., Kos, L. Nucleotide Excision Repair pathway deficiency and Endothelin 3 over-expression promotes melanomagenesis in a UV radiation-induced mouse model. In: $15^{\text {th }}$ Biomedical and Comparative Immunology Symposium. Miami, FL, USA, 2013.

Baldisserotto, B., Garcia, L.O., Benaduce, A.P., Mendonça, R., Nascimento, T.,Gomes, L. C., Chippari Gomes, A., Val., A.L. Sodium fluxes in tamoatá, 
Hoplosternum litoralle, exposed to formation water from Urucu Reserve (Amazon, Brazil). Archives of Environmental Contamination and Toxicology, v.62(1), p.78-84, 2012.

Benaduce, A.P., Grilo, G., Batista, D., Kos, L. UV induces melanomagenesis in a nucleotide excision repair deficient mouse model dependent on the overactivation of endothelin-3 In: $8^{\text {th }}$ International Congress of The Society for Melanoma Research. Tampa, FL, USA, 2011.

Benaduce, A.P., Lahiri, D., Agarwal, A., Kos, L. Effects of Endothelin 3 on Biomechanics of Melanocytes and Melanoma Cells. In: NanoFlorida 2011- The Fourth Annual Nanoscience Technology Symposium. Miami, FL, USA, 2011.

Benaduce, A.P., Lahiri, D., Agarwal, A., Kos, L. Melanocytes and melanoma cells present different mechanical properties that can be modulated by Endothelin 3 . In: XXI International Pigment Cell Conference. Bordeaux, France, 2011.

Lahiri, D., Benaduce, A.P., Kos, L., Agarwal, A. Quantification of Carbon Nanotube Induced Adhesion of Osteoblast on Hydroxyapatite Surface Using Nano-scratch Technique. Nanotechnology, v.22, p.22-31, 2011.

Lahiri, D., Benaduce, A.P., Rouzaud, F., Solomon, J., Keshri, A.K., Kos, L., Agarwal, A. Wear Behavior and In-vitro Cytotoxicity of Wear Debris Generated from Hydroxyapatite-Carbon Nanotube Composite Coating. Journal of Biomedical Materials Research Part A, v.96A, i.1, p.1-12, 2011.

Lahiri, D, Singh, V., Benaduce, A.P., Seal, S., Kos, L., Agarwal, A. Boron nitride nanotube reinforced hydroxyapatite composite: mechanical and tribological performance and in-vitro biocompatibility to osteoblasts. Journal of the Mechanical Behavior of Biomedical Materials, v.4(1), p.44-56, 2011.

Kochhann, D., Benaduce, A.P., Copatti, C. E., Lorenzatto, K.R., Mesko, M. F., Flores, E. M. M., Dressler, V.L., Baldisserotto, B. Protective effect of high alkalinity against the deleterious effects of chronic waterborne cadmium exposure on the detection of alarm cues by juvenile silver catfish (Rhamdia quelen). Archives of Environmental Contamination and Toxicology, v.56, p.770775, 2009.

Benaduce, A.P., Kochhann, D., Flores, E.M.M., Dressler, V.L., Baldisserotto, B. Toxicity of cadmium of silver catfish Rhamdia quelen (Heptapteridae) embryos and larvae at different alkalinities. Archives of Environmental Contamination and Toxicology, v.54(2), p.274-282, 2008. 